\title{
FLEXURAL (MOMENT) CAPACITY OF ULTRA-HIGH PERFORMANCE FIBER REINFORCED CONCRETE BEAMS
}

by

\section{Jamil Madanat}

B.Eng., Ryerson University 2017

\author{
A thesis \\ presented to Ryerson University \\ in partial fulfillment of the \\ requirements for the degree of \\ Master of Applied Science \\ in the program of \\ Civil Engineering
}

Toronto, Ontario, Canada, 2019

(C) Jamil Madanat, 2019 


\section{AUTHOR'S DECLARATION}

I hereby declare that I am the sole author of this thesis. This is a true copy of the thesis, including any required final revisions, as accepted by my examiners.

I authorize Ryerson University to lend this thesis to other institutions or individuals for the purpose of scholarly research.

I further authorize Ryerson University to reproduce this thesis by photocopying or by other means, in total or in part, at the request of other institutions or individuals for the purpose of scholarly research.

I understand that my thesis may be made electronically available to the public. 


\title{
ABSTRACT \\ FLEXURAL (MOMENT) CAPACITY OF ULTRA-HIGH PERFORMANCE FIBER REINFORCED CONCRETE BEAMS
}

\author{
Jamil Madanat \\ Master of Applied Science, Civil Engineering \\ Ryerson University, Toronto, 2019
}

Ultra-High Performance Fiber Reinforced Concrete (UHPFRC) is a relatively new generation of cementitious material exhibiting exceptional mechanical characteristics. One of the main applications of this new material is strengthening existing bridges and the construction of new Igirders during the rehabilitation process. Previous research on (UHPFRC) beam girders and prestressed girders found the analytical moment capacity to be $76 \%$ of the experimental (test) results.

A method based on strain compatibility, equilibrium and the stress-strain relationships is developed to determine the flexural capacity of UHPFRC beams with about $90 \%$ accuracy between experimental and numerical capacities. A testing program of five beam specimens is conducted at Ryerson University Structural Laboratory to verify the experimental results. Furthermore, the results of the finite element numerical simulation of ABAQUS software using concrete damage plasticity (CDP) constitutive model predict the flexural capacity of the tested UHPFRC beams reasonably well. 


\section{Acknowledgments}

The research work presented in this MASc thesis was carried out at the department of civil engineering at Ryerson University under the supervision of Professor Hesham Marzouk.

I would like to extend my sincere appreciation and gratitude for my supervisor Dr. Marzouk for all his support, guidance, and help throughout my research journey at the graduate level. It was my great pleasure working under his supervision. Furthermore, I gratefully appreciate Dr. H. Othman and my colleague Mohtady Sherif for their help and support with the finite element analysis.

Additionally, I would like to thank my colleagues Youssef Hilal and Navneet Singh for their support and help in carrying out the experimental work. Also, I would like to extend my gratitude to the technical staff at the civil engineering labs at Ryerson University. Moreover, the support of Lafarge North America in providing the concrete dry material is also appreciated.

I would like to express my gratitude to the committee members, Dr. Anwar Hossain and Dr. Saber Moradi for kindly reviewing my thesis.

Finally, I thank my dear family for standing by my side and encouraging me throughout my academic journey of pursuing my master's degree. Thank you for your unconditional love and support. 


\section{Table of Contents}

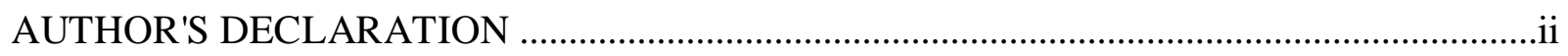

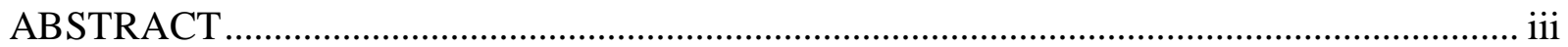

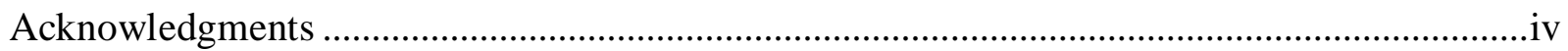

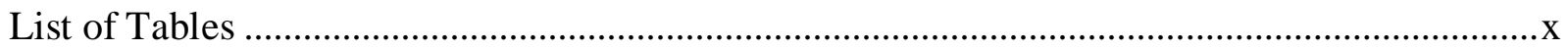

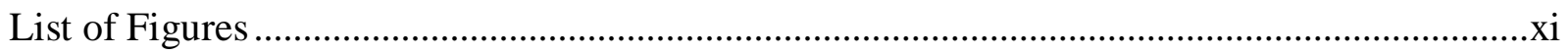

List of Abbreviations ...........................................................................................................

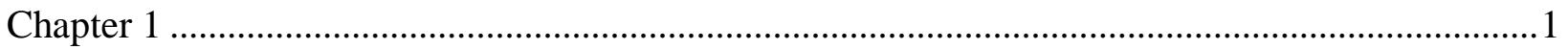

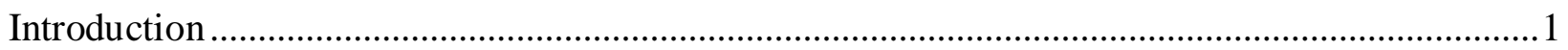

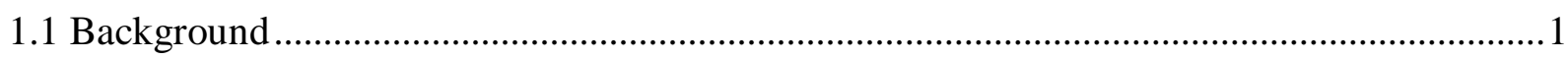

1.2 Research Scope

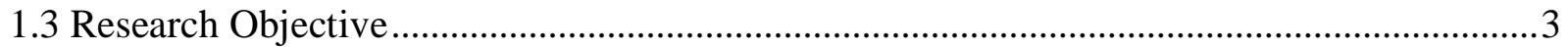

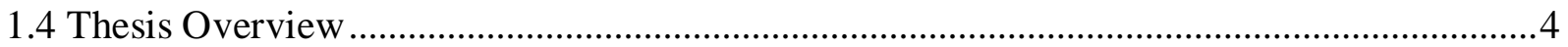

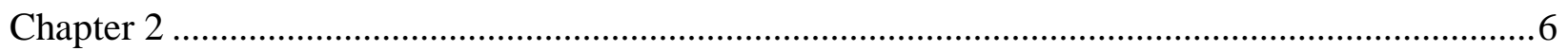

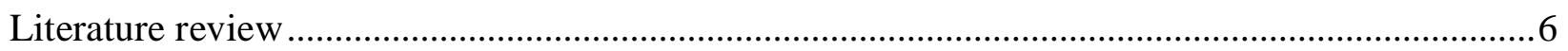

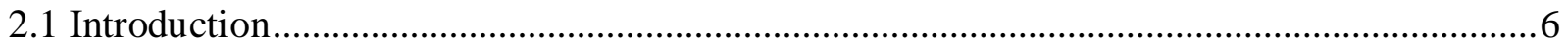

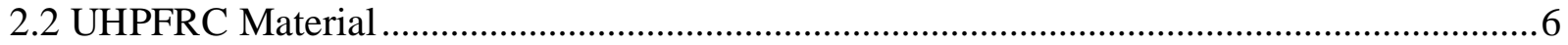

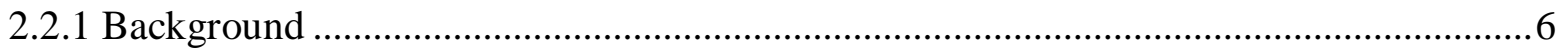

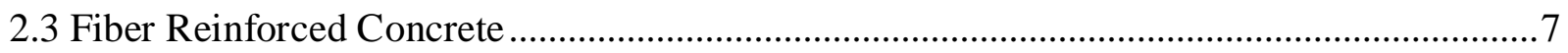

2.3.1 Fiber reinforced cement (FRC) composites …………..................................................... 
2.3.2 Fiber contribution and orientation in concrete 10

2.3.3 Post cracking behaviour of steel fiber reinforced concrete 12

2.3.4 Slip hardening behaviour of steel fiber reinforced concrete .13

2.3.5 Effect of steel fibers on shear resistance for normal strength concrete. 14

2.3.6 Tension stiffening model for normal strength concrete 16

2.3.7 Fracture energy of HSC and UHPFRC 18

2.4 Moment Capacity and Stress Block Parameters..... .24

2.4.1 Moment capacity for high strength concrete columns .... .25

2.4.2 Moment capacity for high strength concrete beams .27

2.4.3 Moment capacity for UHPFRC .29

2.5 Finite Element Modelling .35

2.5.1 Different modelling techniques. .35

2.5.2 Geometric modelling .35

2.5.3 Concrete damage plasticity .36

2.5.4 Mesh size 37

2.6 Previous Numerical Investigations .37

CHAPTER 3 .40

Experimental Procedures. .40

3.1 Introduction 40

3.1.1 Fiber reinforcement .40 


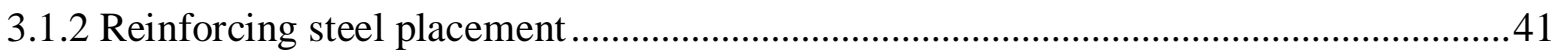

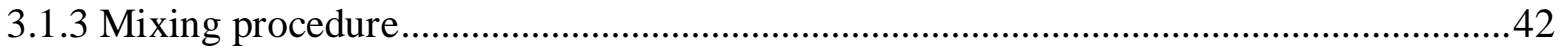

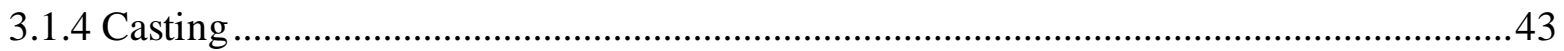

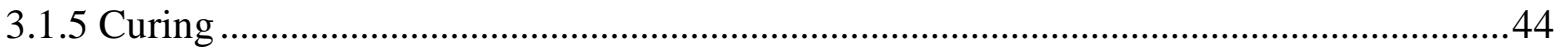

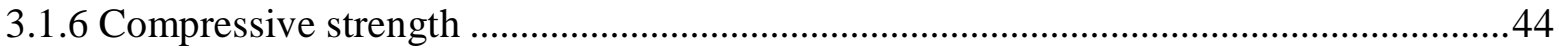

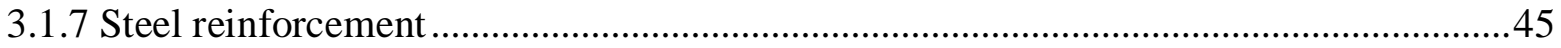

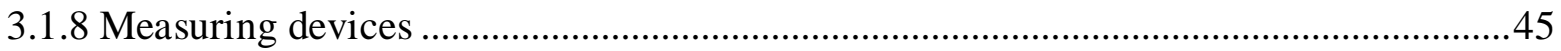

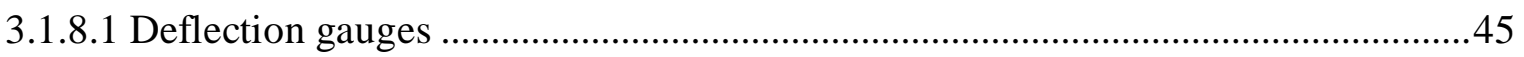

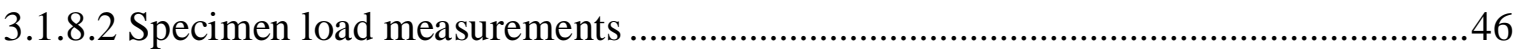

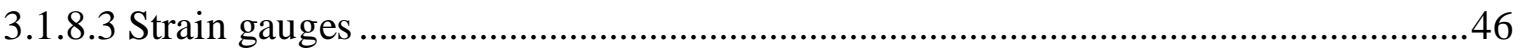

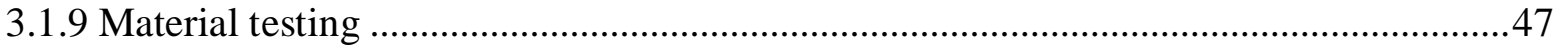

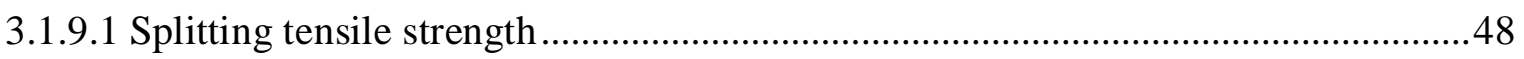

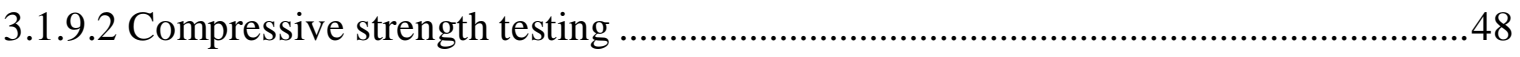

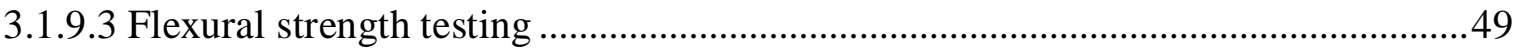

3.2 Flexural Testing Setup of UHPFRC Beams ….............................................................50

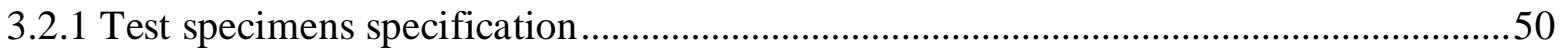

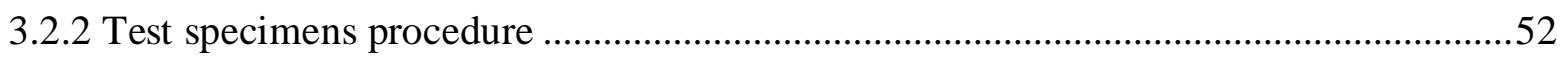

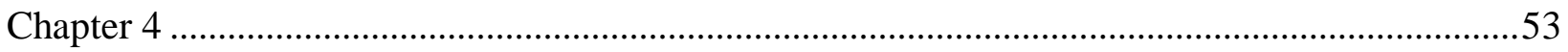

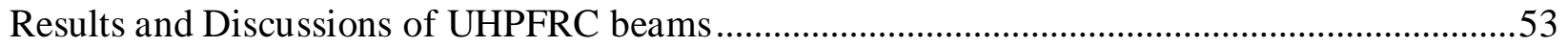

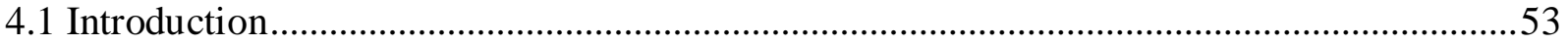


4.2 Results and Observations

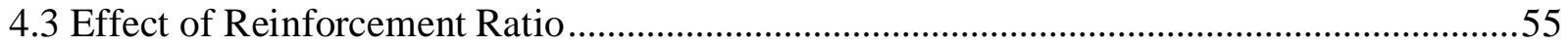

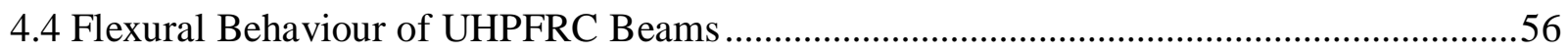

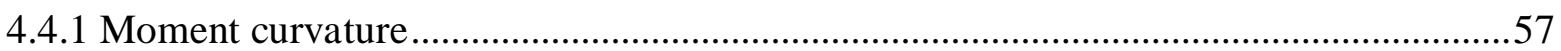

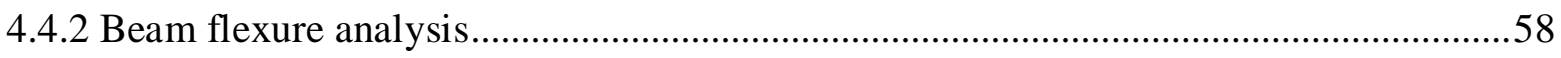

4.4.3 Dobrusky's simplified model (Dobrusky, 2017) .....................................................61

4.4.4 Canadian CSA A23.3-94/American ACI 318-02/ New Zealand NZS 3101-1995.......63

4.4.5 Ryerson Proposed Method (RPM) .........................................................................63

4.5 Moment Capacity Comparison: Experimental Versus Analytical Methods........................66

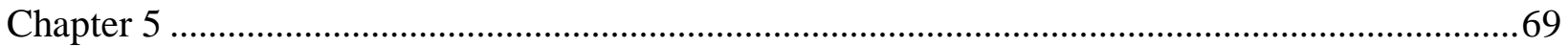

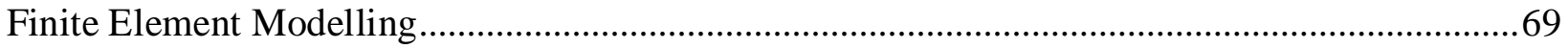

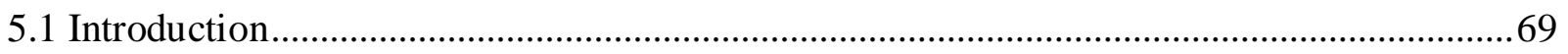

5.2 Development of 3D Finite Element Model .................................................................. 70

5.2.1 Material property and part selection .................................................................. 70

5.2.1.1 The main concrete damage plasticity model parameters ..................................... 71

5.2.2 Monotonic incremental static loading .............................................................. 72

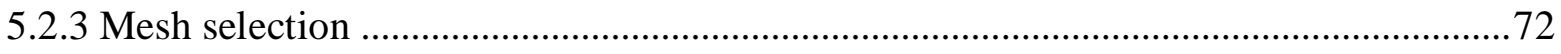

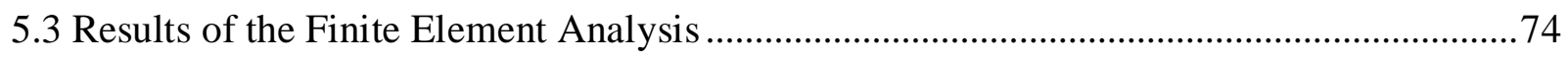

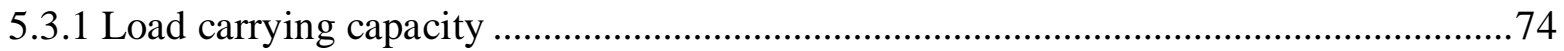

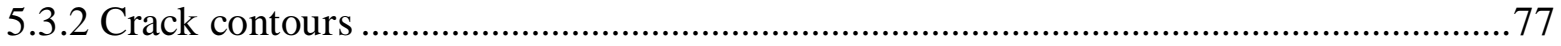


5.4 FE Numerical Validation of Bae et al., (2016).

Chapter 6

Conclusions and Recommendations

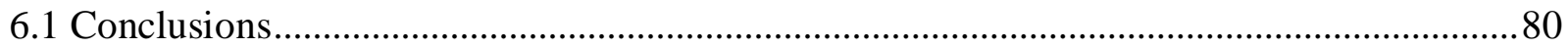

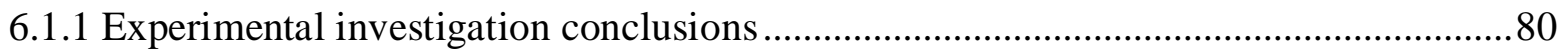

6.1.2 UHPFRC beam flexural analysis conclusions ............................................................

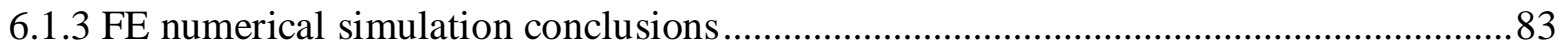

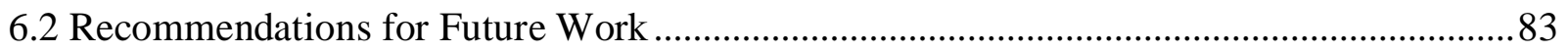

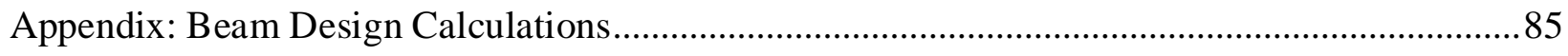

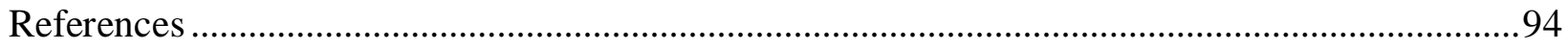




\section{List of Tables}

Table 1: Mechanical properties for UHPFRC (Wille et al., 2011) ...............................................12

Table 2: Tension and fracture properties of UHPFRC (Wahba et al., (2012)) .............................22

Table 3: Mechanical properties of NSC \& UHPFRC (Maca et al., 2013) ...................................23

Table 4: Ductal ${ }^{\circledR}$ mechanical properties (Lafarge North America, 2019)...................................47

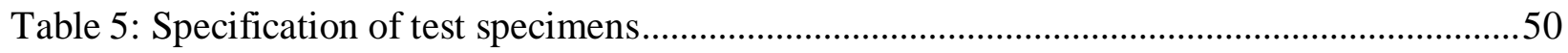

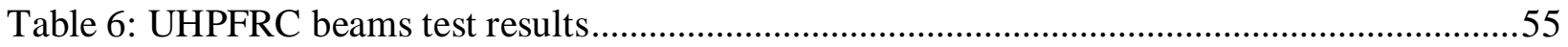

Table 7: Comparison of moment capacity and RPM .........................................................66

Table 8: Comparison of moment capacity for specimen span $915 \mathrm{~mm}$....................................67

Table 9: Comparison of moment capacity for specimen span $1830 \mathrm{~mm}$...................................68

Table 10: Numerical (FE) vs experimental ultimate load capacity ............................................74 


\section{List of Figures}

Figure 1: Stress-strain curves for strain hardening and softening of FRC in tension (Naaman, 2007)

Figure 2: Reinforced concrete's response under tension (Abrishami and Mitchell, 1997) ..........17

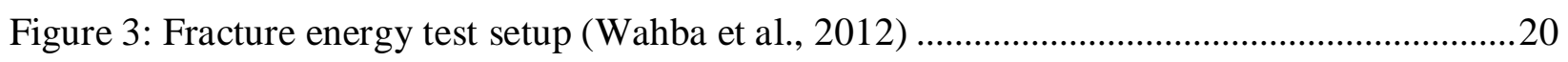

Figure 4: Average tensile strain measurements of specimen FE1 \& FE2 (Wahba et al., 2012) ...21

Figure 5: Tensile behaviour of HPC and UHPFRC (Maca et al., 2013) ....................................23

Figure 6: Fracture energy for strain hardening and softening (Xu \& Wille, 2015).....................24

Figure 7: Experimental vs proposed model for high strength concrete columns (Ozbakkaloglu and

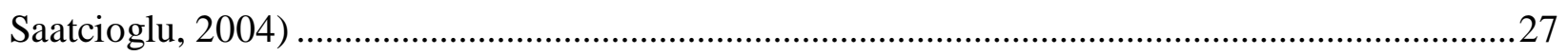

Figure 8: Equivalent rectangular stress block (Oztekin et al., 2003) .........................................28

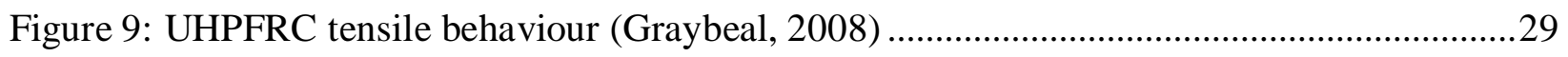

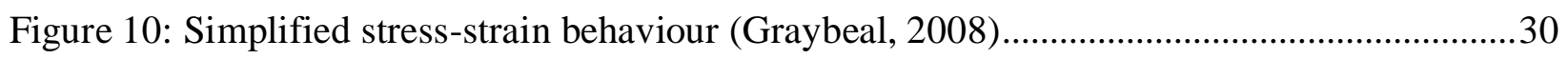

Figure 11: Stress and strain distribution for UHPFRC (Bae et al., 2016)...................................31

Figure 12: Strain hardening of UHPFRC proposed by AFGC and Setra (D’Alessandro, 2013) ..32

Figure 13: Strain softening of UHPFRC proposed by AFGC and Setra (D’Alessandro, 2013) ...32

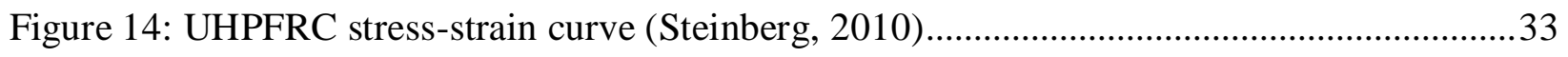

Figure 15: MTS test setup for cylinders equipped with FBG sensors (Yazdizadeh, 2014)...........34

Figure 16: Axial strain vs compressive stress for HSC \& UHPFRC (Yazdizadeh, 2014) ............34

Figure 17: UHPFRC uniaxial tensile relationship for CDP model (Othman, 2016) .....................37

Figure 18: Material Properties of Steel Fibers used for Ductal ${ }^{\circledR}$ Mix (Federal Highway

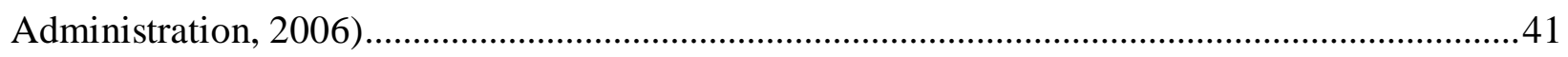

Figure 19: Reinforcement placement showing steel spacers and steel hooks.............................42 
Figure 20: Formwork interior covered with a sealant (silicone) and duct tape

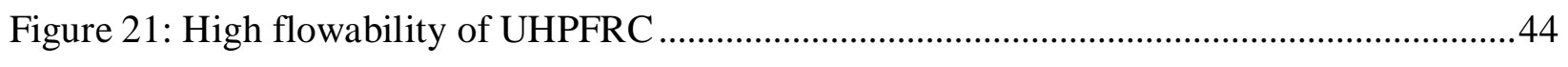

Figure 22: Cylinder end grinding; before (left) and after (right) ............................................45

Figure 23: Attaching strain gauge on steel reinforcement ...................................................4

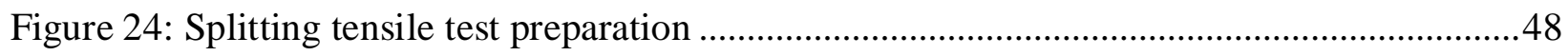

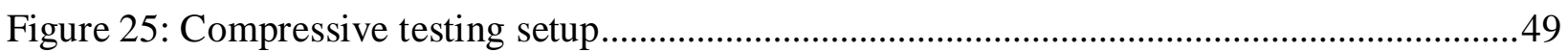

Figure 26: Details of UHPFRC beam specimens (a) 2-20M-S, (b) 4-20M-S, (c) 6-20M-S\&L, (d)

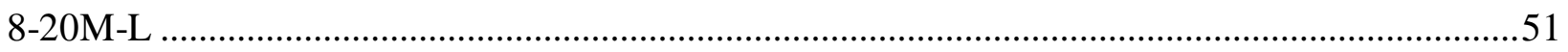

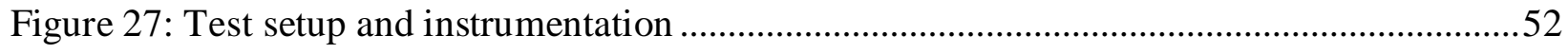

Figure 28: Load-displacement of UHPFRC beams $(\mathrm{S}=915 \mathrm{~mm}$ beam, $\mathrm{L}=1830 \mathrm{~mm}$ beam $) \ldots . .54$

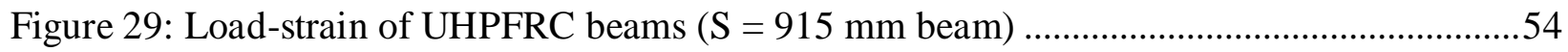

Figure 30: Moment curvature for the 2-20M rectangular section .............................................58

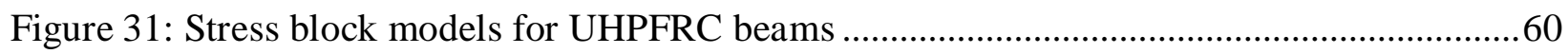

Figure 32: Test specimen details (Bae at al., 2016)..............................................................61

Figure 33: Dobrusky’s proposed model (Dobrusky, 2017) ....................................................62

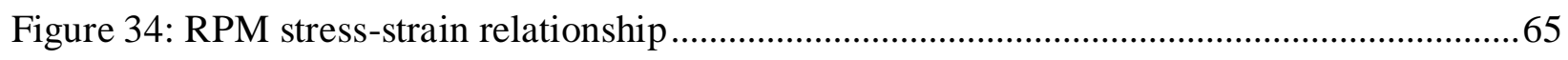

Figure 35: Gowripalan and Gilbert (2000) stress-strain relationship .....................................66

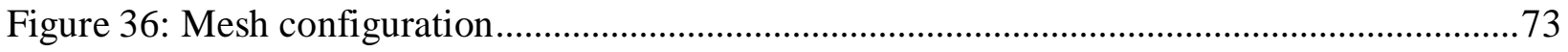

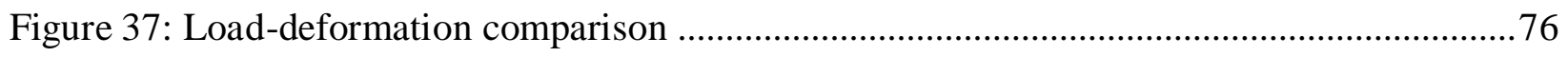

Figure 38: Numerical and experimental crack pattern comparison ............................................78

Figure 39: Load-deformation comparisons between ABAQUS simulation (a) and Bae et al., (2016)

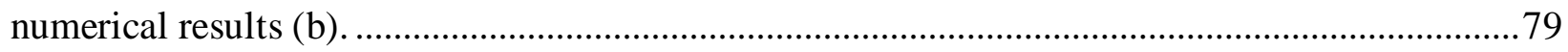

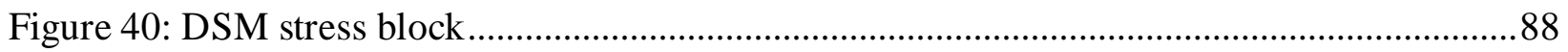




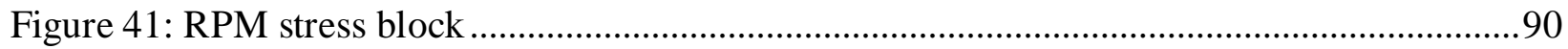




\section{List of Abbreviations}

2D-FE: Two-dimensional Finite Element

3D-FE: Three-dimensional Finite Element

ACI: American Concrete Institute

ASTM: American Society for Testing and Materials

C3D8R: Three-dimensional eight node continuum solid element with reduced integration

CDP: Concrete Damage Plasticity material model

CSA: Canadian Standards Association

DSM: Dobrusky’s Simplified Model

FE: Finite Element

FRC: Fiber Reinforced Concrete

HSC: High Strength Concrete

NSC: Normal Strength Concrete

RC: Reinforced Concrete

RPM: Ryerson Proposed Method

UHPFRC: Ultra-High Performance Fiber Reinforced Concrete 


\section{CHAPTER 1}

\section{INTRODUCTION}

\subsection{Background}

Reinforced concrete structures are a composite material made up of concrete and embedded steel reinforcement that is used a lot in the construction industry. Concrete in nature is a brittle material that can carry large stresses under compression. Nevertheless, it is easily susceptible to cracking under tensile stresses. In order to enhance the tensile strength of concrete structures, steel reinforcement is used to build efficient structures. This reinforcement strengthens the tensile strength of concrete and improves its inherent brittle nature. However, as the concrete compressive strength increases, the brittleness also increases. Thus, concrete behaviour requires the need for more tensile support. To improve the ductility of concrete with high compressive strength, steel fibers are added to the matrix. The use of steel fibers in concrete dates to the 1980 's, and its properties have been researched throughout the years. Steel fibers improve the tensile and compressive strength of concrete in addition to enhancing the post-cracking characteristics. The steel fiber volume content that is commonly used in research and industry is $2 \%$ by volume. Therefore, this fiber content is used in the experimental research presented herein. Other fiber contents such as $3 \%$ and $4 \%$ can be used, however, this will decrease the workability of the matrix.

Ultra-High Performance Fiber Reinforced Concrete (UHPFRC) is a new and promising material exhibiting superior ductility, durability and strength over conventional concrete. There is a lot of ongoing research on the properties of this capable material. The unique and vital aspects of this material are improved durability and superior mechanical properties. UHPFRC has high tensile strength in addition to compressive strength that is greater than $150 \mathrm{MPa}$ (Wille et al., 2012). 
Moreover, this material has enhanced post-cracking strength (Kim et al., 2009), high fracture energy (Othman \& Marzouk, 2017) along with dimensional stability. Additionally, it has been shown that fibers in UHPFRC allow for the development of closely spaced and small width cracks. Thus, allowing the concrete to continue carrying tensile stresses after cracking (Graybeal, 2008).

Due to the improved mechanical characteristics and strength of UHPFRC over conventional concrete, it has unique applications in the construction industry. UHPFRC has several uses in bridge construction due its fast-setting and durable properties. These uses include joint filling (between precast elements), overlays (preventing ingress of de-icing materials), pier jacketing (for better durability under extreme weather) and increasing the overall load-bearing capacity of bridges $\left(\right.$ Ductal $\left.^{\circledR}, 2019\right)$. UHPFRC is used in other structures such as buildings (increasing load bearing capacity of slabs) and hydraulic structures such as dams (improving the dam's strength and longevity against impact damage). Furthermore, UHPFRC has other specialized uses in offshore structures, punching shear zones in slabs, and blast resistant structures (Naaman, 2007).

\subsection{Research Scope}

The scope of this research is to investigate the flexural capacity of UHPFRC beam specimens under monotonic incremental static loading. To achieve this goal, the research presented in this study is divided into an experimental, analytical, and a numerical investigation. The experimental program examines the ultimate load capacity of beam specimen subjected to four-point static loading to failure. The second component of this research examines building codes and design guidelines for obtaining the flexural capacity of UHPFRC beam specimen. Lastly, the third stage of this research is a numerical study that employs a general-purpose program; ABAQUS software (Simulia, 2019). A built-in model called Concrete Damage Plasticity (CDP) is employed to consider stiffness degradation and the nonlinearity of concrete materials. The numerical model is 
calibrated using the results and boundary conditions of the experimentally tested specimen. Afterwards, the simulation results are validated with the tested UHPFRC beams and the validity of the CDP material model is assessed.

\subsection{Research Objective}

The main objective from this investigation is to find an analytical method for calculating the flexural capacity of UHPFRC with better accuracy than the $76 \%$ presented by using the stress block assumption used by both the Canadian and American codes in previous literature (Graybeal, 2008). In order to do this, an experimental program has been developed using varying beam spans. Additionally, a numerical study has been conducted to verify the experimental results. The experimental and numerical results will then be compared with analytical methods to examine their applicability and suitability. The following categories examine each research phase in more details:

1. To investigate the mechanical properties of UHPFRC materials and steel reinforcement that are needed to define the new stress block.

2. To design the experimental testing program which focuses on the structural behaviour of fullscale UHPFRC beams subjected to monotonic static loading. The design variables that will be investigated are the span $(915 \mathrm{~mm}, 1830 \mathrm{~mm})$ and the steel reinforcement ratio $(1.27 \%, 2.54 \%$ and 4.02\%). The main data that will be recorded during the testing are the mid-span deflection, steel reinforcement strain, and the monotonic load applied incrementally until beam failure. Another important procedure will be marking of the surface cracks during the loading phase, which will be used for comparison purposes with the FE analysis simulation crack patterns. 
3. To develop an accurate FE analysis of the tested beams using ABAQUS software (Simulia, 2019) using the mechanical properties captured in the experimental investigation. These properties will be used for calibrating the FE models in order to accurately predict the static response of the UHPFRC beams under monotonic incremental loading. The validity of the FE model will be investigated by comparing the numerical response with the experimental behaviour of the beam specimens. Moreover, the CDP constitutive model and its material parameters will be investigated to determine their replication accuracy of the tested beams' response.

\subsection{Thesis Overview}

This thesis is divided into the following six chapters.

Chapter 1: presents a brief introduction to identify the problems, objectives, scopes and the outline of the research study.

Chapter 2: examines background information and the recent development in concrete, particularly on the flexural capacity of UHPFRC beams. Literature on the stress block for normal, high and ultra-high concrete will be also examined. Additionally, a brief summary of finite element analysis and the use of ABAQUS software in modelling UHPFRC beams will be summarized.

Chapter 3: outlines the experimental investigation of UHPFRC rectangular beams subjected to four-point static loading. The details of formwork preparation, steel reinforcement placement, instrumentation, mixing, and casting of the five UHPFRC beam specimen with variable lengths and steel reinforcement ratios are described. Moreover, a summary of the testing procedure will also be presented.

Chapter 4: presents the results and observations of the experimental program. The results of the flexural capacity are analyzed by investigating the effect of the design variables (span and 
reinforcement ratio). Building code design guidelines and recommendations found in literature on the flexural capacity of UHPFRC beams will be analyzed analytically and presented. Furthermore, the flexural capacity results of the analytical methods will be summarized and compared to those found in the experimental investigation.

Chapter 5: discusses the use and implementation of 3D-FE analysis in calibrating and modelling the experimentally tested beam specimen. The applicability of the CDP model in ABAQUS for modelling UHPFRC beams under monotonic incremental static loading is addressed. The numerical responses (including load-deformation response) and damage patterns are compared to the experimental specimen.

Chapter 6: summarizes the main findings of the experimental, analytical and the finite element numerical research. In addition, this chapter outlines future research recommendations. 


\section{CHAPTER 2}

\section{LITERATURE REVIEW}

\subsection{Introduction}

Concrete is a composite material that contains unique elements such as fine and coarse aggregates, water, and cement that forms a matrix composition. This basic matrix composition is often combined with other material to enhance strength and durability of concrete. Such material includes silica fume and chemical admixtures. The blending of the basic matrix composition elements yields normal strength concrete that is used in everyday construction of various structures in our society. Normal strength concrete is defined as having a compressive strength around 40 MPa, while high strength concrete has a compressive strength between 60-100 MPa. However, advancements in technical chemical knowledge and Nano-technology combined with scientific curiosity have led scientists and researchers in the past few decades to investigate concrete with much higher compressive strengths. This exceptional concrete is defined as ultra-high performance fiber reinforced concrete (UHPFRC) with a minimum compressive strength of $150 \mathrm{MPa}$.

\subsection{UHPFRC Material}

\subsubsection{Background}

In the past few decades higher concrete compressive strengths were achieved using heat and pressure curing. For example, scientists were able to achieve a compressive strength up to 800 $\mathrm{MPa}$ using pressure and heat curing with temperatures as high as $400^{\circ} \mathrm{C}$ and $50 \mathrm{MPa}$ pressure (Wille et al., 2012). Other scientists were able to reach compressive strengths up to $500 \mathrm{MPa}$ using similar curing techniques and large fiber volume content. However, this technique of using high 
temperatures, excessive pressure and large fiber volume content is not efficient for bulk applications and is usually discouraged. Additionally, large fiber volume content can lead to a decrease in the concrete workability.

UHPFRC with a compressive strength of $150 \mathrm{MPa}$ and higher can be achieved at normal temperature conditions and with moist curing techniques. This concrete is becoming very popular and achieving high compressive strengths has been the target for many scientists and engineers in the past few decades. As previously mentioned, heat and pressure curing are not feasible options for bulk applications which promoted scientists to look for other ways of obtaining high compressive strengths. Extensive research in North America has shown that adjusting the concrete matrix by adding elements such as silica fume and short steel fibers can enhance durability and increase compressive strength (Wille et al., 2011).

\subsection{Fiber Reinforced Concrete}

The addition of steel fibers to the concrete during the mixing phase provides many advantages such as enhancing the durability and performance of the structure. In addition, concrete's inherent brittle nature can be improved by providing steel fibers which enhances ductility. The steel fibers are usually added to the mix by volume between $1-5 \%$. Steel fibers trigger strain hardening and softening to the structure during its service life. Strain hardening is a desirable stage in the life of concrete since it encompasses multiple cracks that prolong the service life of the structure.

\subsubsection{Fiber reinforced cement (FRC) composites}

Naaman (2007) examined fiber reinforced cement composites (FRC) under tensile loading to determine if the response is "strain softening" or "strain hardening". The paper examines FRC composites and concluded that "strain-hardening" is more suitable for structural applications. The 
fiber and matrix can be described as one composite, hence the commonly used name "fiber reinforced cement composites". The matrix described here is the combination of mortar, cement paste, and concrete. Fiber reinforced cement composites (FRC) have gained popularity in the past four decades. This is the case, since a better understanding of the fiber-matrix interface has been attained. Some examples of such development include: increased availability of all types of fibers, addition of polymers to the matrix which enhances the bond between the matrix and fibers, and the use of micro-fillers such as fly ash and silica fume which enhance strength and durability.

Fiber reinforced cement can be classified into two types: strain-softening and strain-hardening. Strain hardening is the preferred type of use in the matrix. In strain softening, localization occurs directly after the first crack. However, in strain hardening, multiple cracking occurs before localization takes place. This is illustrated in Figure 1. 


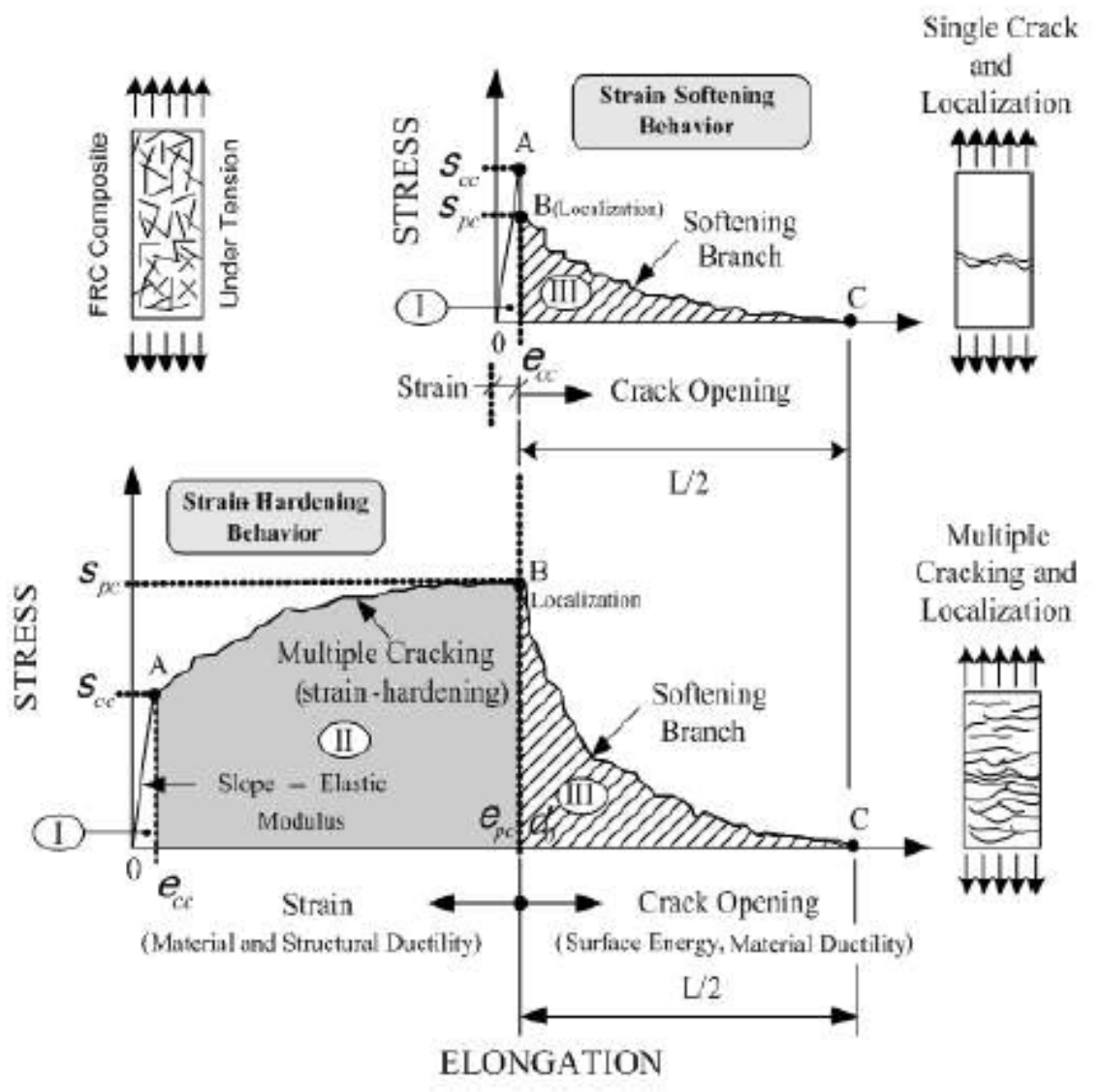

Figure 1: Stress-strain curves for strain hardening and softening of FRC in tension (Naaman, 2007)

The fiber used in concrete can be made from different material (E.g., wood, steel, glass), shapes (E.g., smooth or deformed), lengths and section types (E.g., circular, square, or rectangular). Combining different geometries, shapes, and mechanical properties can result in a stronger bond between the fibers and the matrix. Due to the enhanced properties and great ductility of fiber reinforced concrete, it can be used in a wide variety of applications in construction. For example, FRC can be used in prestressed concrete, offshore structures, long span bridges, and high-rise structures. Additionally, FRC can be used in specific structural regions such as punching shear zones in slabs and beam-column joints in seismic prone areas. Moreover, FRC can be used for 
repair and rehabilitation of existing structures. Fibers used in concrete structures contribute to the overall structural performance which helps maintain the integrity of the structure.

\subsubsection{Fiber contribution and orientation in concrete}

There are different ways to account for the steel fibers in the shear design of fiber reinforced concrete. Two of these biggest formulations will be discussed here. The first group considers that the fibers provide a separate shear contribution to that provided by the concrete shear. This is accounted for by using a fiber factor (Eq. 2-1) proposed by Minelli (2005),

$F=v_{f} \frac{l_{f}}{d_{f}}$

Where, $F$ is the fiber factor; $v_{f}$ is the fiber volume; $l_{f}$ is the length of the fiber; and $d_{f}$ is the diameter of the fiber. Some of the research in this group is proposed by Mansur et al., (1986) and Ashour et al., (1992).

The second group considers the fiber contribution as part of the concrete and is taken care of by the enhanced tensile post cracking strength provided by the fibers. One of the promising models in this group is proposed by Minelli and Plizzari (2006) which adjusts the shear capacity formulation given in the Eurocode2. This adjustment is done through an added toughness parameter for adjusting the ratio of longitudinal reinforcement. This is done since the fibers improve the shear capacity similar to the longitudinal reinforcement.

Aoude et al., (2012) formulated an equation for straight steel fibers in order to account for the number of fibers per unit area $\left(N_{f i b}\right)$,

$N_{f i b}=\frac{v_{f}}{A_{f}} \alpha \eta_{l}$ 
Where, $v_{f}$ is the fiber volume; $A_{f}$ is the cross-sectional area of the fiber; $\alpha$ is an orientation factor that accounts for the fiber's random orientation and is taken as 0.375 ; and $\eta_{l}$ is a length factor that considers the embedment length of the fibers across the cracks and can be taken as 0.5.

Research has shown that the anchorage of hooked-end fibers improve its pullout resistance. The contribution of hooked-end fibers was investigated by Alwan et al., (1999) which shows that this contribution does not depend on the fiber embedment length or the matrix type. This contribution $\left(\Delta P^{\prime}\right)$ proposed by Alwan et al., (1999) can be calculated as,

$\Delta P^{\prime}=\frac{3.05}{\cos \left(\frac{45^{\circ} \times \pi}{180^{\circ}}\right)} x\left(f_{f y} x \frac{\pi\left(\frac{d_{f}}{2}\right)^{2}}{6}\right)$

Where, $f_{f y}$ is the yield strength of the fibers (in psi), and $d_{f}$ is the diameter of the fiber (in in.).

Another investigation by Rossi et al., (2017) examined the cracking behaviour of UHPFRC beams under four-bending using experimental and probabilistic numerical modelling. The concrete mix in their study includes $2.5 \%$ fiber volume that are $13 \mathrm{~mm}$ in length and $0.2 \mathrm{~mm}$ in diameter. In their investigation, Rossi et al., (2017) propose that in order to accurately determine the mechanical properties of UHPFRC, inverse analysis using three-point bending tests on notched beams should be considered in order to determine the post-cracking and tensile strengths of concrete which are important in defining an accurate numerical model for concrete embedded with steel fibers.

The three-point bending tests were performed numerically on notched beams sawed at both $45^{\circ}$ angle and parallel $\left(0^{\circ}\right)$ to the UHPFRC beam length. Both orientations show good agreement with the experimental results. However, beams sawn parallel to the beam lengths show greater postcracking and peak load energy than those sawed at $45^{\circ}$. This is the case because of the fiber orientation which is expected to be parallel to the beam length because of the unique UHPFRC 
casting that is characterized by its high flowability and self-consolidation. It is worth noting that correct fiber orientation in concrete can sew the cracks more efficiently.

\subsubsection{Post cracking behaviour of steel fiber reinforced concrete}

Wille et al., (2011) examined straight steel fibers for strength and ductility, including twisted and hooked steel fibers (for comparison) in ultra-high performance fiber reinforced concrete (UHPFRC) which contains $2 \%$ steel fibers with diameter of $0.2 \mathrm{~mm}$ and length of $13 \mathrm{~mm}$. This material which is produced by Lafarge ${ }^{\odot}$ is known commercially as Ductal ${ }^{\circledR}$.

Wille et al., (2011) compared different mechanical properties of steel fibers such as compressive strength and post cracking stress $\left(\sigma_{\mathrm{pc}}\right)$ for different fiber manufacturers. As can be seen from Table 1, the highest compressive strength and post cracking stress achieved were $240 \mathrm{MPa}$ and $12 \mathrm{MPa}$, respectively, and belong to $\operatorname{Ductal}^{\circledR}$.

Table 1: Mechanical properties for UHPFRC (Wille et al., 2011)

\begin{tabular}{|c|c|c|c|c|c|c|c|c|}
\hline \multirow[t]{2}{*}{ Name } & \multicolumn{4}{|l|}{ Fiber } & \multicolumn{3}{|c|}{ Mechanical properties } & \multirow[t]{2}{*}{ Reference } \\
\hline & Material & $d_{f}(\mathrm{Mm})$ & $\ell_{f}(\mathrm{~mm})$ & $V_{\mathrm{f}}(\%)$ & $\sigma_{p c}(\mathrm{MPa})$ & $\varepsilon_{p c}(\%)$ & $f_{c}(\mathrm{MPa})$ & \\
\hline RPC & Steel & 0.15 & 12 & 2.4 & $7.8^{\mathrm{a}}$ & $\mathrm{n} / \mathrm{a}$ & Max. 230 & Behloul et al. [4] \\
\hline M1Q & Steel & 0.15 & 6 & 2.5 & 9 & $\mathrm{n} / \mathrm{a}$ & 150 & Schmidt et al. [36] \\
\hline Ceracem & Steel & 0.3 & 20 & 2.5 & 9.7 & 0.25 & 199 & Jungwirth [16] \\
\hline Ductal & Steel & 0.2 & $13-15$ & 2 & $12^{\mathrm{a}, \mathrm{b}}$ & 0.30 & $160-240$ & $\begin{array}{l}\text { Orange et al. [29], } \\
\text { Chanvillard and Rigaud [8] }\end{array}$ \\
\hline HFC & Steel & 0.2 & 13 & 2 & $13^{\mathrm{c}}$ & $\mathrm{n} / \mathrm{a}$ & 133 & Markovic [21] \\
\hline HPFRCC & Steel & 0.3 & 30 & 2 & $12^{\mathrm{d}}$ & 0.46 & 84 & Sujiravorakul [38] \\
\hline
\end{tabular}

${ }^{\mathrm{a}}$ Moderate heat treatment, ${ }^{\mathrm{b}}$ fiber surface treatment, ${ }^{\mathrm{c}}$ I-shaped specimen, ${ }^{\mathrm{d}}$ twisted fiber

The focus of Wille et al., (2011) was obtaining compressive strength greater than $150 \mathrm{MPa}$ by developing UHPFRC with the following properties: tensile strength $>13 \mathrm{MPa}, \sigma_{\mathrm{pc}} \geq 0.3 \%$, low fiber content $(\leq 2.5 \%)$. Obtaining high tensile strength and ductility $\left(\sigma_{\mathrm{pc}} \geq 0.3 \%\right)$ were possible by optimizing the mechanical bond between the cement and fibers and by using deformed fibers (Wille et al., 2011). It is worth mentioning that post cracking stress $\left(\sigma_{\mathrm{pc}}\right)$ more than $0.3 \%$ is not 
possible using straight steel fibers, thus, if the goal is high post cracking stress then deformed fibers should be used.

With hooked steel fibers, the post cracking strain obtained was $0.46 \%$ with fiber volume $1-2 \%$. On the other hand, twisted fibers improved the post cracking strain from $0.33 \%$ to $0.61 \%$ by increasing the fiber volume from $1-2 \%$. This high post cracking strain for twisted steel fibers is one of the highest found in published literature. However, further improvements can be made by enhancing the fiber twist ratio (Wille et al., 2012).

\subsubsection{Slip hardening behaviour of steel fiber reinforced concrete}

Other researchers such as Kim et al., (2009) investigated the slip hardening behaviour for twisted steel fiber and compared it with other fiber types such as straight and hooked steel fibers. UHPFRC has revolutionized the construction industry with its unique benefits. The steel fibers in UHPFRC not only improve the ductility of concrete's inherent brittle nature, but also improve the energy absorption and load carrying capacities (Kim et al., 2011).

As previously mentioned, the advantage of steel fiber inclusion in the matrix is triggering strain hardening which is a desirable state since it allows for multiple cracking to occur, thus, increasing the load bearing capacity. In order to trigger strain hardening, the post cracking strength must be greater than the first cracking strength, that is $\sigma_{\mathrm{pc}} \geq \sigma_{\mathrm{cc}}$ (Kim et al., 2009). One method to ensure that $\sigma_{\mathrm{pc}} \geq \sigma_{\mathrm{cc}}$ is to increase the fiber volume fraction to $8 \%$. However, this approach is not efficient because it is costly and impedes the workability during mixing. Kim et al., (2009) uses a unique approach to ensure that $\sigma_{\mathrm{pc}} \geq \sigma_{\mathrm{cc}}$ and that is accomplished by improving the bond strength between the fiber and matrix. This approach triggers strain hardening with low fiber volume fraction. In order to enhance the bond strength and improve the pullout resistance of the fiber, Kim et al., 
(2009) used twisted (T-) steel fibers. These fibers have a polygonal cross-sectional shape and display untwisting moment resistance (Kim et al., 2009).

Kim et al., (2009), developed an equation (Eq. 2-4) for calculating the equivalent bond strength for the different steel fibers under investigation.

$\tau_{e q}=\frac{2 x \text { Pullout Stress Energyxd }}{L_{f}^{2}}$

Where, $\tau_{e q}$ is the equivalent bond strength; $d_{f}$ the fiber diameter; $L_{f}$ the fiber length; and pullout stress energy is a measure of the amount of pullout energy associated with the fiber's sectional area (Kim et al., 2011).

The pullout stress energy for the smooth, twisted, and hooked fibers were measure by Kim et al., (2009) and are 3.7 MPa-m, 21.7 MPa-m, and 5.3 MPa-m, respectively. The diameter of the smooth and twisted fibers is $0.3 \mathrm{~mm}$, while for hooked fiber it is $0.38 \mathrm{~mm}$. The length of the three fibers is $30 \mathrm{~mm}$. The calculated equivalent bond strength for the smooth, twisted, and hooked fibers is 2.44 MPa, 14.46 MPa, and 4.50 MPa, respectively. The twisted (T-) fiber's special mechanical bond and "untwisting pullout mechanism" gives it superior advantage over smooth and undeformed fibers (Kim et al., 2009). This is evident by the high T-fiber's pullout stress energy and equivalent bond strength.

\subsubsection{Effect of steel fibers on shear resistance for normal strength concrete}

The ACI code does not include specific design guidelines and equations for calculating the shear resistance of concrete reinforced with steel fibers. Therefore, Aoude et al., (2012) examined the effect of steel fibers on the shear capacity, failure mechanism, and crack control. Studies have shown that steel fibers can enhance shear resistance and potentially act as a substitute for shear 
reinforcement (Dinh et al., 2010). This is possible since steel fibers can resist and redistribute diagonal tensile stresses after cracking (Aoude et al., 2012). By controlling diagonal tensile cracks, the fibers improve post-cracking resistance and shear performance. Steel fibers can be used as a replacement for shear reinforcement if the minimum fiber dosage is $60 \mathrm{~kg} / \mathrm{m}^{3}$ and the fibers meet the requirements in Chapter 5 of the ACI code; in addition to specific loading limits and material dimensions in Chapter 11.

Aoude et al., (2012) conducted experimental investigations on nine reinforced, normal strength concrete beams with hooked-end fibers $(0,0.5 \%$, and $1 \%$ by volume) subjected to four-point bending. The investigation examined steel fiber reinforced beams with and without shear reinforcement (stirrups), in addition to some longitudinal reinforcement. Moreover, two different beam sizes were used $(150 \times 250 \mathrm{~mm}$ and 300x500 mm). The testing procedure was conducted using an MTS machine with a $11400 \mathrm{kN}$ capacity.

The experimental results show that beams with cross-section of $150 \times 250 \mathrm{~mm}$ reinforced with bottom longitudinal reinforcement $(2-15 \mathrm{M})$ and sufficient steel fibers $(0.5 \%$ and $1 \%)$ can exclude shear reinforcement. Nevertheless, beams with cross-section of 300x500 mm reinforced with bottom longitudinal reinforcement (4-25M), top reinforcement (2-20M), and steel fibers $(0.5 \%$ and $1 \%$ ) show some shear resistance yet are not adequate to avoid shear failure due to larger crosssections. In this case, shear resistance can be improved with higher steel fiber content ( $2 \%$ by volume). The third set of beams have the cross-section and reinforcement as the aforementioned beam (with bottom and top reinforcement), however, they include transverse reinforcement (10M at $275 \mathrm{~mm})$. This last set of beams show that the addition of steel fibers $(0.5 \%$ and $1 \%)$ did not increase the maximum load-carrying capacity, albeit, they did show improvements in the ductility and post-peak response. 
The improvement in beam shear strength that has resulted from the use of steel fibers has been reported during the past three decades by several researchers such as Naaman et al. (2007) and Wille et al. (2011). Several researchers provided an excellent review of the contribution of steel fibers to beam shear design. The researchers reviewed the design guidelines with several models and design codes. The improvement in the shear strength which results from the use of fibers in the concrete mix was modeled by many researchers under two concepts: 1 ) the fiber factor that is related to the length and diameter of the fiber, and 2) based on the contribution of the fibers to the tension and shear properties of concrete.

\subsubsection{Tension stiffening model for normal strength concrete}

When talking about steel fibers, it is important to note their effect on tension stiffening which refers to concrete's ability in transferring tension along the cracks (Collins and Mitchell, 1991). This has many advantages such as enhancing the biaxial response of stressed elements (particularly in stressed regions) (Abrishami and Mitchell, 1996). The main reason for incorporating fibers in concrete revolves around the ability of fibers to undergo larger tension stresses. Thus, the concrete is able to carry large loads, allows for post cracking strength, and improves the bond between the flexural rebar and matrix (Abrishami and Mitchell, 1997). It is worth noting that steel fibers cannot replace reinforcing steel because of the fiber's random orientation. Although, reinforcing steel does not oppose tensile stress.

Figure 2 presents the response of reinforced concrete under tension. $\mathrm{N}_{\mathrm{c}}$ and $\mathrm{N}_{\mathrm{s}}$ refer to the ability of concrete and steel in carrying tension, respectively. It can be seen that under initial loading, concrete carries more tension than the reinforcement. However, as the loading increases, concrete's ability in carrying tension significantly reduces, yet it increases in the steel reinforcement. Figure 2 also presents the response of the reinforcement alone. 


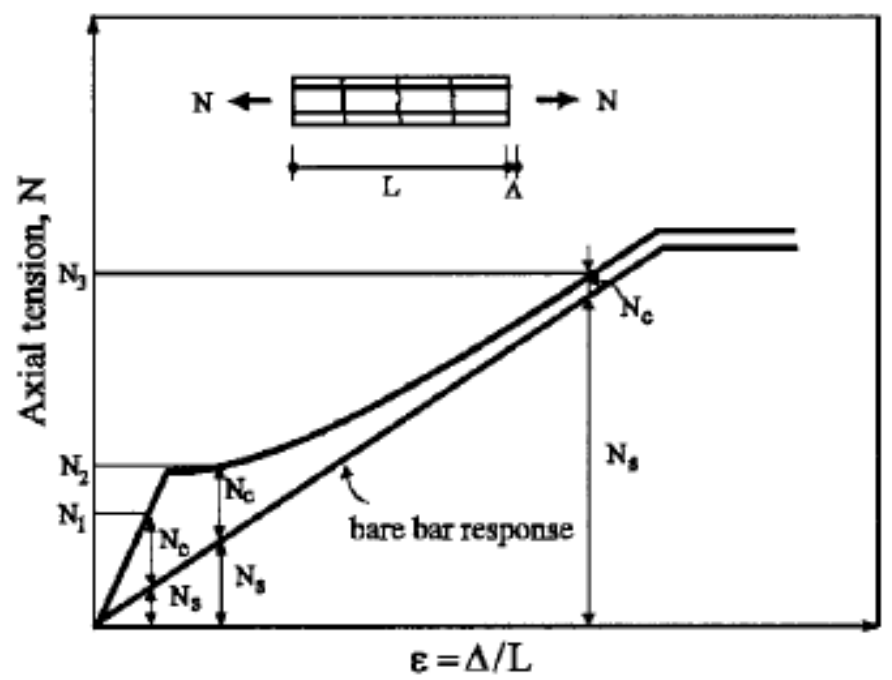

Figure 2: Reinforced concrete's response under tension (Abrishami and Mitchell, 1997)

A model (presented in Eq. 2-5) for predicting tension stiffening was proposed by Abrishami and Mitchell (1997).

$f_{C}=\frac{N-E_{S} A_{S} \epsilon}{A_{C}}$

Here, $f_{c}$ is the concrete's average tensile stress; $N$ is the total load applied; $A_{S}$ is the reinforcement area; $E_{S}$ is the elastic modulus of steel; $A_{C}$ is the area of concrete; and $\epsilon$ is the specimen's strain. The fiber's influence is already included in $f_{c}$. Equation 2-5 for predicting concrete's tensile stress showed comparable predictions with the experimental results. In addition, the inclusion of steel fiber ( $1 \%$ by volume) increased the tensile strength of concrete by $0.6 \mathrm{MPa}$ (Abrishami and Mitchell, 1997).

Currently, there are few models for predicting the force in the steel fibers at the crack location. There are far more models for normal and high strength concrete, yet fewer ones for fiber 
reinforced concrete. Abrishami and Mitchel (1997) developed a model for predicting the tensile force carried by the fibers. Their model is presented in Eq. 2-6.

$N_{f}=\frac{1}{6} V_{f} E_{f} A_{c}\left(\epsilon-\epsilon_{y}\right) \geq \frac{1}{6} V_{f} A_{c} f_{y f}$

Where, $N_{f}$ is the force carried by fibers; $V_{f}$ is the fibers by volume percent; $E_{f}$ is the steel fiber's modulus of elasticity; $A_{c}$ is the concrete's cross-sectional area; $f_{y f}$ is the fiber's yield strength; $\epsilon$ is the strain in the concrete; $\epsilon_{y}$ is the yielding strain in the reinforcing bar.

The proposed model by Abrishami and Mitchell (1997) presented in Eq. 2-6 predicts the tension stiffening behaviour of fiber reinforced concrete with good accuracy compared with test results. In addition, it was shown that concrete members reinforced with steel fibers presented better tension stiffening than those without fibers. This enhanced tension stiffening lies in the fiber's ability in transferring stresses across the cracks.

\subsubsection{Fracture energy of HSC and UHPFRC}

Fracture energy refers to the energy released per unit area during fracturing. It is a measure of how much energy is released when the element fails (fractures) during its service life when subjected to loading. Therefore, the higher the fracture energy the more durable, ductile and stronger the concrete will be.

Often, the concept of fracture energy for concrete is confused with metals. The fracture energy for concrete is the area under the descending portion of the stress-strain diagram, and not the area under the full diagram such as the case for metals (Marzouk \& Chen, 1995). The fracture energy and tension stiffening properties of high strength concrete (HSC) were determined by Marzouk \& 
Chen (1995). Moreover, the fracture energy for UHPFRC is about 100 times that of NSC (normal strength concrete) as confirmed by Wahba et al., (2012) and later by Maca et al., (2013).

Marzouk and Chen (1995) examined the fracture energy of 48 high-strength concrete (HSC)

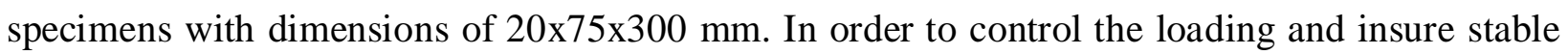
postpeak response, the test specimens are notched on both ends (notch dimensions of $11 \times 3 \mathrm{~mm}$ ) using a circular diamond concrete saw. The HSC specimens are tested under direct uniaxial tension using a special test setup comprising of a loading frame and wedge-type frictional grips. The use of this special testing equipment is required in order to attain reliable post-peak response. The servo-hydraulic testing machine consisted of an MTS 850 structure test system along with a highspeed data acquisition system. Additionally, strain measurements were attained by attaching 6 electrical resistance strain gauges ( $6 \mathrm{~mm}$ long) and 4 concrete strain gauges $(50 \mathrm{~mm}$ long) on both sides of the test specimens. The strain gauge readings along with the load-deformation data is captured using the data acquisition system.

The fracture energy was obtained using the postpeak behaviour concept proposed by Hillerborg (1985). The fracture energy $\left(G_{f}\right)$ can be calculated by integrating the stress-displacement curve as shown in the following equation,

$G_{f}=\int_{0}^{\delta_{\max }} f_{t} d \delta_{t}$

Where, $f_{t}$ is the tensile stress which is a function of tensile displacement $\delta_{t}$; and $\delta_{\text {max }}$ is the maximum tensile displacement when the tensile stress approaches zero (towards the end of tension softening). The fracture energy term proposed by Hillerborg (1985) can be expressed as a fracture energy density $\left(W_{f}\right)$ function as follows, 
$W_{f}=\frac{G_{f}}{w_{c}}=\int_{0}^{\epsilon_{\max }} f_{t} d \epsilon_{t}$

[Eq. 2-8]

Where, $\epsilon_{t}$ is the tensile strain; $\epsilon_{\max }$ is the maximum tensile strain when the tensile stress approaches zero (towards the end of tension softening); and $w_{c}$ is the fracture process zone width.

The fracture energy density $\left(W_{f}\right)$ of concrete is a representation of the area under the stress-strain curve in tension. Furthermore, Hillerborg (1985) noted that this energy absorbed by concrete is mainly linked with the descending branch in tension. Test results by Marzouk and Chen (1995) concluded that the fracture energy of high strength concrete is 10 times the area of the ascending part of the stress-strain curve of normal strength concrete and about five times the area under the ascending portion of the stress-deformation curve.

Wahba et al., (2012) at Ryerson University investigated the fracture energy experimentally by using 200x300x1000 mm UHPFRC beams subjected to four-point bending. A fiber optic strain gauge with a length of $150 \mathrm{~mm}$ was installed on the beam, $40 \mathrm{~mm}$ above the bottom surface to measure the strain along the fracture zone. As can be seen in Figure 3, the test setup in their investigation consisted of a Material Testing System (MTS) Model 815 connected to a data acquisition system to measure load, strain and deflection. It should be noted that a separate data acquisition system was used in their investigation to capture changes in the wavelength from the fiber optics cable. The recording frequency was $0.25 \mathrm{~Hz}$ at a displacement rate of $0.008 \mathrm{~mm} / \mathrm{s}$.

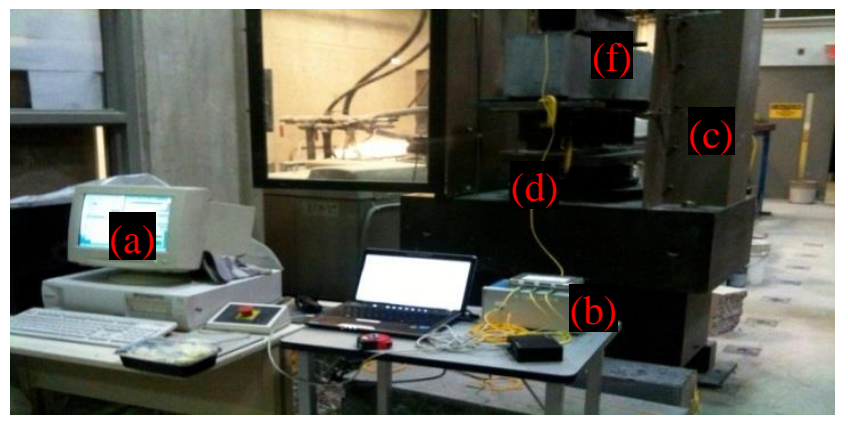

(a) MTS acquisition system

(b) Fiber optic wavelength acquisition system

(c) MTS machine

(d) Fiber optics cable

(f) Test specimen

Figure 3: Fracture energy test setup (Wahba et al., 2012) 
Due to the brittleness of concrete, capturing the complete load-deformation curve is a problematic task. This brittleness problem of concrete can be improved by the addition of steel fibers which enhances the ductility of the material. In such cases, the use of UHPFRC greatly enhances the ductile property which in turn facilitates the capturing of the complete load-deformation behaviour.

Figure 4 displays the load-strain relationship of beam specimen FE1 and FE2. The inclusion of steel fibers allowed the load-strain to increase up to $90 \%$ of the ultimate load. After that, there was a significant increase in the strain with a slight increase in the load. It is interesting to note that during their testing, surface cracks were only observed at around $80-90 \%$ of the ultimate load. This is peculiar to UHPFRC due to the presence of steel fires which hold internal cracks tightly, thus, delaying their emergence to the surface.

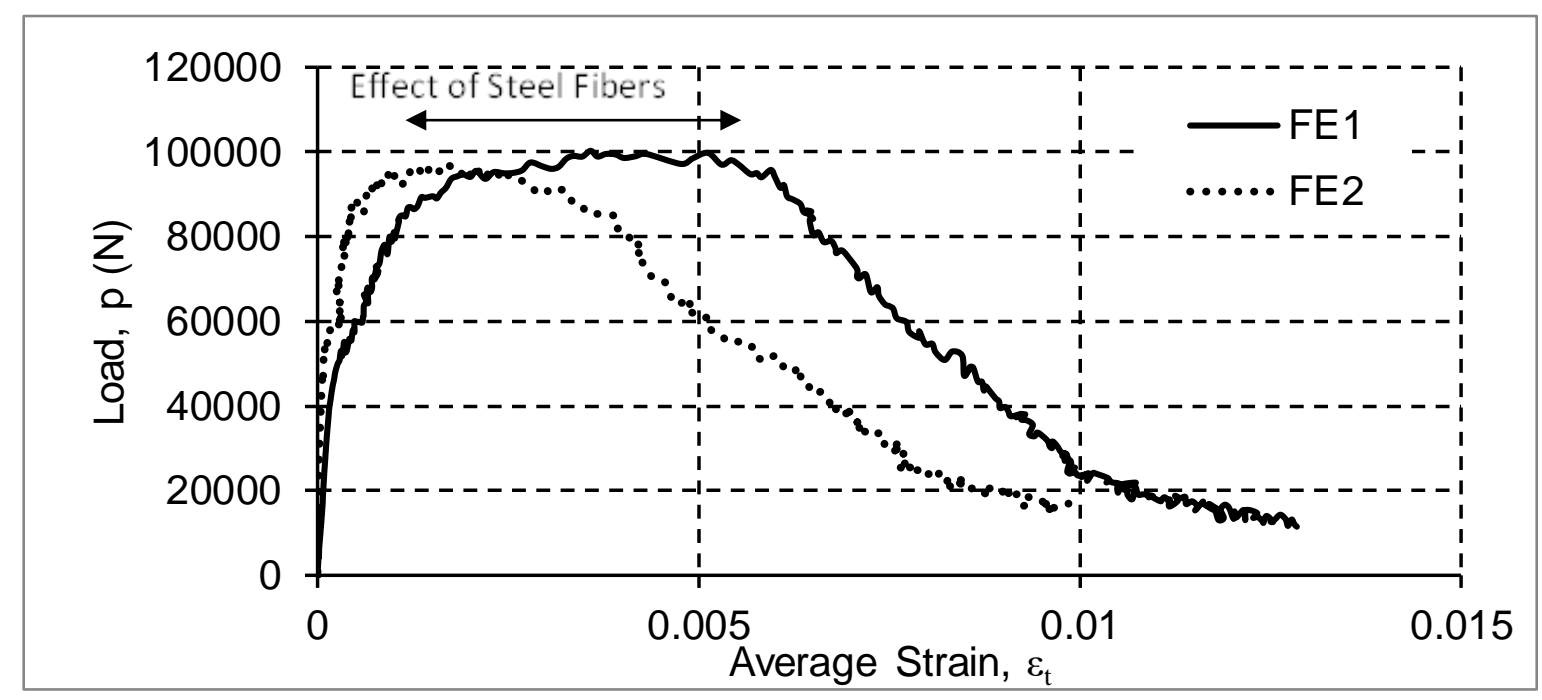

Figure 4: Average tensile strain measurements of specimen FE1 \& FE2 (Wahba et al., 2012) 
Table 2 summarizes tension and fracture properties of UHPFRC for the tested beam specimen of Wahba et al., (2012). As can be observed, the fracture energy obtained is 100 times that of conventional concrete.

Table 2: Tension and fracture properties of UHPFRC (Wahba et al., (2012))

\begin{tabular}{ccccccc}
\hline $\begin{array}{c}\text { Specimen } \\
\text { Name }\end{array}$ & $\begin{array}{c}\mathrm{f}_{\mathrm{c}}^{\prime} \\
(\mathrm{MPa})\end{array}$ & $\begin{array}{c}\mathrm{f}_{\mathrm{u}} \\
(\mathrm{kN})\end{array}$ & $\begin{array}{c}\epsilon_{\mathrm{p}} \\
\times 10^{-6}\end{array}$ & $\begin{array}{c}\mathrm{G}_{\mathrm{F}} \\
(\mathrm{N} / \mathrm{m})\end{array}$ & $\begin{array}{c}\mathrm{E}_{\mathrm{t}} \\
(\mathrm{GPa})\end{array}$ & $\begin{array}{c}\mathrm{f}_{\mathrm{r}} \\
(\mathrm{MPa})\end{array}$ \\
\hline FE1 & 163 & 100.25 & 3500 & $18,839.4$ & 58 & 8.68 \\
\hline FE2 & 137 & 97.5 & 2700 & $16,852.4$ & 57 & 8.44 \\
\hline
\end{tabular}

The fracture energy was also tested by Maca et al., (2013) and it was observed that it is 100 times that of conventional concrete (Table 3). Maca et al., (2013) investigated the fracture energy by conducting three-point bending testing on UHPFRC prisms with dimensions of 400x100x100 mm and a notch that is $5 \mathrm{~mm}$ wide and $30 \mathrm{~mm}$ long. Deflection in the specimen's center was captured using LVDTs. The fracture energy was found using the work of fracture method. According to Maca et al., (2013), the load-deflection curve used to calculate the work of fracture $\left(W_{f}\right)$ is as follow,

$W_{f}=\int_{0}^{u_{u}} P d u$

Where, $P$ is the load obtained from the load-deflection curve; $u_{u}$ is the final displacement when the load is decreased to zero. Next, the fracture energy $\left(G_{f}\right)$ can be calculated from the recommendation of RILEM TC 162 as

$G_{f}=\frac{W_{f}+m \cdot g \cdot u_{u}}{b \cdot\left(h-a_{0}\right)}$

Where, $m$ is the specimen weight (support to support); $g$ is the gravitational acceleration; $u_{u}$ is the final displacement; $b$ is the beam width; $h$ is the beam height; and $a_{0}$ is the notch length. 
Table 3: Mechanical properties of NSC \& UHPFRC (Maca et al., 2013)

\begin{tabular}{cccc}
\hline Property & Unit & NSC & UHPFRC \\
\hline $\begin{array}{c}\text { Compressive } \\
\text { strength }\end{array}$ & $\mathrm{MPa}$ & 42.8 & 151.7 \\
\hline $\begin{array}{c}\text { Effective } \\
\text { fracture energy }\end{array}$ & $\mathrm{J} / \mathrm{m}^{2}$ & 165 & 19847 \\
\hline
\end{tabular}

In addition to fracture energy, the tensile behaviour (an important parameter related to fracture energy) was tested by Maca et al., (2013) on dog-bone shaped specimens with a length of $330 \mathrm{~mm}$ and a cross-sectional area of $30 \times 30 \mathrm{~mm}$ for the narrow part. The stress-strain behaviour of UHPFRC measured using uniaxial direct tensile testing is shown in Figure 5. It is evident that UHPFRC has superior strain hardening which allows for the development of multiple cracks; followed by strain softening. It is clear by now that short straight steel fibers added to the concrete matrix greatly enhances the tensile and fracture properties of UHPFRC.
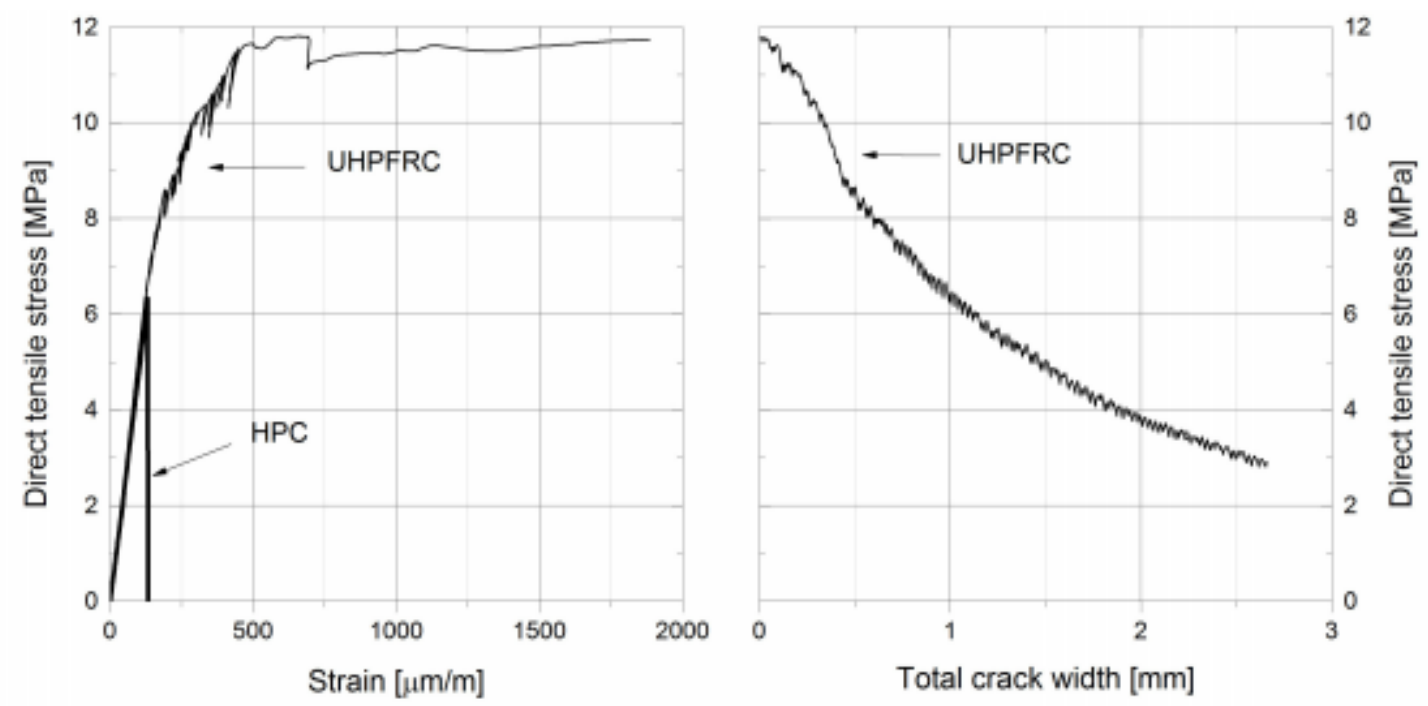

Figure 5: Tensile behaviour of HPC and UHPFRC (Maca et al., 2013) 
Fracture energy dissipation for strain hardening and softening was also examined by Xu and Wille (2015). In their investigation, it was observed that the fracture energy dissipation for strain hardening is greater than that for softening (Figure 6). This is characterized by the development of multiple cracking.

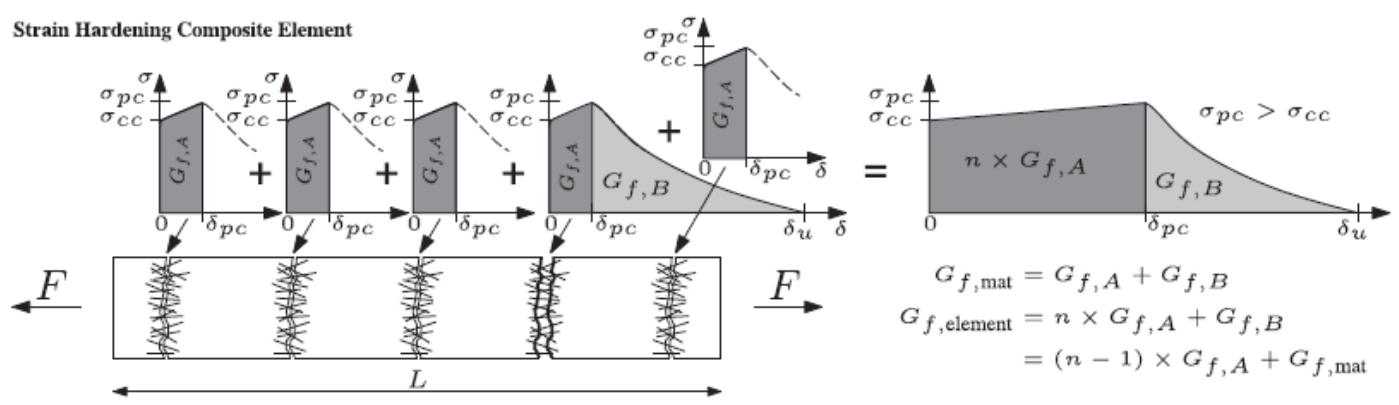

Figure 6: Fracture energy for strain hardening and softening (Xu \& Wille, 2015)

\subsection{Moment Capacity and Stress Block Parameters}

The Whitney stress block is used to calculate the flexural (moment) capacity of concrete structures subjected to bending. This stress block was originally formulated for normal strength concrete which makes its use for higher strengths a questionable matter. UHPFRC has a much greater concrete compressive strength than normal strength concrete. In addition to the increased compressive strength, UHPFRC has a higher tensile strength than that of conventional concrete.

The original stress block model ignores the effect of tensile strength because normal strength concrete has a very low tensile strength compared to its compressive strength. Therefore, its effect can be safely eliminated from design. This assumption is invalid for UHPFRC due to its higher tensile strength that needs to be taken into consideration. 


\subsubsection{Moment capacity for high strength concrete columns}

The rectangular stress block is an important concept in the design of reinforced concrete structures. Using the correct rectangular stress block parameters ensures accurate and safe design. A variety of codes where investigated to determine their applicability with higher concrete column strengths. The rectangular stress block model defined in the Canadian code CSA A23.3-94 is applicable for high strength concrete up to $125 \mathrm{MPa}$ (Canadian Standards Association 1994, p. 199). The $\alpha_{1}$ and $\beta_{1}$ parameters used in CSA A23.3-94 are,

$\alpha_{1}=0.85-0.0015 f_{c}^{\prime} \geq 0.67$

$\beta_{1}=0.97-0.0025 f_{c}^{\prime} \geq 0.67$

Where, $f_{c}^{\prime}$ is the concrete compressive strength in MPa.

The New Zealand code NZS 3101-1995 is applicable for HSC with compressive strengths between 60-100 MPa (Standards New Zealand 1995, p. 520). The $\alpha_{1}$ and $\beta_{1}$ parameters used in the New Zealand code are

$\alpha_{1}=0.85$ for $f_{c}^{\prime} \leq 55 \mathrm{MPa}$

[Eq. 2-13]

$\alpha_{1}=0.85-0.004\left(f_{c}^{\prime}-55\right) \geq 0.75$ for $f_{c}^{\prime}>55 \mathrm{MPa}$

$\beta_{1}=0.85$ for $f_{c}^{\prime} \leq 30 \mathrm{MPa}$

$\beta_{1}=0.85-0.008\left(f_{c}^{\prime}-30\right) \geq 0.65$ for $f_{c}^{\prime}>30 \mathrm{MPa}$

The Norwegian code NS 3473-1989 allows the use of high strength concrete with compressive strengths up to $105 \mathrm{MPa}$ based on 100x100x100 mm cube tests (The Norwegian Council for Building Standardisation, 1989). However, the strength limit based on standard cylinder tests is 94 MPa. 
The American code ACI 318-02 (American Concrete Institute) uses a rectangular stress block with a constant value of 0.85 for the $\alpha_{1}$ parameter and a constant value of 0.85 for the $\beta_{1}$ parameter for concrete with strength up to $30 \mathrm{MPa}$. The value of the $\beta_{1}$ parameter is reduced (by 0.08 ) for each additional $10 \mathrm{MPa}$ strength beyond $30 \mathrm{MPa}$ but has a limit of 0.65 .

Ozbakkaloglu and Saatcioglu (2004) proposed new stress block parameters for high strength concrete columns with compressive strengths up to $130 \mathrm{MPa}$. In their model, $\alpha_{1}$ and $\beta_{1}$ are equal to 0.85 for strengths up to $30 \mathrm{MPa}$ and for every $10 \mathrm{MPa}$ increase in compressive strength, and the stress block parameter of 0.85 decreases by 0.014 and 0.020 , respectively. The proposed parameters are,

$\alpha_{1}=0.85-0.0014\left(f_{c}^{\prime}-30\right) \geq 0.72$

$\beta_{1}=0.85-0.0020\left(f_{c}^{\prime}-30\right) \geq 0.67$

Where, $f_{c}^{\prime}$ is the column compressive strength in MPa. Figure 7 compares the proposed moment capacity values against the experimental values for 145 high strength column specimens. Ozbakkaloglu and Saatcioglu (2004) proposed model shows good accuracy comparable to experimental results which makes it a desirable design-based model. 


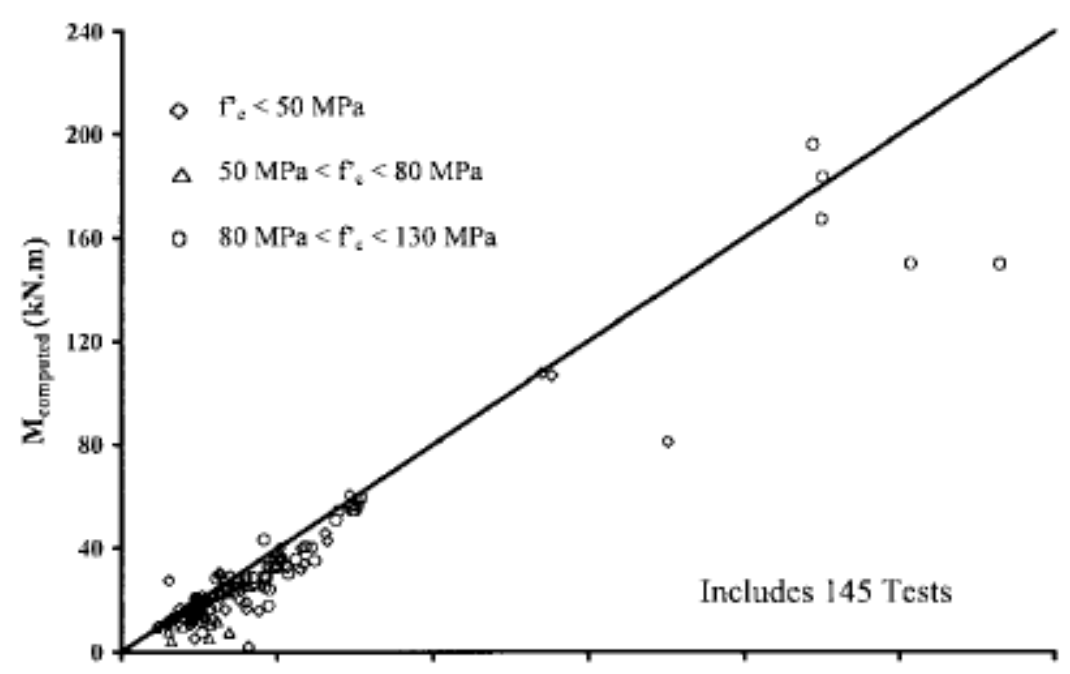

Figure 7: Experimental vs proposed model for high strength concrete columns (Ozbakkaloglu and Saatcioglu, 2004)

\subsubsection{Moment capacity for high strength concrete beams}

Oztekin et al., (2003) proposed a model for HSC beams using a modified stress-strain and equivalent stress block parameters. These modified stress-strain and stress block parameters are based on the Hognestad model for ordinary concrete. The modified stress-strain curve for high strength concrete is given in Eq. 2-19 (Oztekin et al., 2003),

$\sigma_{c}=f_{c}\left(k \frac{\epsilon_{c}}{\epsilon_{c u}}-(k-1)\left(\frac{\epsilon_{c}}{\epsilon_{c u}}\right)^{2}\right)$

Where,

$k=2-\left[\frac{f_{c}-40}{70}\right]\left(60 \mathrm{MPa} \leq f_{c} \leq 94 \mathrm{MPa}\right)$

$\epsilon_{c u}=\left[2.2+0.015\left(f_{c}-40\right)\right] 10^{-3}\left(60 \mathrm{MPa} \leq f_{c} \leq 94 \mathrm{MPa}\right)$

Where, $\epsilon_{c u}$ is the ultimate strain of concrete; $\epsilon_{c}$ is the concrete strain; and $f_{c}$ is the compressive strength of concrete. 
In addition to the aforementioned equations, the modified stress block parameters for high strength concrete are,

$k_{2}=\left(\epsilon_{c}-x\right) / \epsilon_{c}$

$k_{1}=2 k_{2}$

$k_{3}=F_{a} / f_{c} k_{1} \epsilon_{c}$

$F_{a}=\frac{1}{6} f_{c} \epsilon_{c u}(k+2)$

[Eq. 2-25]

Where, $k_{1}, k_{2}$ and $k_{3}$ are the stress block parameters shown in Figure $8 ; F_{a}$ is the area of the stressstrain curve (shown in Eq. 2-24). These parameters are valid for high performance concrete with strengths between 60-94 MPa.

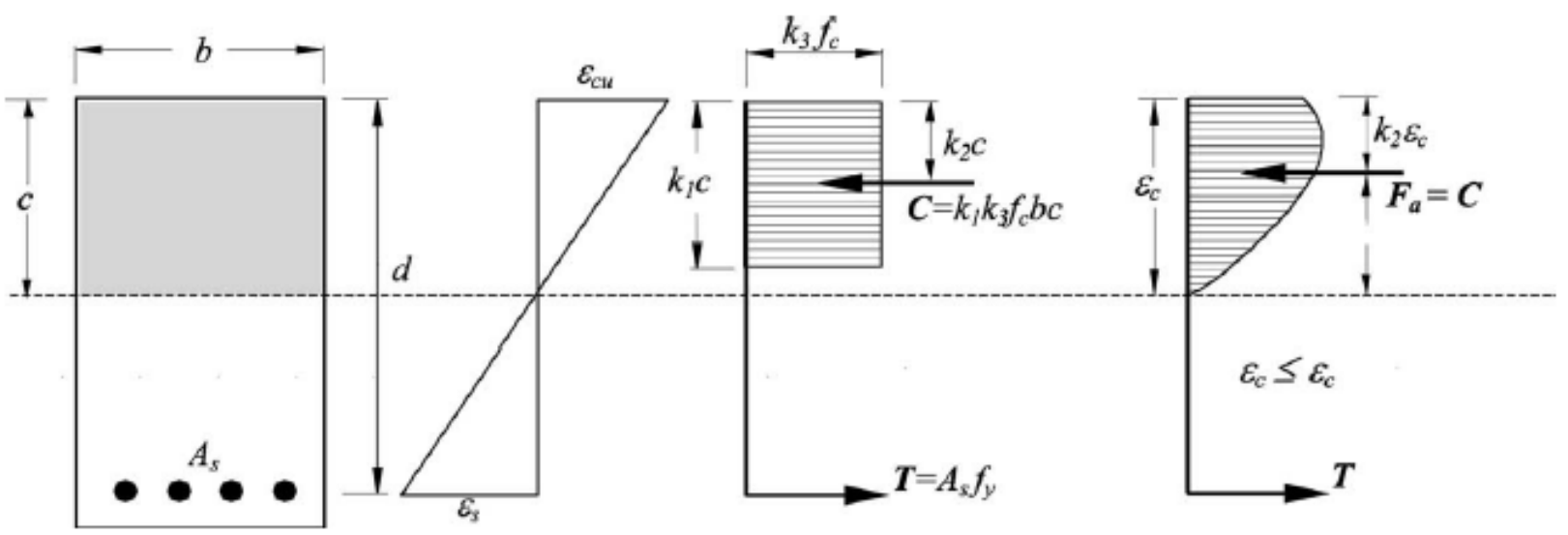

Figure 8: Equivalent rectangular stress block (Oztekin et al., 2003)

In Oztekin et al. (2003) proposed model, the strain distribution is uniform to easily calculate the neutral axis depth. 


\subsubsection{Moment capacity for UHPFRC}

Previous stress block models were originally formulated for conventional concrete and neglect any effect of concrete's tensile strength. The current models do not work well with UHPFRC for two reasons: omission of concrete's tensile strength and any steel fiber effect.

When examining the flexural behaviour of UHPFRC it is also necessary to consider the tensile behaviour of this material. This tensile behaviour undergoes different stages from the point of loading, namely a linear elastic stage followed by strain hardening that is then proceeded by a softening portion (Figure 9). Strain hardening is important for designing UHPFRC structures since at this stage of loading the steel fibers are fully employed and the material has great tensile capacity (Xu \& Wille, 2015). However, the tensile capacity is lost in the softening phase along with fiber pullout.

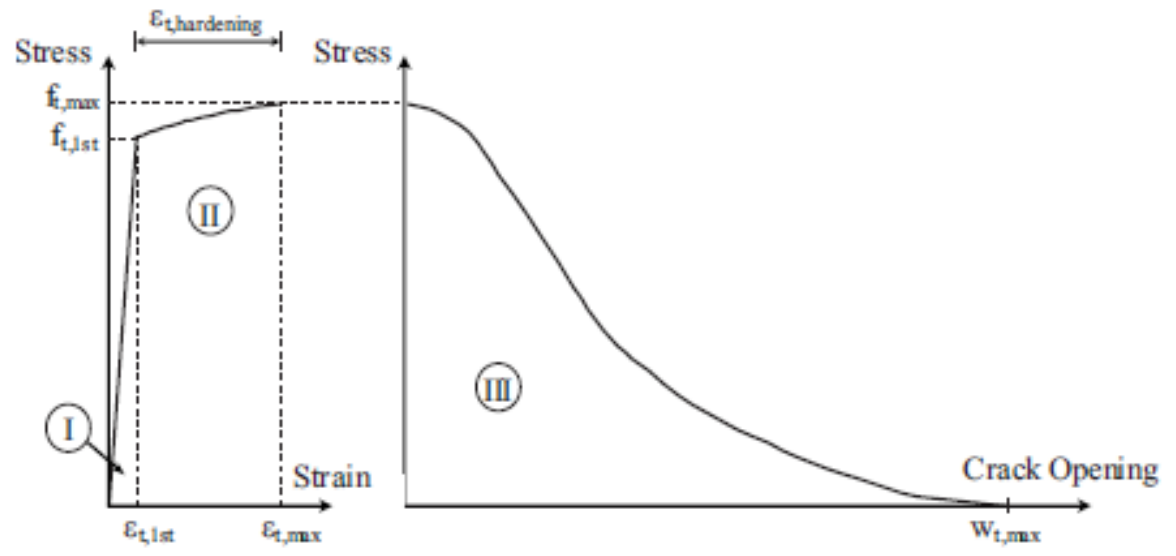

Figure 9: UHPFRC tensile behaviour (Graybeal, 2008)

Using conventional stress block parameters of 0.85 for $\alpha_{1}$ and 0.65 for $\beta_{1}$ with a maximum of 193 MPa concrete compressive strength, Graybeal, (2008) achieved a moment capacity within $73 \%$ of the experimental value. Graybeal formulated a simplified uniaxial stress-strain behaviour for his experimental investigation of prestressed I-girder that can be used in design. This simplified 
method includes a compressive strength of $165 \mathrm{MPa}$ (85\% of the tested strength), tensile capacity of 10.3 MPa, and a limited tensile strain (Figure 10) that is only $70 \%$ of the observed strain along the girder's tensile fiber (Graybeal, 2008). Using this simplified stress-strain model, Graybeal was able to get a moment capacity that is within $76 \%$ of the capacity observed experimentally.

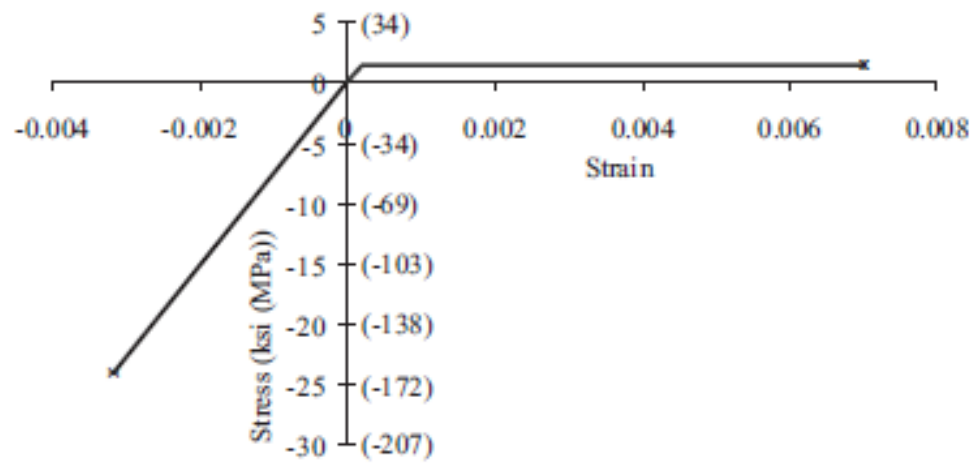

Figure 10: Simplified stress-strain behaviour (Graybeal, 2008)

In other literature, Bae et al., (2016) modified the rectangular stress block and used a triangular stress distribution in compression (Figure 11). In their analysis they investigated nine flexural strength models examining both the neutral axis location and the flexural capacity of the tested beams. It was shown that the ACI code presented low accuracy for the neutral axis depth due to the larger area of the rectangular stress block, as opposed to the triangular stress distribution (Bae et al., 2016). On the other hand, the models with the triangular stress distribution showed high accuracy comparable with test results. Bae at al., (2016) models provide good results for flexural capacity calculations as is verified against previous research on 22 test results. The recommended shape under compression in the stress block is triangular, as shown in Figure 11. Moreover, Eq. 226 and Eq. 2-27 are used in their proposed method for calculating the neutral axis location and the moment capacity. 


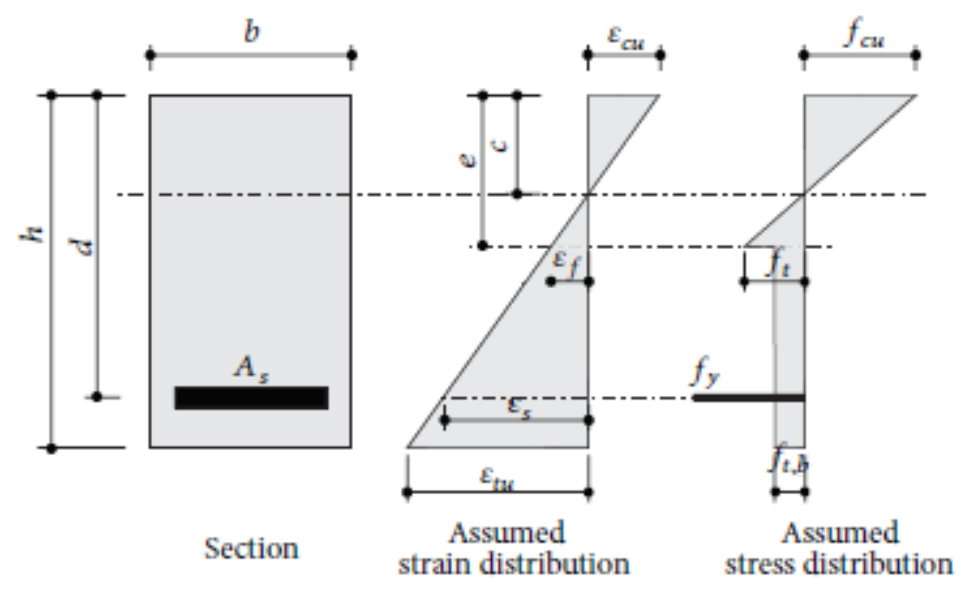

Figure 11: Stress and strain distribution for UHPFRC

(Bae et al., 2016)

The neutral axis depth along with the moment capacity is,

$C=\frac{A_{s} f_{y}+\gamma f_{t} b h}{\alpha_{1} f_{c}^{\prime} \beta_{1} b-0.5(\eta-1) f_{t} b+\gamma \eta f_{t} b}$

$M=\left(\alpha_{1} f_{c}^{\prime} \beta_{1} c b\right)\left(\frac{c}{2}\right)+\left\{f_{t}(e-c) b\right\}\left(\frac{2}{3}\right)(e-c)+\left\{\gamma f_{t}(h-e) b\right\}\left(e-c+\frac{h-e}{c}\right)+A_{s} f_{y}(d-c)[\mathrm{Eq}$.

$e=\left(e_{\text {sfibers }}+0.003\right)(c / 0.003)$

Where, $\alpha_{1}$ and $\beta_{1}$ are stress block parameters for UHPFRC (Graybeal, 2008); $f_{y}$ is the yield of strength of steel; $\gamma$ is the ratio between post cracking and ultimate tensile strength; $f_{t}$ is the tensile strength of concrete; $b \& h$ are the width and height of the rectangular cross-sectional area, respectively; $f_{c}^{\prime}$ is the concrete compressive strength; $\eta$ is a ratio between the ultimate tensile and compressive concrete strains plus one; $A_{s}$ is the area of flexural reinforcement; $d$ is the effective depth measured from the top compression fiber to the centroid of main flexural reinforcement; and $c$ being the neutral axis depth and $e_{\text {sfibers }}$ is taken as 0.0035 .

Another proposed model for UHPFRC is a stress-strain relationship composed of two parts shown in Figures 12 and 13. These models formulated to be used in metric units, were developed assuming that "plane sections remain plane" to simplify the analysis. The strain hardening model (Figure 12) is intended to be used when proper orientation of fibers is utilized in order for strain hardening to be achieved (Sorelli et al., 2007). If fibers are not properly oriented, the strain 
softening model (Figure 13) can be used. According to literature, both models can be used by designers due to the improved behaviour they offer.

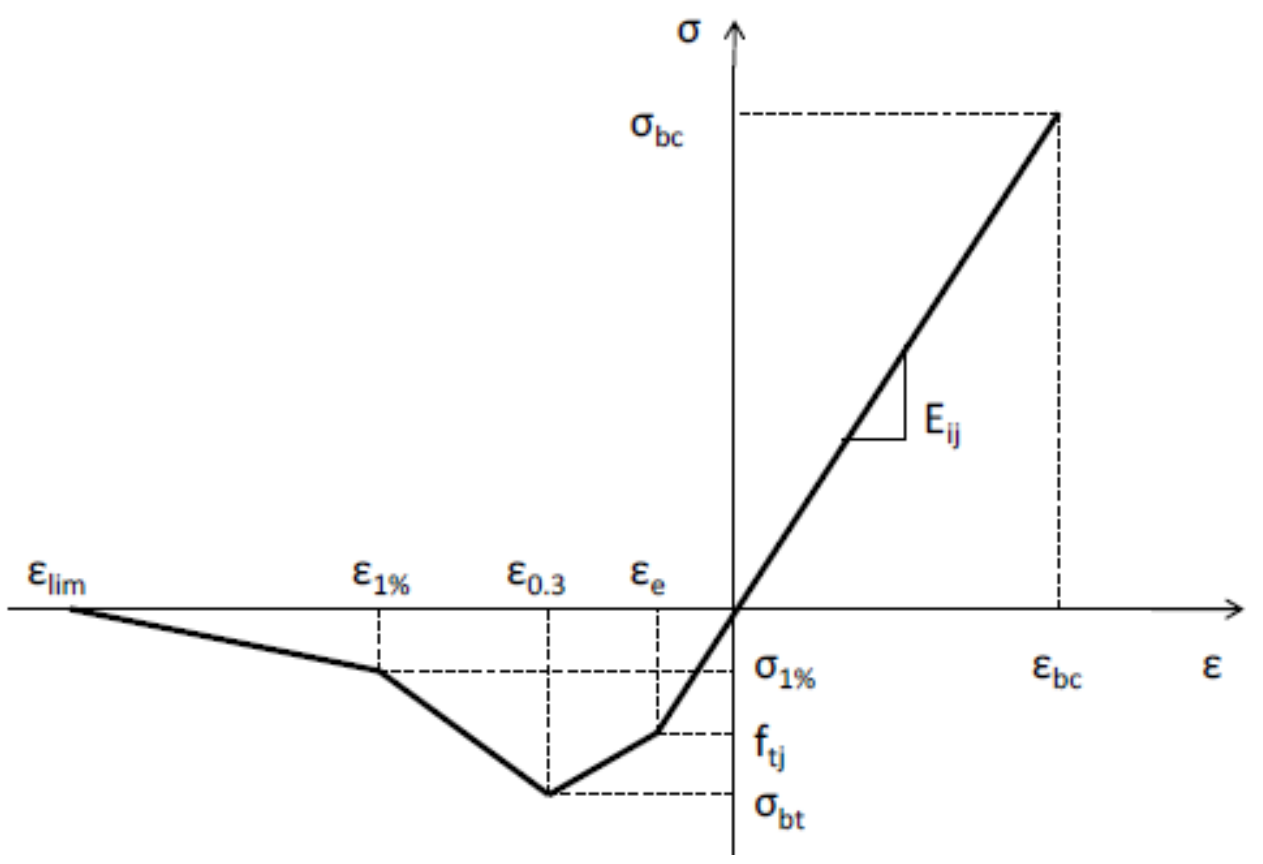

Figure 12: Strain hardening of UHPFRC proposed by AFGC and Setra (D’Alessandro, 2013)

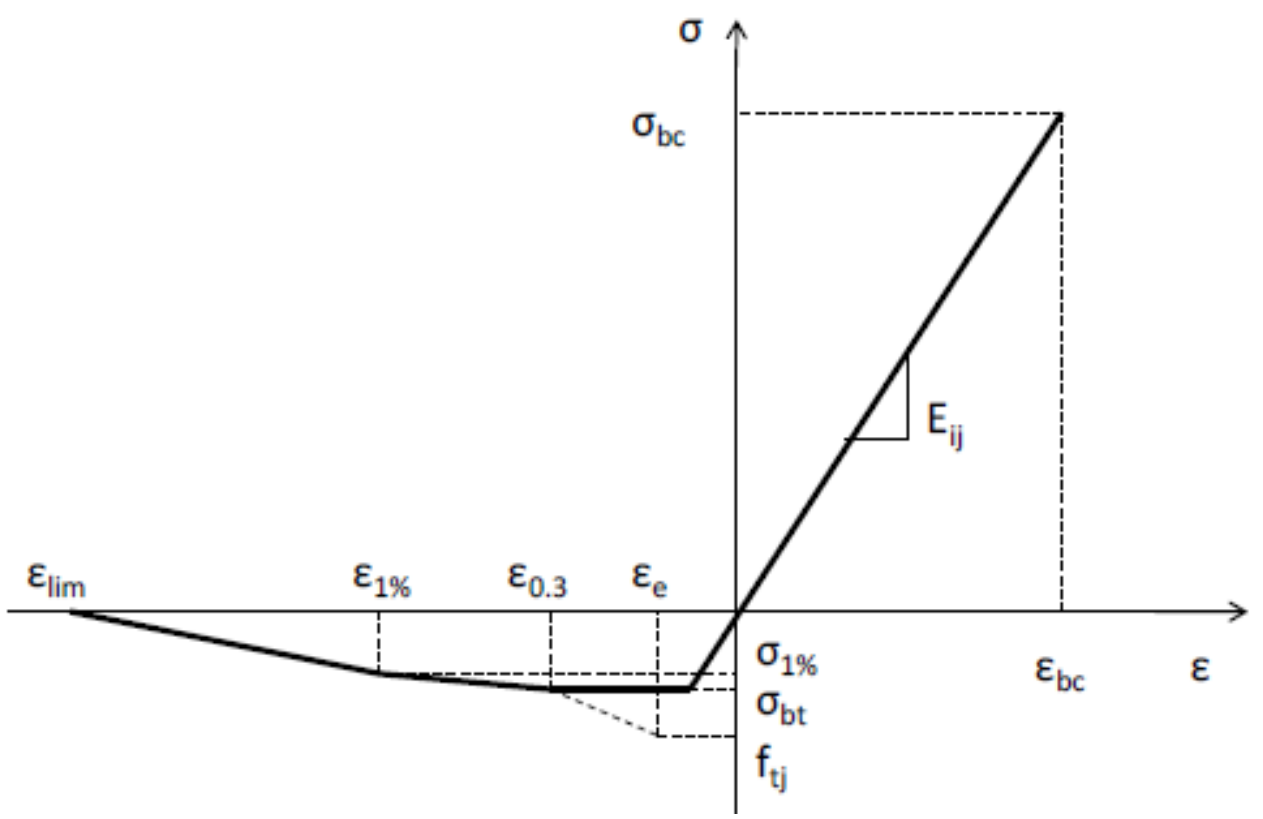

Figure 13: Strain softening of UHPFRC proposed by AFGC and Setra (D’Alessandro, 2013) 
Steinberg (2010) used Monte Carlo Simulation to compare different models including the aforementioned AFGC-Setra. A new developed and simplified model was formulated for the detailed stress-strain model shown in Figures 12 and 13. This new model assumes a constant stress between $\epsilon_{u 0.3}$ and $\epsilon_{u 1 \%}$ instead of the linearly decreasing tensile stress to $\epsilon_{1 \%}$ shown in Figure 12 for strain hardening (Steinberg, 2010). Moment capacity was the primary parameter in Steinberg's evaluation of the different models. The modified AFGC-Setra model (Figure 14) produced good moment capacity results (Steinberg, 2010).

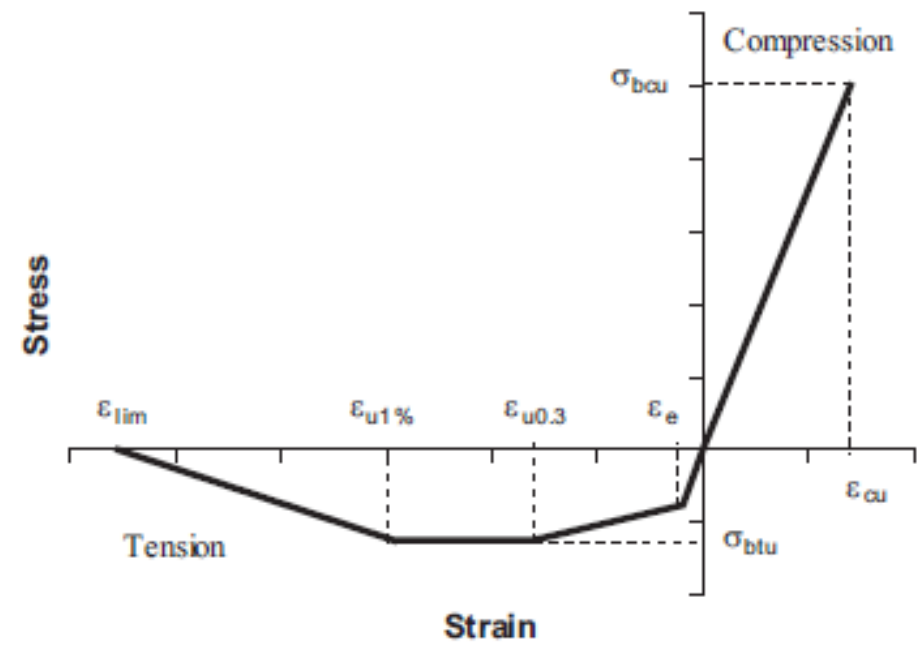

Figure 14: UHPFRC stress-strain curve (Steinberg, 2010)

A new stress-strain model was proposed at Ryerson University by Yazdizadeh (2014) for UHPFRC. This model was found by testing HSC and UHPFRC 100x200 mm cylinders equipped with fiber optic sensors as shown in Figure 15. A special type of sensors called fiber Bragg grating (FBG) were embedded in the centre of the cylinders to capture the elastic modulus and strain. The cylinders were tested using an MTS machine (Model 815). The developed stress-strain model has a strain of 0.0035 and 0.005 at maximum stress with an ultimate descending strain of 0.008 , as shown in the idealized curve in Figure 16. 


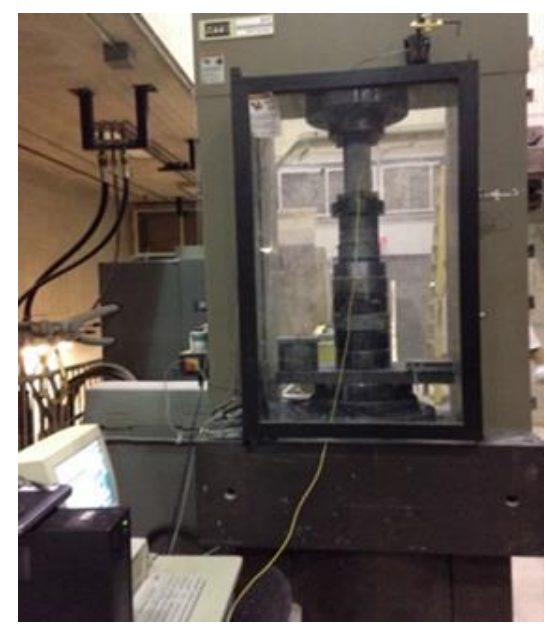

Figure 15: MTS test setup for cylinders equipped with FBG sensors (Yazdizadeh, 2014)

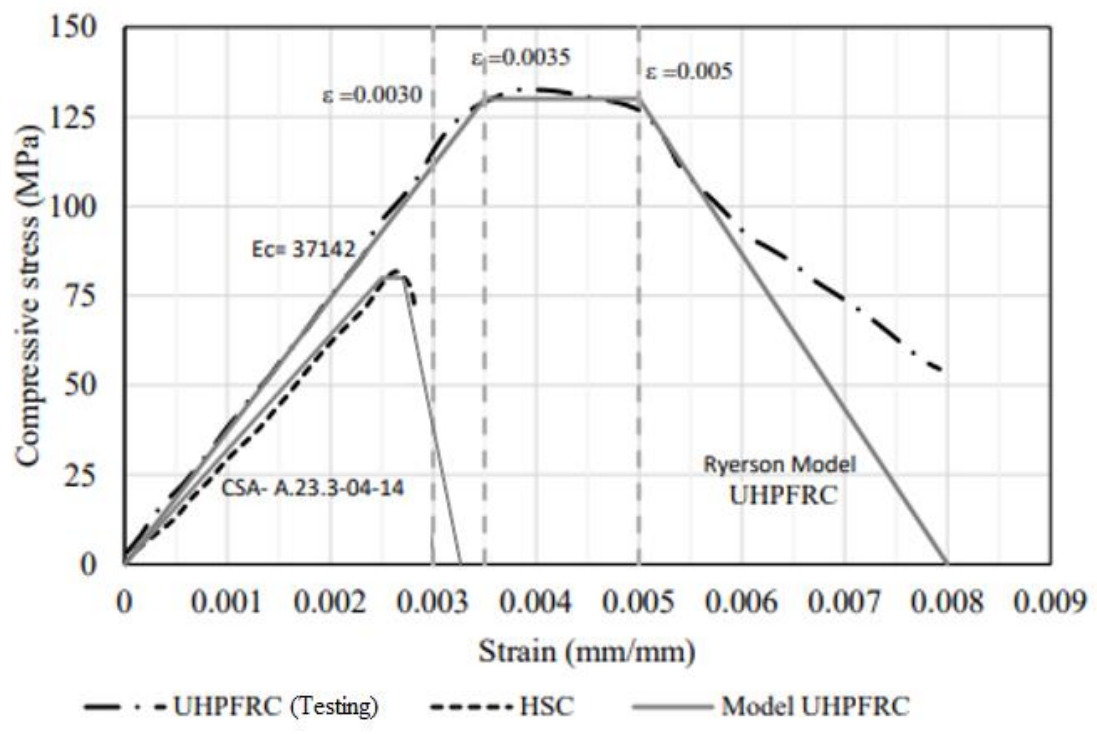

Figure 16: Axial strain vs compressive stress for HSC \& UHPFRC (Yazdizadeh, 2014) 


\subsection{Finite Element Modelling}

Finite element (FE) modelling is a powerful and accurate numerical method analysis for simulating the response of structures subjected to static and dynamic loading. This research uses ABAQUS version 6.14 for the FE analysis of UHPFRC beams under four-point monotonic incremental static loading (Simulia, 2019). Versatility of ABAQUS makes it a powerful simulation program for modelling almost any geometry (Simulia, 2019); including both linear and nonlinear problems. The research presented here focuses on modelling nonlinear, 3D problems under monotonic static loading using ABAQUS.

\subsubsection{Different modelling techniques}

The modelling of four-point loading in ABAQUS can be performed using two solution strategies. The first would be to preselect a load that will eventually cause failure in the beam. This method is useful if the load causing failure is known beforehand, albeit, it requires many increments to complete the simulation. However, for the analysis presented in this research this option is not suitable since the failure-load cannot be predicted accurately beforehand due to the behaviour of UHPFRC. The second option would be to select a reference point for the load above the beam surface and allow the load to be applied in selected increments until failure. This method ensures that the specimen under investigation will eventually fail in a shorter duration than the first method. The second method is used for the simulation in this research (see Chapter 5).

\subsubsection{Geometric modelling}

When modeling structures using FE software, it is best to model the simple beam to resemble the real structure to ensure accurate analysis. Static loading problems can be modeled as $2 \mathrm{D}$ or $3 \mathrm{D}$, 
however, due to the accuracy of 3D modelling, 3D is generally preferred when structures become more complex. The structures investigated in this research are modelled using 3D simulations.

Modelling steel reinforcement in FE can be done in several ways. Smeared analysis of reinforcement, discrete elements, or embedded elements can all be used to model reinforcements. The major drawback of the smeared analysis is the lack of local response effect and for the discrete elements' method is the restriction of concrete meshing by the location of the steel reinforcement (Belytschko et al, 2014). Nevertheless, the embedment element analysis does not restrict concrete meshing as it allows the reinforcement to be placed anywhere (Simulia, 2019).

\subsubsection{Concrete damage plasticity}

ABAQUS has a built-in model called concrete damage plasticity (CDP) for modelling the behaviour of plain and reinforced concrete structures. The CDP model is proposed for monotonic loading by Lublinear et al., (1989). CDP is a popular model for reinforced concrete structures due to the wide variety of concrete types that it can model in addition to allowing the user to include damage parameters for tension and compression along with yield strengths. Complete mathematical formulation for the CDP model can be found in the ABAQUS theory manual (Simulia, 2019) and Lublinear et al., (1989). The main input parameters in the CDP model required to describe the yield surface are the plastic flow potential eccentricity $(\epsilon)$, dilation angle $(\psi)$, shape factor $\left(K_{c}\right)$, and the biaxial to uniaxial strength ratio $\left(\sigma_{b o} / \sigma_{c o}\right)$. In addition to the aforementioned CDP parameters, other parameters essential to defining the behaviour of UHPFRC are required, such as the uniaxial tensile response (Figure 17) which is used as input in the numerical analysis. To define the uniaxial tensile curve, three parameters are required, namely: elastic modulus (E), fracture energy $\left(\mathrm{G}_{\mathrm{F}}\right)$, and the tensile strength $\left(\mathrm{f}_{\mathrm{t}}\right)$. 


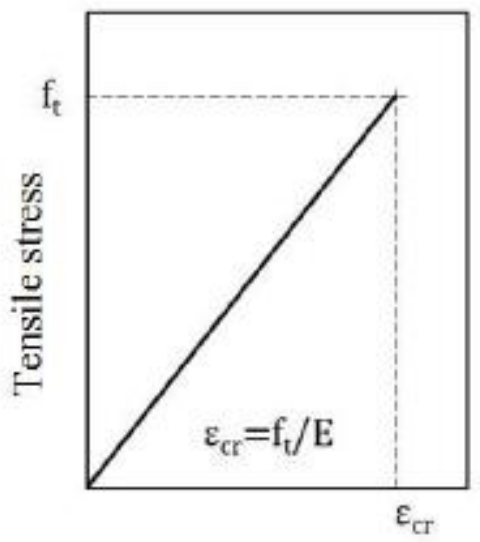

Axial strain

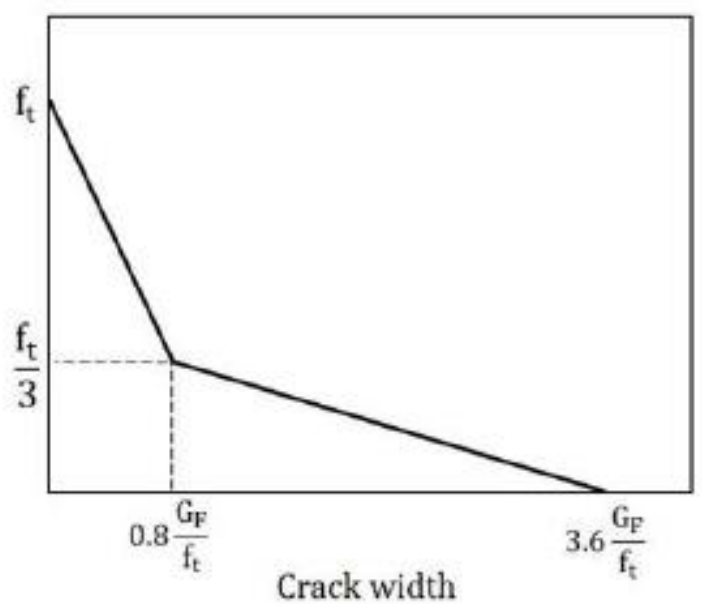

Crack width

Figure 17: UHPFRC uniaxial tensile relationship for CDP model (Othman, 2016)

\subsubsection{Mesh size}

Mesh selection is an important step in creating any FE model. This is especially critical for nonlinear analysis where the material is described by a softening constitutive relationship. The mesh size can be based on the crack width, half the steel fiber length, fracture mechanics related to the aggregate size, or on numerical convergence studies (Marzouk and Chen, 1995; Hussein and Marzouk, 2000; Marzouk and Chen, 1993).

\subsection{Previous Numerical Investigations}

A numeric study by Naeimi and Moustafa (2017) aims at exploring UHPFRC behaviour of structural elements (dog-bone and uniform prism concrete tensile specimen) until failure using FE analysis. The validity of "Total Strain Crack Model" is investigated numerically using a FE program called DIANA software. 
Naeimi and Moustafa (2017) used the smeared crack approach in their investigation since it is suited for the nature of the numerical analysis. In this approach, the cracked element can be considered as a continuum. This is possible by accounting for the stiffness change by using proper stress-strain relationships (Naeimi and Moustafa, 2017).

Material behaviour explored by the smeared crack method can be modelled by either multidirectional fixed-crack or the total strain rotating-crack methods. The later method is the one used in their study. In this method, the stresses and strains are evaluated in the crack directions in order to describe the tensile and compressive behaviour (Naeimi and Moustafa, 2017). The aim is inputting a macro UHPFRC behaviour where the interaction between the paste and fibers at different stages is investigated (Naeimi and Moustafa, 2017). Moreover, the FE numerical model calculated the crack width as the cubic root of the element volume.

The numerical simulation results present good agreement with the experimental testing. The total strain crack model was able to capture the elastic and strain hardening regions. However, the softening part was not fully captured (Naeimi and Moustafa, 2017).

Other research by Sing et al., (2017) investigated 4-UHPFRC beams with different spans and cross-sectional areas, both experimentally and numerically. The beams were loaded under fourpoint loading until failure. The experimental data are used to calibrate the numerical model that is performed using the FE analysis software. The stress-strain curves for both tension and compression obtained in the experimental investigation were used in the material model in FE. For modelling the concrete, they used an 8-node brick element with reduced integration (C3D8R) while for the reinforcing steel they used a 3D truss element (T3D2). The reinforcing steel and concrete were fully bonded and the reinforcements were embedded into the concrete. The bottom supports and the two loading plates were modeled with an 8 -node brick element (C3D8R) and 
assuming steel for material properties. Concrete damage plasticity (CDP) was used for defining the behaviour of the tested specimen and for predicting the flexural behaviour. The moment capacities obtained from the numerical and experimental analysis are in close proximity with a $5 \%$ difference only. Sing el al., (2017) concluded that the overall load-deformation behaviour of UHPFRC beams can be accurately predicted using the calibrated CDP model.

In other literature, the applicability of the CDP is examined by Othman and Marzouk (2017) on UHPFRC plates with different steel reinforcement ratios subjected to impact loading. The choice of CDP is driven by its capability in considering stress-strain relationships, tensile and compressive strain rates, as well as damage parameters which are an integral part of dynamic analysis. The simulation is performed using 3D-FE model with reduced-integration brick elements (C3D8R) meshing for the concrete specimens and drop-weight. The steel fibers are not modeled separately, since it is assumed that they are distributed uniformly throughout the matrix. Moreover, the strain hardening was modeled as a function of crack opening. In their study, they concluded that the CDP model is useful and accurate in predicting the behaviour of UHPFRC with $2 \%$ steel fibers and compressive strength $150 \mathrm{MPa}$ compressive strength.

Based on the aforementioned research findings in this section, a complete and accurate FE analysis simulation for UHPFRC structures is possible when both of the tensile and compressive behaviours, along with proper damage parameters, are considered in the numerical modelling. 


\section{CHAPTER 3}

\section{EXPERIMENTAL PROCEDURES}

\subsection{Introduction}

The experimental program in this research examines the flexural capacity of UHPFRC beams. A total of 5 beam specimens were tested under monotonic static loading. The testing took place in the Structural Laboratory at Ryerson University, Toronto, Canada.

This chapter presents an overview of the full experimental procedure including formwork preparation, placement of reinforcing steel, mixing, casting, curing, and finally the testing procedure. In addition, different measurement instrumentation will also be presented. The focus of the research presented here is to explore the structural and mechanical properties of UHPFRC with a fiber volume content of $2 \%$. It should be noted that the concrete dry materials used in this investigation are produced by Ductal ${ }^{\circledR}$ which is an UHPFRC brand of Lafarge North America.

\subsubsection{Fiber reinforcement}

The fibers used in this experimental investigation are straight steel fibers that are $13 \mathrm{~mm}$ in length and $0.2 \mathrm{~mm}$ in diameter and $2 \%$ by volume. These fibers are commonly used in the industry with extensive research. Figure 18 shows some of the material properties of the fibers used here. 


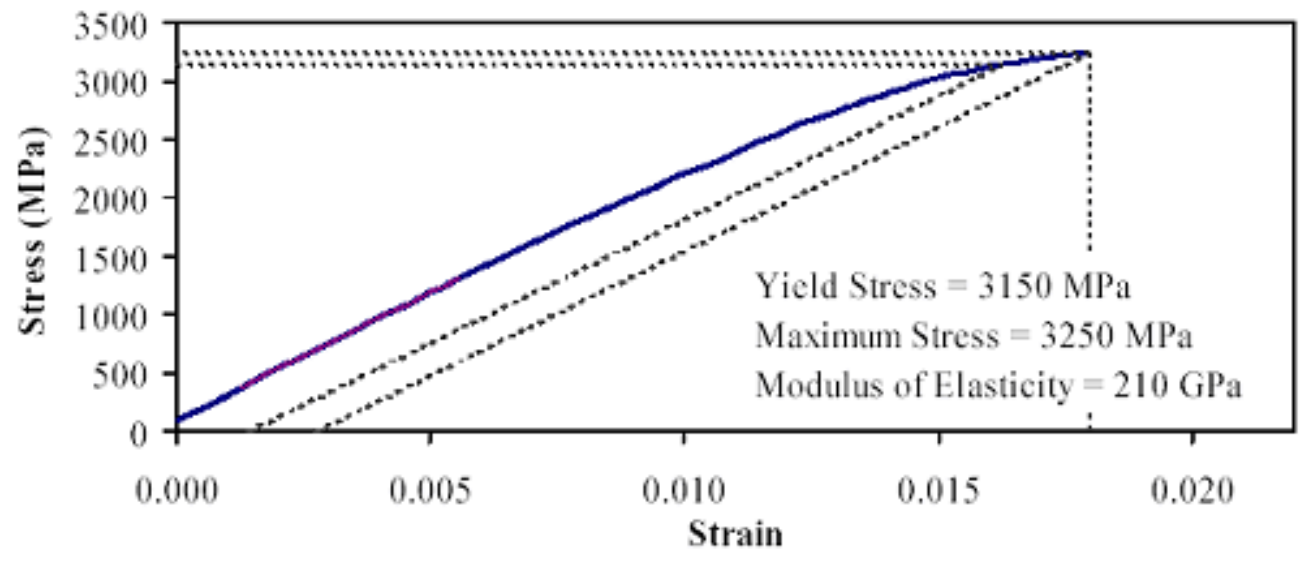

Figure 18: Material Properties of Steel Fibers used for Ductal ${ }^{\circledR}$ Mix (Federal Highway Administration, 2006)

\subsubsection{Reinforcing steel placement}

After the wooden formwork (mold) for the test specimen is completed, the reinforcing steel is placed inside the wooden molds. In order to maintain the specified cover for the bars, plastic chairs are placed at the bottom of the molds and then the bars were placed on top. Multiple chairs are used for each bar to prevent steel sagging during casting. To do this, at least three chairs are used for each bar, two at the ends and the rest spread along the reinforcement length. Following this procedure, the reinforcements and chairs were tied together using zip ties (Figure 19).

For specimen reinforced with six bars $(6-20 \mathrm{M})$, a clearance of $20 \mathrm{~mm}$ is required between the two bottom layers of reinforcement. To achieve this clearance, $20 \mathrm{~mm}$ spacers are placed between the steel as shown in Figure 19. Along with the chairs and steel bars, zip ties are also used to tie the two reinforcement layers with the spacers.

In addition to the reinforcing steel, two steel hooks (M20) are placed inside the molds (Figure 19) in order to lift the beams after curing and transport them elsewhere. The hooks are also used in the demolding process when the beam specimens are removed from the formwork. 


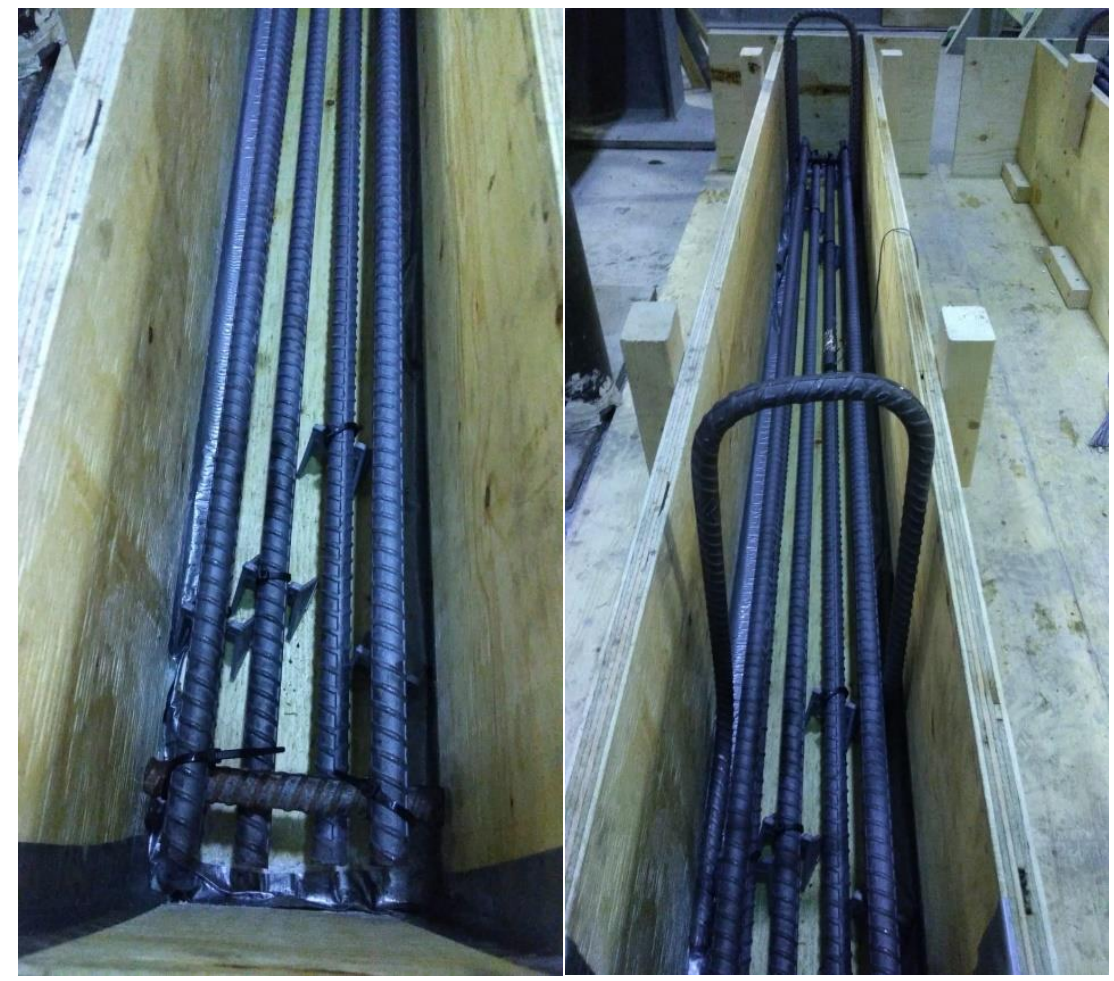

Figure 19: Reinforcement placement showing steel spacers and steel hooks

\subsubsection{Mixing procedure}

One of the first steps to achieving proper workability of concrete is the proper mixing of the different materials. The mixing procedure for this investigation is done according to the Lafarge North America specification $\left(\right.$ Ductal $\left.^{\circledR}\right)$. The cement used is a premix type with the different elements such as silica fume and fine aggregates already blended together. First, the cement is loaded to the mixer and then water and superplasticizers are slowly added to allow for even distribution of the raw materials. Next, the steel fibers are evenly added until the mix eventually reached the desired consistency.

The workability of the mix is tested in accordance with ASTM C1437 using a flow table test. A slump cone filled with UHPFFRC is removed and the concrete can flow freely. Once the UHPFRC 
settles down, the average diameter of the slump is measured. The average diameter is measured again after the flow table is dropped 20 times. According to Graybeal (2005), a flow of above 200 $\mathrm{mm}$ for UHPFRC can be easily placed. The flow measured in this investigation has a diameter of $250 \mathrm{~mm}$ which is same as the flow table diameter.

\subsubsection{Casting}

After the mixing is done, the concrete is carried by a steel bucket from the mixing area and transported to wooden beam formwork (molds) with a $178 \times 305 \mathrm{~mm}$ cross sectional area. Prior to casting of the concrete, the interior of the molds are sprayed with oil in order to ease the demolding process and not break the formwork. Furthermore, the interior edges of the molds are covered with a sealant (silicone) and duct tape (Figure 20) to prevent the liquid concrete from seeping through the gaps due to the high flowability of UHPFRC (Figure 21). This high flowability and selfconsolidating of UHPFRC eliminates the need for any vibration.

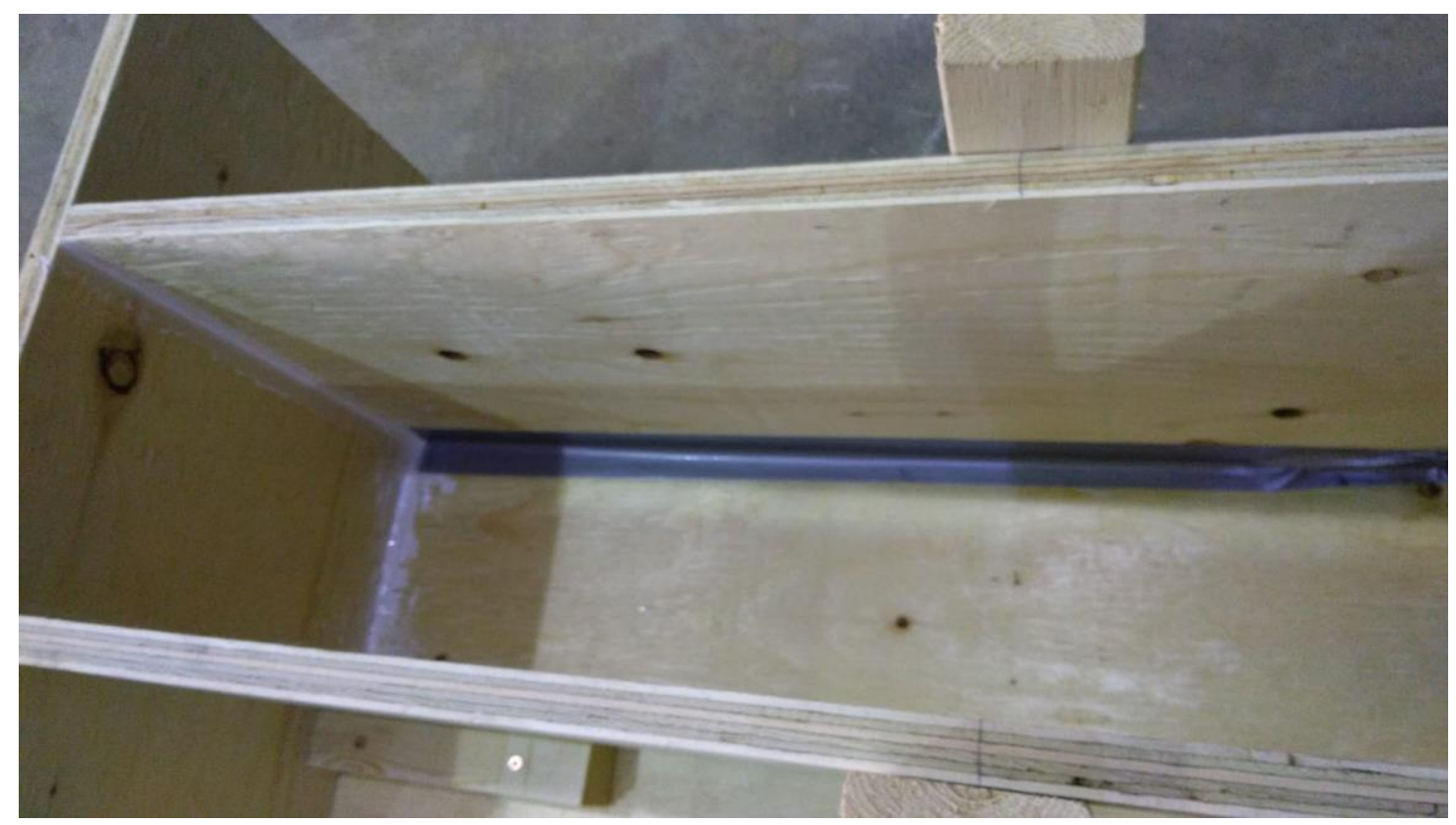

Figure 20: Formwork interior covered with a sealant (silicone) and duct tape 


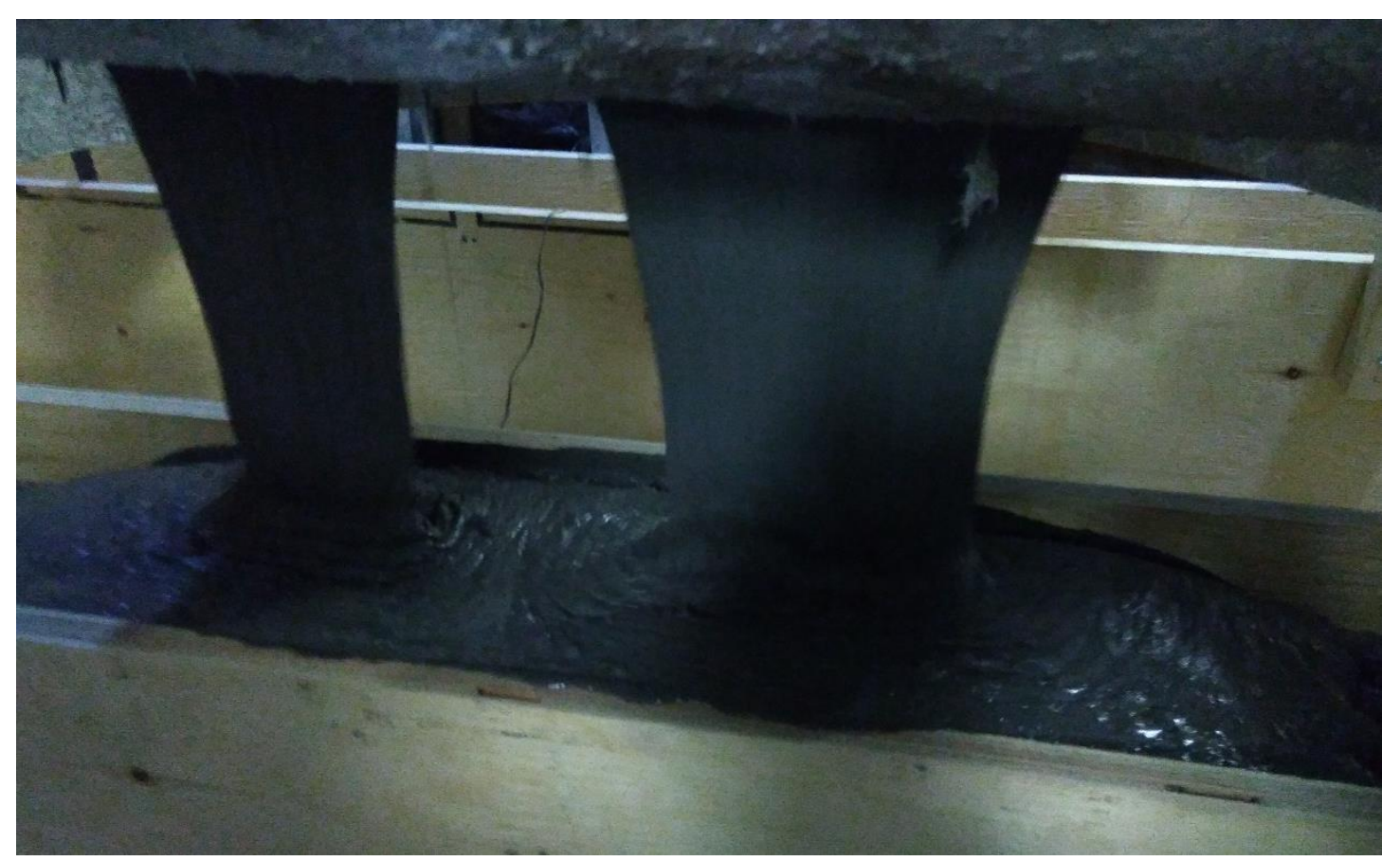

Figure 21: High flowability of UHPFRC

\subsubsection{Curing}

Following casting, the concrete is cured for 28 days. The curing process for UHPFRC is different than that of traditional concrete. Lafarge North America curing specifications requires the concrete to be covered with a layer of plastic sheeting. Additionally, water is added to the concrete and plastic surface to achieve uniform curing temperature for the top beam surface. Similarly, the cylinders and prisms are cured using moist burlap for seven days then removed from the moulds and left to dry in the laboratory at normal air conditions until testing.

\subsubsection{Compressive strength}

In order to perform proper compressive testing, surface preparation is needed. The cylinder surfaces (top and bottom) need to be grinded. This grinding process results in a smooth, flat surface that ensures the cylinder is fixed in place during testing. Several cylinders are grinded prior to 
testing which took place on the same day as the beam specimen testing. The tool used for this purpose is a concrete specimen end grinding machine, Model MIC-196-1-30 equipped with adjustable feeding time and timer functions (Figure 22).
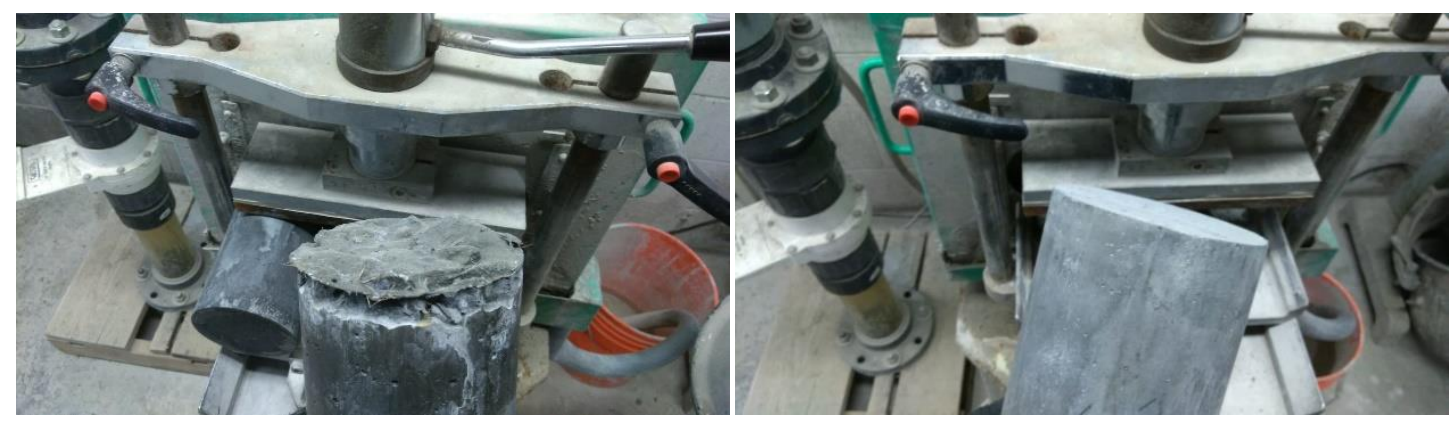

Figure 22: Cylinder end grinding; before (left) and after (right)

\subsubsection{Steel reinforcement}

The reinforcing steel bars used in this investigation have a nominal diameter of $20 \mathrm{~mm}(20 \mathrm{M})$ conforming to CAN/CSA-G40.20-M92. The grade of the deformed steel is 400W with a modulus of elasticity of $200 \mathrm{GPa}$. Additional details regarding the arrangement and placement of the reinforcing steel are presented in subsequent sections.

\subsubsection{Measuring devices}

The following sub-sections outline the different measuring instruments used in this investigation.

\subsubsection{Deflection gauges}

In order to capture the midspan displacement (deflection) of the test specimen, linear variable displacement transformers (LVDT) are used. These LVDTs are placed directly under the center of the specimen (Figure 27). 
LVDTs measure the change in position of the specimen and send the information to a data acquisition system. This process is repeated for each load increment until complete failure of the specimen.

\subsubsection{Specimen load measurements}

A hydraulic jack (manufactured by Enerpac Inc.) with a load cell total capacity of 300,000 lbf is supplied with a hand pump that applies load to the specimen at specified increments until complete failure. The hydraulic pump was connected to a data acquisition system (System 6000) that uses a StrainSmart ${ }^{\circledR}$ software with a scan rate of 10 scans per second.

\subsubsection{Strain gauges}

The strain gauge used in this experiment is an electric strain gauge (ESG) that is $10 \mathrm{~mm}$ long. The gauge resistance and factors are $120 \Omega$ and $2.10 \pm 1 \%$, respectively. Before attaching the strain gauge, the bar is first grinded to attain a flat, smooth surface. Next, an alcohol solution is applied to clean the grinded surface, followed by a metal conditioner and neutralizer to complete the cleaning process and neutralize the bar surface. Once the grinded surface is clean, the strain gauge is glued to the steel bar. In order to protect the strain gage during casting, it is covered by protective sheeting (aluminium foil tape and rubber tape) as shown in Figure 23.

The other end of the strain gauge is attached to a data acquisition system that records the strain in the reinforcing steel at each loading increment. 


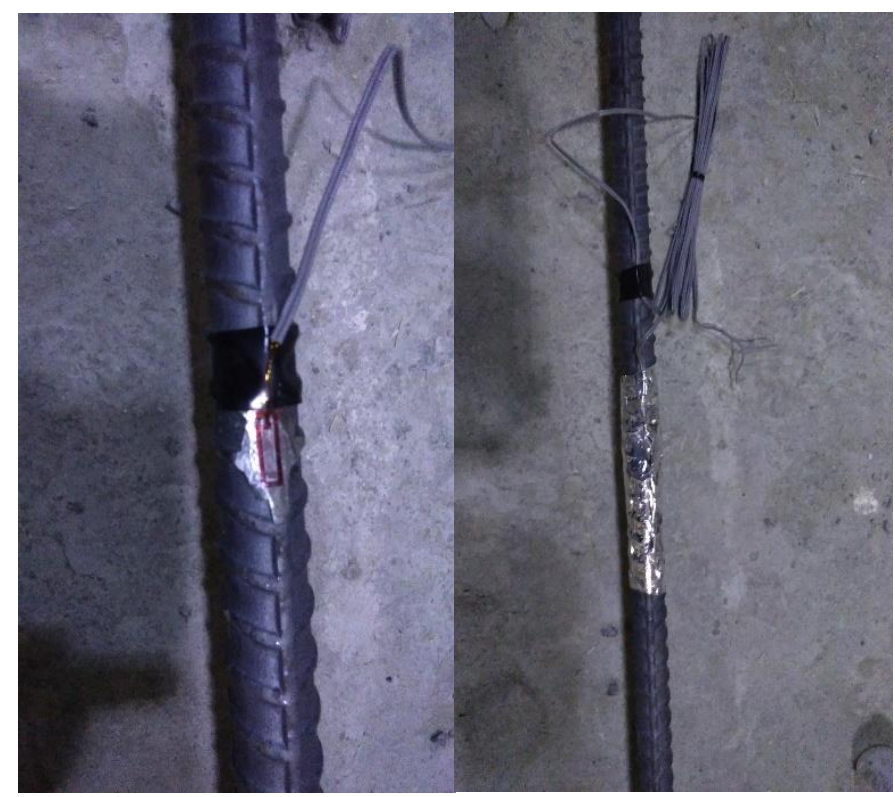

Figure 23: Attaching strain gauge on steel reinforcement

\subsubsection{Material testing}

In order to determine the mechanical properties of UHPFRC, cylinder and prism testing are required. The tensile and compressive testing are conducted on 100x200 mm cylinders. This section provides the apparatus used to measure some of the mechanical properties of UHPFRC. The mechanical properties of UHPFRC with $2 \%$ fiber content are reported in Table 4 . The tested mechanical properties in this experimental investigation are reported in the following chapter.

Table 4: Ductal ${ }^{\circledR}$ mechanical properties (Lafarge North America, 2019)

\begin{tabular}{cc}
\hline Density & $2400-2565 \mathrm{~kg} / \mathrm{m}^{3}$ \\
\hline Compressive strength & $150-180 \mathrm{MPa}$ \\
\hline Elastic modulus & $45-50 \mathrm{GPa}$ \\
\hline Splitting strength & $7-12 \mathrm{MPa}$ \\
\hline Flexural strength & $30-40 \mathrm{MPa}$ \\
\hline Creep coefficient & 0.3 \\
\hline Poisson Ratio & 0.2 \\
\hline
\end{tabular}




\subsubsection{Splitting tensile strength}

A digital compression testing machine (Model KA-400) was used to measure the splitting tensile strength of concrete. This instrument measures the splitting (indirect) tensile strength of concrete. As can be seen in Figure 24, the cylinder is fixed horizontally, and the load is applied in both directions (top and bottom) at a constant rate until failure occurs. It is worth noting that no endgrinding is required here since both cylinder ends are free during testing. The splitting tensile strength test has been conducted according to ASTM C496.

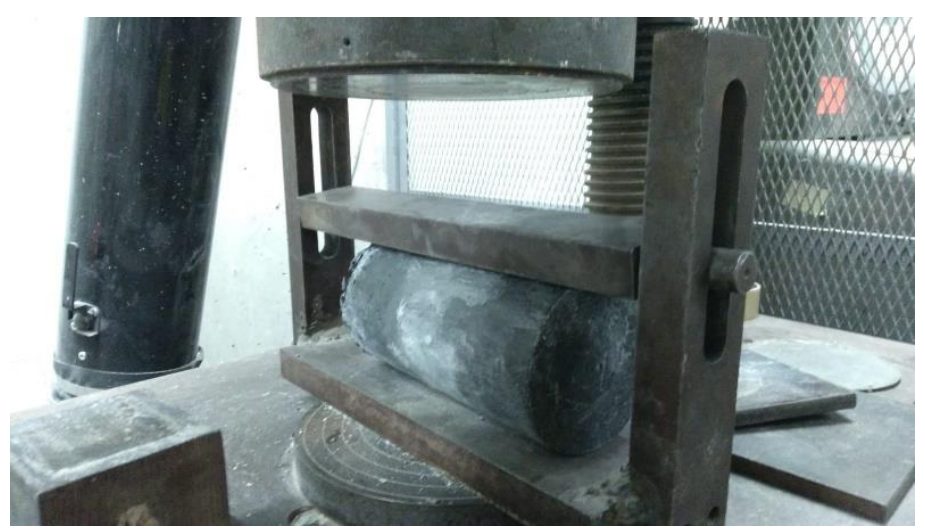

Figure 24: Splitting tensile test preparation

\subsubsection{Compressive strength testing}

The compressive strength testing machine consists of a Material Testing System (MTS) Model 815 with a load frame (Model 315.04). The MTS is connected to a data acquisition system (System 6000) and used in this investigation for testing the concrete compressive strength. Moreover, compressive testing has been conducted according ASTM C39. The recording frequency was 0.5 $\mathrm{Hz}$ and the loading rate for all five cylinders was $0.36 \mathrm{~mm} / \mathrm{min}$. The MTS setup showing the test specimen (cylinder), load frame, MTS machine and the data acquisition system are shown in Figure 25. 


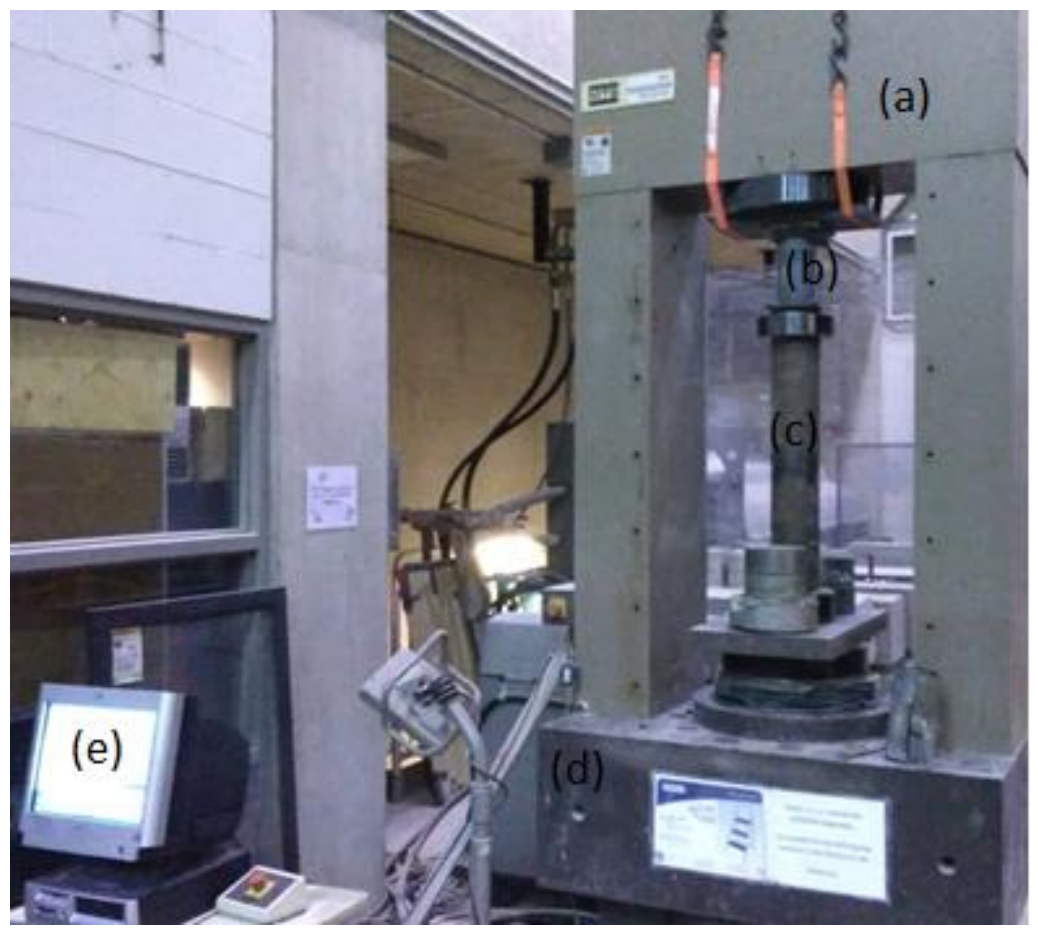

(a) Load Frame

(b) Test Specimen

(c) Loading Cylinder

(d) MTS Machine

(e) Data Acquisition

System

Figure 25: Compressive testing setup

\subsubsection{Flexural strength testing}

Flexural strength testing is conducted on 100x100x400 mm prisms (300 mm clear span) using three-point bending test procedure. The analysis and testing are performed according to ASTM C1609 specifications using a Material Testing System (MTS) Model 370. The loading rate for all five prisms is $0.36 \mathrm{~mm} / \mathrm{min}$ with a recording frequency of $0.5 \mathrm{~Hz}$. 


\subsection{Flexural Testing Setup of UHPFRC Beams}

\subsubsection{Test specimens specification}

In the experimental investigation, five UHPFRC beams are tested for flexure under four-point loading. Beam specifications are presented in Table 5 and Figure 26. Prior to testing, five strain gauges are attached to the center of the reinforcing steel while the other ends of the gauges are attached to a data acquisition system. The acquisition system records the strain in the reinforcing steel at each load increment supplied by the hydraulic pump.

Moreover, the LVDT's are placed at the bottom center of each beam to capture the displacements. Similar to strain gauges, the LVDT's are also connected to an acquisition system that recoded displacements with each load increment. Load-displacement and steel strain data will be presented in later sections.

Table 5: Specification of test specimens

\begin{tabular}{|c|c|c|c|c|c|}
\hline $\begin{array}{l}\text { Specimen } \\
\text { Name }\end{array}$ & $\begin{array}{c}\text { Span, } \\
\text { L } \\
(\mathrm{mm})\end{array}$ & $\begin{array}{c}\text { Cross } \\
\text { Section } \\
\left(\mathrm{mm}^{2}\right)\end{array}$ & $\begin{array}{l}\text { Span to Depth } \\
\text { Ratio, L/d }\end{array}$ & $\begin{array}{l}\text { Shear Span to } \\
\text { Depth Ratio, a/d }\end{array}$ & $\begin{array}{l}\text { Steel Ratio, } \\
\mathrm{p}_{\mathrm{w}}\end{array}$ \\
\hline $2-20 \mathrm{M}-\mathrm{S}$ & 915 & \multirow{5}{*}{$178 \times 305$} & 3.5 & 1.15 & 0.0127 \\
\hline 4-20M-S & 915 & & 3.5 & 1.15 & 0.0254 \\
\hline 6-20M-S & 915 & & 3.6 & 1.21 & 0.040 \\
\hline 6-20M-L & 1830 & & 7.3 & 2.42 & 0.040 \\
\hline $8-20 \mathrm{M}-\mathrm{L}^{*}$ & 1830 & & $6.9 \& 45.8$ & $2.30 \& 15.25$ & $0.0254 \& 0.169$ \\
\hline
\end{tabular}

*Doubly reinforced 

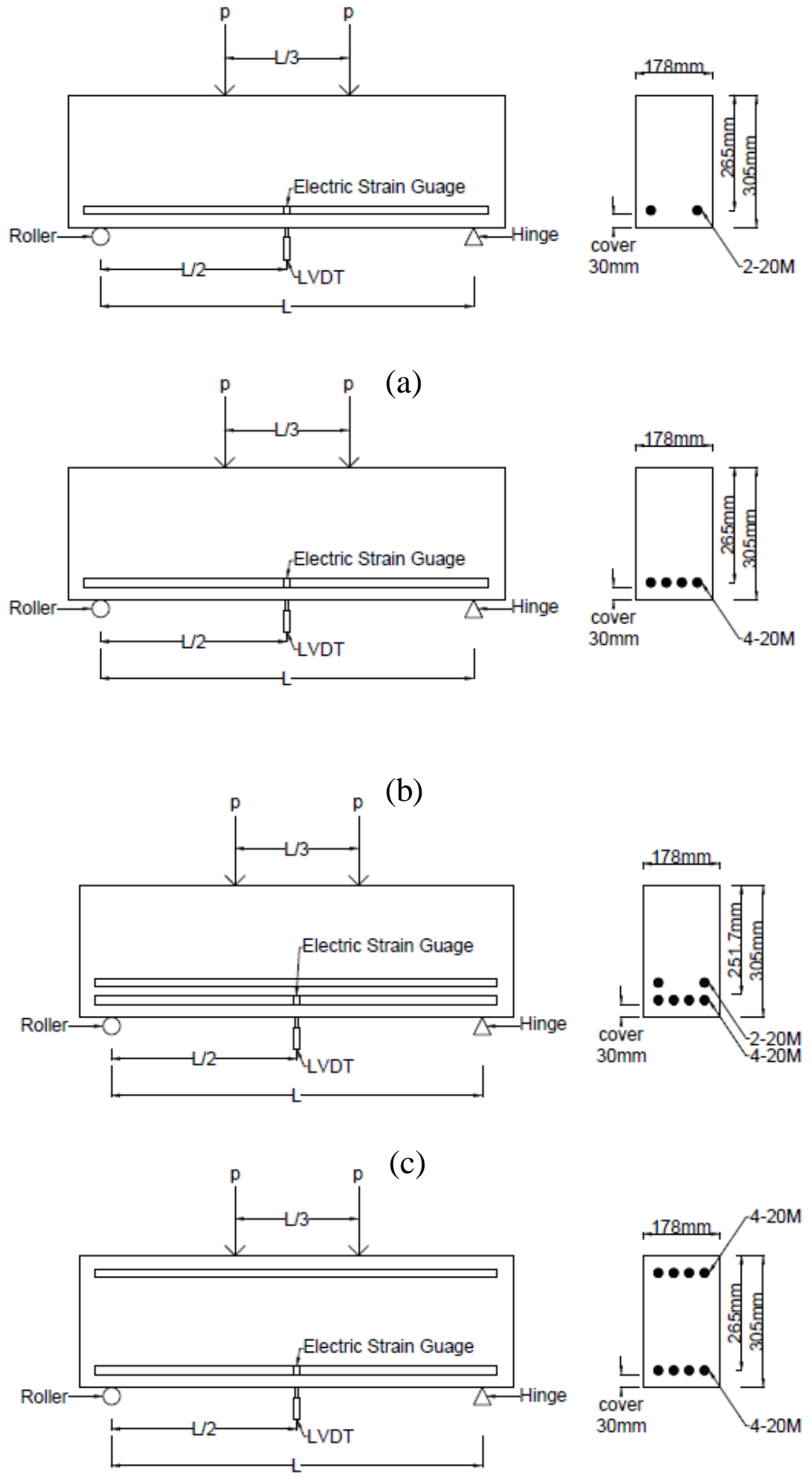

(d)

Figure 26: Details of UHPFRC beam specimens (a) 2-20M-S, (b) 420M-S, (c) 6-20M-S\&L, (d) 8-20M-L 


\subsubsection{Test specimens procedure}

The testing procedure for all specimens is performed using a loading frame connected to a hydraulic jack that applies monotonic load increments on the specimens as shown in Figure 27. All specimens have an initial load increment of $20 \mathrm{kN}$ which is later increased to $30 \mathrm{kN}$ to minimize the duration of testing. This is done due to the superior strength of UHPFRC. Furthermore, the beam surfaces are inspected for any cracks between load increments, which are marked thereafter.

It is worth noting that the loading beam (Figure 27) rests on steel cylinders in addition to rectangular steel plates. These plates are used to distribute the stresses between the steel cylinders and the test specimen. This process distributes stresses evenly instead of concentrating them at a specific location which allows the testing to continue successfully until beam failure.

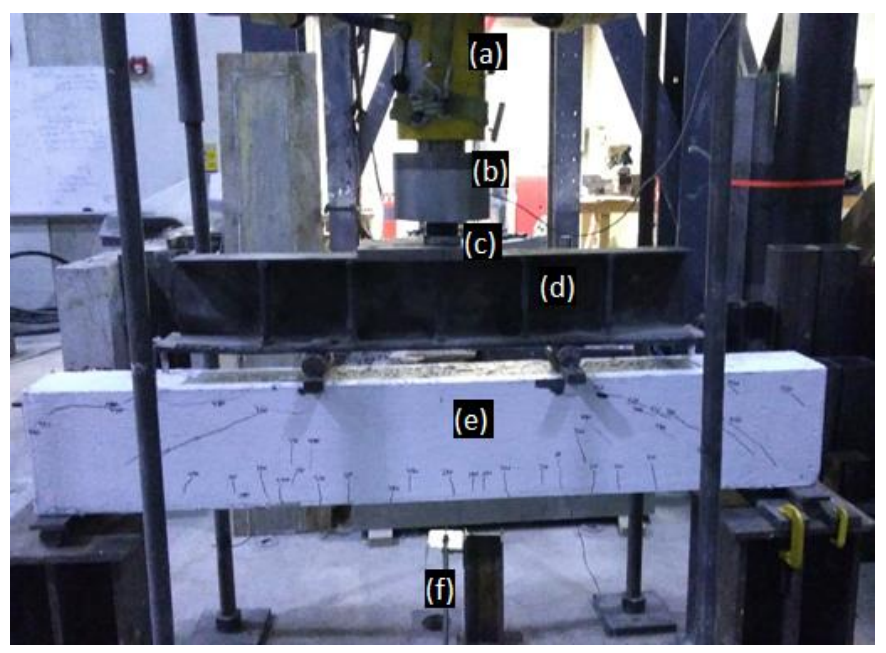
(a) Hydraulic Pump
(b) Load Cell
(c) Spacers
(d) Loading Beam
(e) Test Specimen
(f) LVDT

Figure 27: Test setup and instrumentation 


\section{CHAPTER 4}

\section{RESULTS AND DISCUSSIONS OF UHPFRC BEAMS}

\subsection{Introduction}

This chapter gives an overview of the results of the experimental investigation whose specimens are outlined in Chapter 3. The design variables in this investigation are the span $(915 \mathrm{~mm}, 1830$ $\mathrm{mm})$ and the steel reinforcement ratios $(1.27 \%, 2.54 \%$ and $4.02 \%)$. The limited load capacity of our equipment in the laboratory restricted the spans and beam reinforcements. The following sections will discuss the experimental results and observations, followed by an investigation of the moment capacity of various building code design guidelines and other design models found in literature. Finally, a comparison between the experimental moment capacity and those obtained by various methods will be presented.

\subsection{Results and Observations}

Capturing the complete load-deformation graph of conventional concrete is a difficult task due to its brittle nature. This problem is resolved in UHPFRC by the inclusion of steel fibers which enhance the ductility of concrete and allows it to undergo both strain hardening and softening.

Figure 28 shows the load-displacement graphs for the tested specimen. The figure displays the maximum load and mid-span displacement before failure for each specimen. It is worth noting the gap between the ascending and descending parts. The inclusion of steel fibers in the concrete allows for multiple internal cracks before the appearance of surface cracks. The fibers also bridge the gap between cracks which improves the long-term durability of structures. However, in 
conventional concrete, the lack of steel fibers facilitates the quick emergence of internal cracks which in turn hastens the failure of the structure.

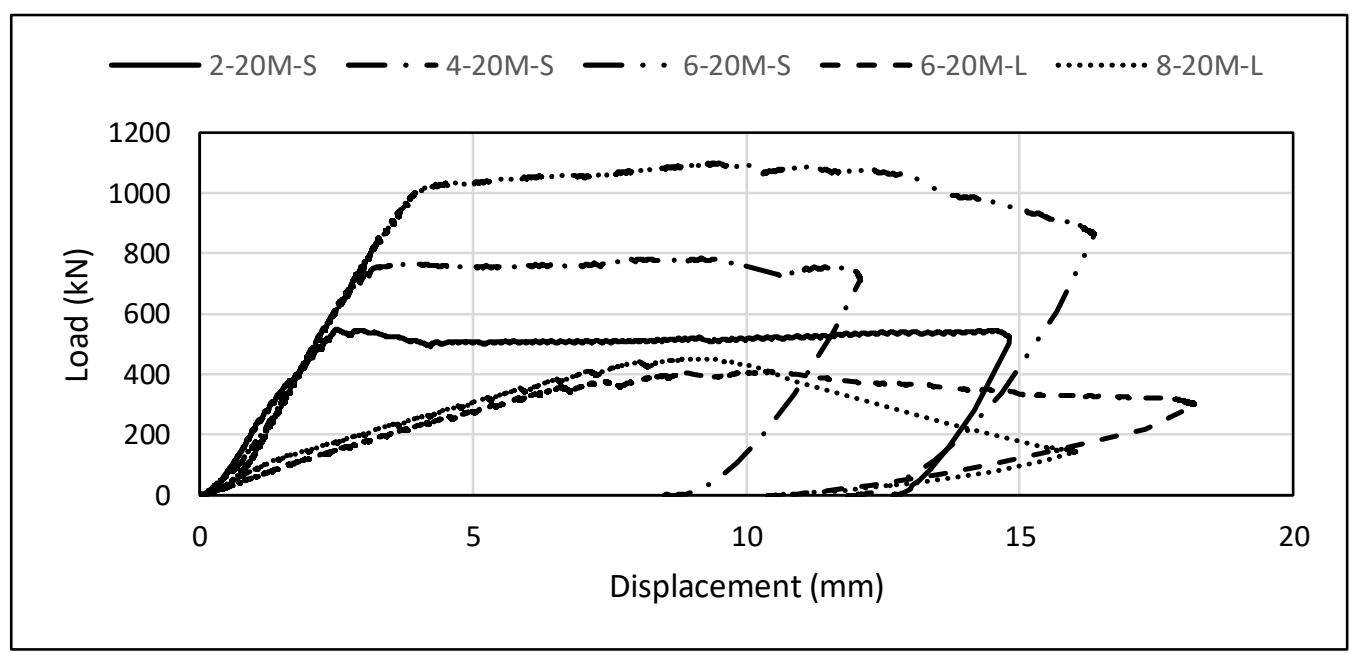

Figure 28: Load-displacement of UHPFRC beams ( $\mathrm{S}=915 \mathrm{~mm}$ beam, $\mathrm{L}=$ $1830 \mathrm{~mm}$ beam)

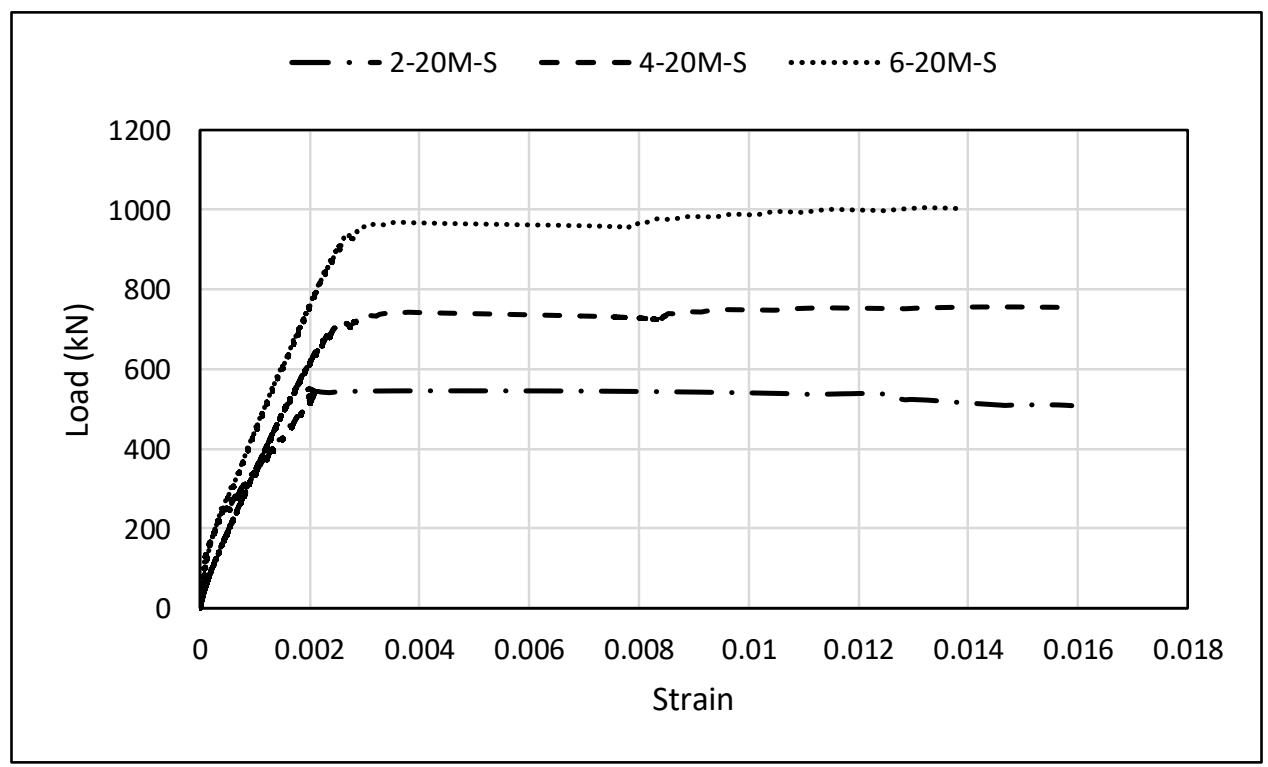

Figure 29: Load-strain of UHPFRC beams $(\mathrm{S}=915 \mathrm{~mm}$ beam) 
As mentioned previously, strain gauges are attached at mid-span on the reinforcing steel to monitor the reinforcement strain. The average maximum strain for the short-span beams is 0.01588 . Table 6 summarizes the test results of tested specimen in this investigation.

Table 6: UHPFRC beams test results

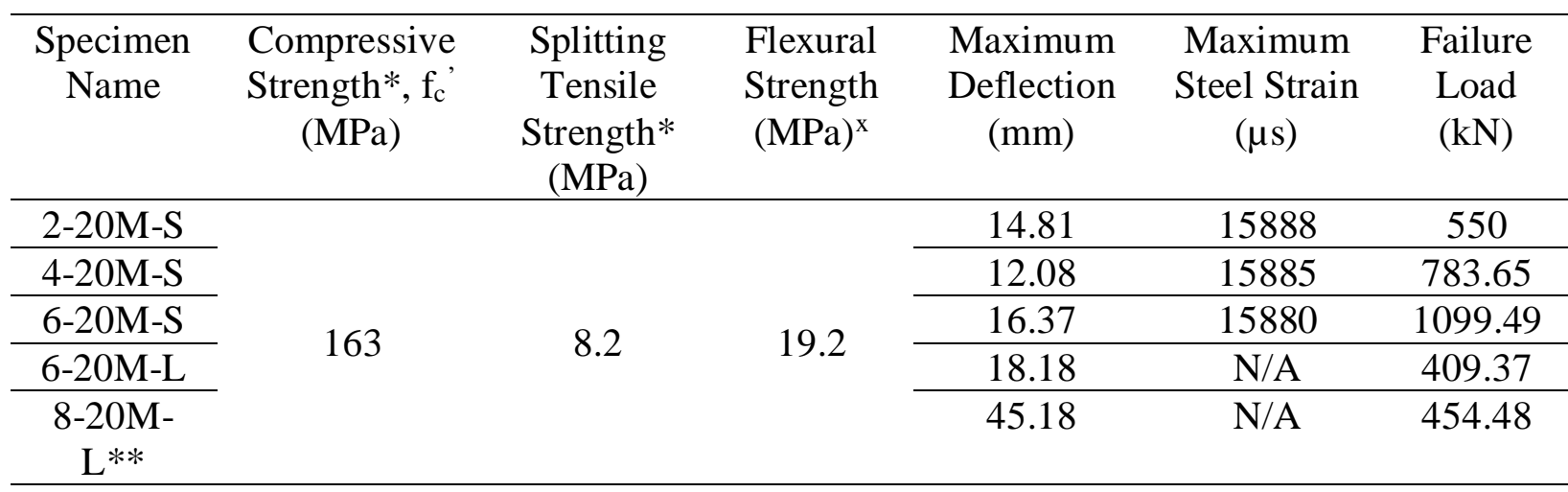

*Average of 5 cylinders

**Doubly reinforced

${ }^{\mathrm{x}}$ Average of 5 prisms

\subsection{Effect of Reinforcement Ratio}

The tested beams in this investigation failed in two different modes. Beams with a span of $915 \mathrm{~mm}$ failed in flexure, while $1830 \mathrm{~mm}$ span beams failed in a flexural-shear mode. All beams have the same cross-sectional area, yet they vary in length. Shorter span specimen (2-20M-S, 4-20M-S and 6-20M-S) have a span of $915 \mathrm{~mm}$, while the longer beams (6-20M-L and 8-20M-L) have a span of $1830 \mathrm{~mm}$. The reinforcement ratios for the 2-20M-S, 4-20M-S, 6-20M-S, 6-20M-L and 8-20M$\mathrm{L}$ beams are $1.27 \%, 2.54 \%, 4 \%, 4 \%$ and $2.54 \%$ \& $16.9 \%$ (for the doubly reinforced beam), respectively. Different beam spans $(915 \mathrm{~mm} \& 1830 \mathrm{~mm})$ were chosen to study the effect of varying the reinforcement ratios on the flexural capacity.

The 2-20M-S had an ultimate capacity of $550 \mathrm{kN}$ with a maximum mid-span deflection of 14.81 $\mathrm{mm}$. The second beam, 4-20M-S failed at a load of $783.65 \mathrm{kN}$ and had a maximum deflection of 
$12.08 \mathrm{~mm}$. Next, the 6-20M-S failed at a load of $1099.49 \mathrm{kN}$ with a maximum deflection of 16.37 mm. Finally, the longer span beams (6-20M-L \& 8-20M-L) failed at loads of $409.37 \mathrm{kN}$ and 454.48 $\mathrm{kN}$, respectively. The maximum mid-span deflections for these longer span beams were $18.18 \mathrm{~mm}$ and $45.18 \mathrm{~mm}$, respectively. Furthermore, it is observed that as the reinforcement ratio doubled $(1.27 \%>2.54 \%)$, the ultimate load capacity was increased by $30 \%$ for shorter span beams and by $29 \%$ for longer span beams.

It is interesting to note that all tested beams underwent significant loading before failure. This loading was accompanied by numerous surface cracks that didn't appear on most beams until higher loading increments were applied. The high ultimate load capacity and crack control are attributed to the presence of steel fibers which hold the concrete tightly, thus, significantly improving the strength of the beams.

\subsection{Flexural Behaviour of UHPFRC Beams}

There is extensive research on the behaviour and characteristics of the stress block of UHPFRC beams. One key area of interest that is the focus of this research is the flexural capacity of UHPFRC beams. Numerous studies have been conducted on the conventional concrete stress block and the current design guidelines are tailored towards this concrete. Albeit, design guidelines lack proper procedure for the UHPFRC flexural stress block. Calculating the moment capacity of UHPFRC is complicated due to the presence of steel fibers in the concrete. Their presence induces additional tensile forces since the steel fibers shift the location of the neutral axis. Thus, the effect of steel fibers makes traditional design guidelines obsolete for determining the flexural capacity of UHPFRC. 
The following sections look at various analytical methods for calculating the moment capacity of UHPFRC beams. It is worth noting that the calculations in this section are valid for concrete that uses Ductal ${ }^{\circledR}$ with $2 \%$ steel fibers (which has been used in the experimental investigation in this research).

\subsubsection{Moment curvature}

In this investigation, the beam specimens were tested under four-point static loading in order to determine the load-deformation behaviour of UHPFRC. Another way of representing the loaddeformation is through moment-curvature analysis which employs the strain-compatibility approach. In order to plot moment-curvature graphs, few key points should be examined. These important points are: first cracking, yield, and finally the ultimate point (after which failure occurs). To determine the correct moment-curvature for the first point (cracking), the cracking strain is chosen (when concrete tensile capacity is exceeded). Next, tensile and compressive forces in the concrete section are calculated for different neutral axis locations until these forces equal each other. At this point, the moment and curvature are calculated, and this point is defined as "the cracking point". Afterwards, the yield strain is chosen and the same procedure for "cracking" is repeated until force equilibrium is achieved. The yield point is determined when the steel strain has reached the yield strain (that is equal to the concrete strain). The location of the neutral axis is determined, and the moment capacity and the curvature of the beam are then calculated. Following "cracking" and "yield" points, the ultimate strain is chosen, and the same force equilibrium approach is utilized to determine the moment-curvature point. Finally, additional points can be

calculated in order to complete the moment-curvature graph. Here, different strains beyond "yield" are chosen and for each strain, the force-equilibrium concept is used in order to find the correct neutral axis location and subsequently calculate the moment and the curvature. The more strains 
are chosen, the more complete the moment-curvature graph will be. However, since this is a tedious method to perform by hand, the use of computer software and spread sheets are highly recommended. The moment curvature for the $2-20 \mathrm{M}$ rectangular section is shown in Figure 30 . The maximum load shown agrees well with the moment capacities for the 2-20M section shown in Tables 8 and 9.

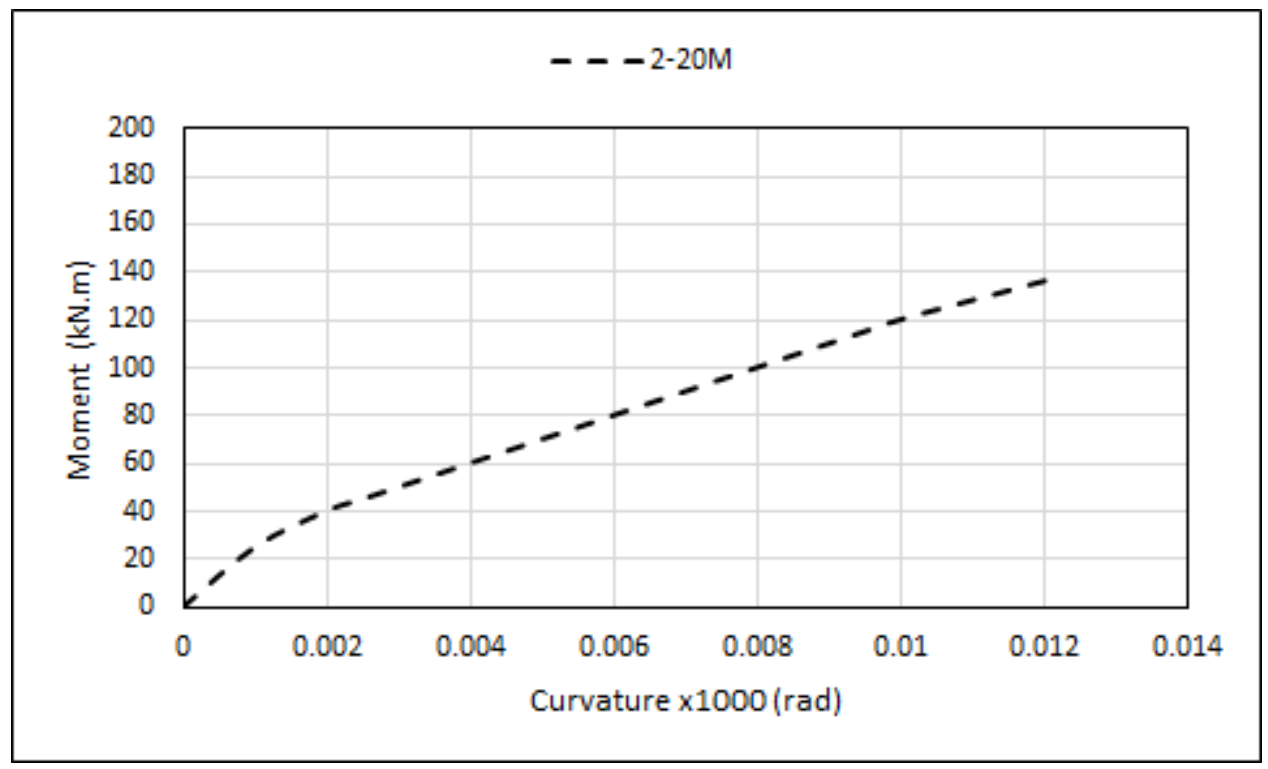

Figure 30: Moment curvature for the 2-20M rectangular section

\subsubsection{Beam flexure analysis}

Bae at al., (2016) investigated the stress block of nine different types of flexural strength models and recommended the stress block shown in Figure 31 for UHPFRC beams. The authors investigated the models by comparing their flexural capacities with the experimental results. Upon their investigations, the authors proposed a new stress block for obtaining the neutral axis location and moment capacity for UHPFRC beams. The stress block shown in Figure 31 (b) gave the highest accuracy to the experimental results. The trick to achieving desirable and accurate results with UHPFRC is the inclusion of the effect of steel fibers in the model as well as using the correct 
stress block parameters. Equations 4-1 and 4-2 shown below are used by Bae at al., (2016) for calculating the neutral axis location along with the moment capacity. The following is a description of the terms used in these equations. The gamma $\gamma$ term used here is the ratio between post cracking and ultimate tensile strengths. Through trial and error, it was observed that a gamma value of 0.7 yields the best results (this value is valid for the design in this study which uses Ductal ${ }^{\circledR}$ concrete and straight smooth steel fibers (2\% by volume)). The $\alpha$ and $\beta$ terms for UHPFRC are taken as $0.85 \& 0.65$, respectively (Graybeal, 2008). In addition, $f_{t}$, the tensile strength of the fiber concrete is taken as $9 \%$ of the compressive strength (9\% of $163 \mathrm{MPa} ; 14.7 \mathrm{MPa})$. The width $(b)$ and height $(h)$ of the beam specimen are $178 \mathrm{~mm}$ x $305 \mathrm{~mm}$. Furthermore, $f_{c}^{\prime}$ is the concrete compressive strength $(163 \mathrm{MPa}), f_{y}$ the yield strength of reinforcing steel (400 MPa), $\eta$ is a ratio between the ultimate tensile and compressive concrete strains plus one and is taken as 1.4 (this value is valid for the design in this study which uses Ductal ${ }^{\circledR}$ concrete and straight smooth steel fibers ( $2 \%$ by volume)), $A_{s}$ is the area of flexural reinforcement and $d$ is the effective depth measured from the top compression fiber to the centroid of main flexural steel bars. Numerical results for different reinforcements are presented in Tables 8 and 9. 


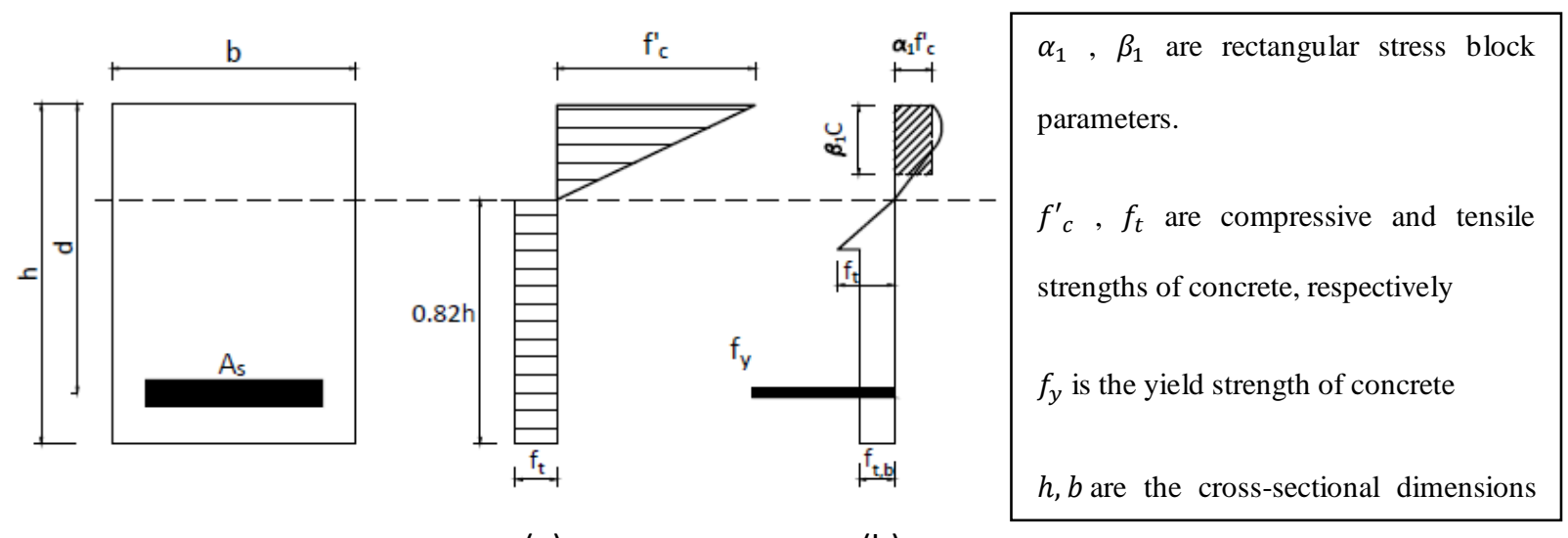

(a)

(b)

(a) Dobrusky’s simplified method (Dobrusky, 2017) and (b) Bae et al. (Bae et al., 2016)

Figure 31: Stress block models for UHPFRC beams

$C=\frac{A_{s} f_{y}+\gamma f_{t} b h}{\alpha_{1} f_{c}^{\prime} \beta_{1} b-0.5(\eta-1) f_{t} b+\gamma \eta f_{t} b}$

$M=\left(\alpha_{1} f_{c}^{\prime} \beta_{1} c b\right)\left(\frac{c}{2}\right)+\left\{f_{t}(e-c) b\right\}\left(\frac{2}{3}\right)(e-c)+\left\{\gamma f_{t}(h-e) b\right\}\left(e-c+\frac{h-e}{c}\right)+A_{s} f_{y}(d-c)$

[Eq. 4-2]

Where,

$e=\left(e_{\text {sfibers }}+0.003\right)(c / 0.003), c$ being the neutral axis depth and $e_{\text {sfibers }}$ is taken as 0.0035 .

The experimental program of Bae at al., (2016) was conducted to verify the applicability of the investigated models. The test program was performed using four-point loading flexural strength testing by an actuator with a $2000 \mathrm{kN}$ capacity on an UHPFRC beam with a total length of $4.6 \mathrm{~m}$ (4.3 between the supports). The beam has a cross-sectional area of 200x350 $\mathrm{mm}$ and reinforced with tension steel rebars in two layers along with stirrups at $150 \mathrm{~mm}$ spacing as shown in Figure 32. Strain gauges were attached on both the steel reinforcement (at the beam center) and the top of the concrete beam to verify the neutral axis depth. Additionally, deflection instrumentation was 
mounted on the test specimen to capture the mid-span deflection at the bottom of the beam. It is interesting to note that no crack localization occurred in the beam before the crushing of concrete.

The tested beam failed at a maximum load of $179 \mathrm{kN}$ in addition to a deflection of $98 \mathrm{~mm}$ at the onset of concrete crushing. The model that Bae at al., (2016) suggested (shown in Figure 31) resulted in a load capacity of $175 \mathrm{kN}$ which is very close to the $179 \mathrm{kN}$ capacity of the tested beam ( $2.23 \%$ error). Additionally, the neutral axis depths of the tested beam and the suggested flexural model are $93 \mathrm{~mm}$ and $91.3 \mathrm{~mm}$, respectively. Furthermore, Bae at al., (2016), concluded that the best shape for the UHPFRC stress block in compression is triangular, while the tensile shape can be varied depending on the content of the fibers. Lastly, another reason for the high accuracy of the suggested flexural strength model is that the tensile behaviour of UHPFRC considers strain softening in addition to strain hardening and the complete plastic behaviour.

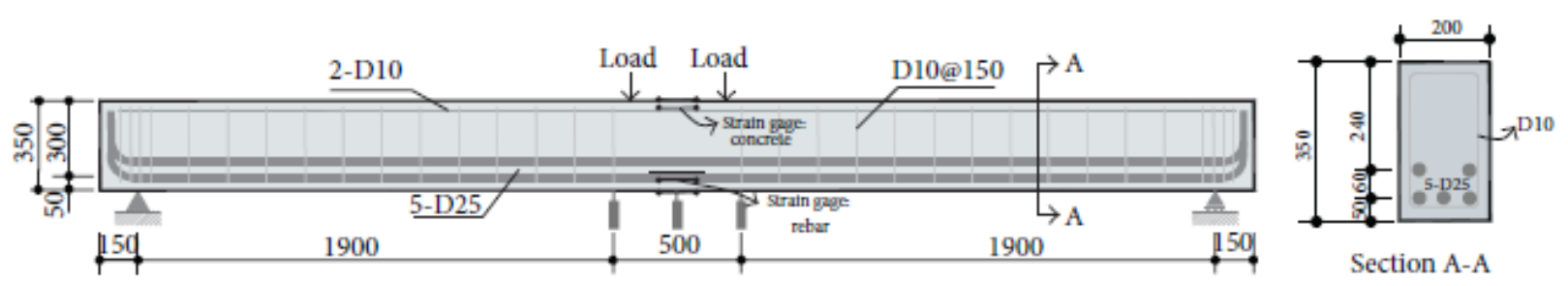

Figure 32: Test specimen details (Bae at al., 2016)

\subsubsection{Dobrusky's simplified model (Dobrusky, 2017)}

The next method presented for obtaining the flexural capacity is a simplified French model proposed by Dobrusky (2017). Dobrusky's simplified model (DSM) is unique because it saves computational time and cost that are associated with section integration which is usually performed in the fiber-beam model (Dobrusky, 2017). This process is possible because the model works directly in the moment-curvature space. In addition, Dobrusky's simplified model reduces the 
computation to one numerical loop (Dobrusky, 2017). In this model, there is a decrease in the curvature outside the nonlinear hinge during the softening period (Dobrusky, 2017). Therefore, a macroscopic constitutive damage law is proposed for the moment-curvature. This model assumes that the plain and reinforced concrete structures have the same neutral axis location $(0.18 \mathrm{xh})$ as shown in Figure 31.

Dobrusky's simplified model for predicting bending behaviour takes into consideration strain hardening (Point A to B) and strain softening (Point B to C) of UHPFRC as shown in Figure 33. This method is based on a modified force-based fiber-beam formulation where curvature at its non-linear hinge is imposed by progressive loading (Dobrusky, 2017). The force-based approach is time-consuming and has many disadvantages, with the main one being the inability in providing a description of the behaviour after softening occurs. Dobrusky's modified method is more favourable over the fiber-beam method because the progressive loading which is driven by curvature can continue in the softening phase by overcoming the peak load (Dobrusky, 2017). Moreover, this model can capture a snap-back effect in the force-displacement relationship (Dobrusky, 2017).
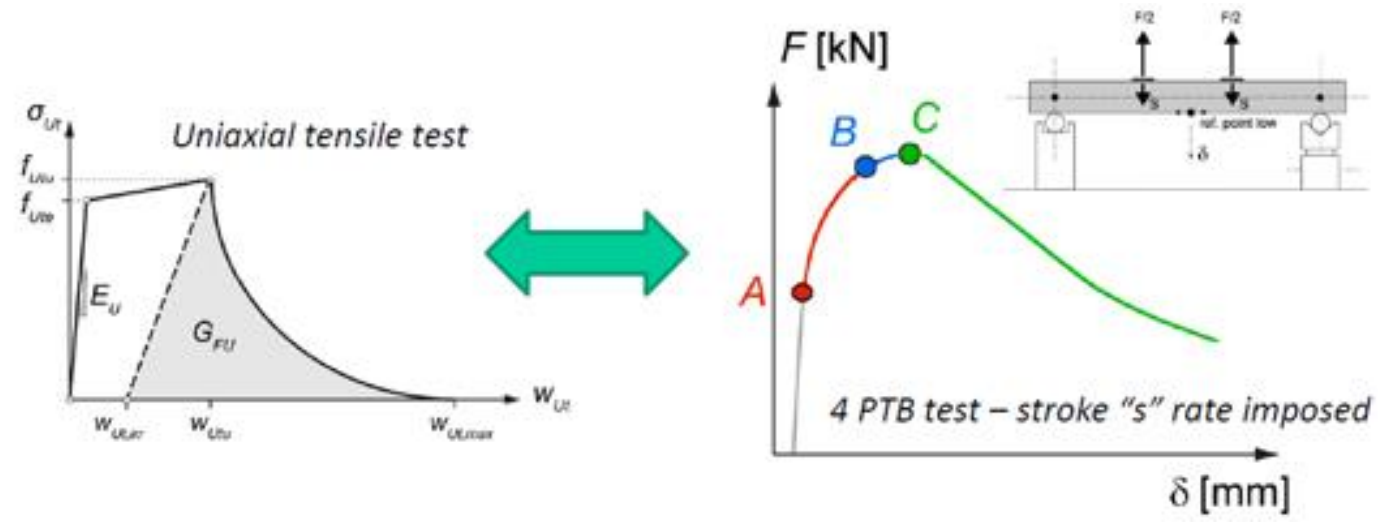

Figure 33: Dobrusky's proposed model (Dobrusky, 2017) 
Dobrusky's proposed force equation for point "C" (Figure 33) at peak force is:

$F_{C}=\frac{f_{t} \cdot b \cdot h^{2}}{0.383 \cdot L}$ Dobrusky (2017)

Here, $F_{t}$ (maximum tensile strength) is the maximum stress at point $\mathrm{C}$ and is $9 \%$ of the concrete compressive strength $(163 \mathrm{MPa})$. The terms " $b$ " and " $h$ " are the section dimensions $(178 \times 305$ $\mathrm{mm}$ ), while $L$ is the span of the beam. The moment capacity of the plain unreinforced beam was found to be:

$M=F \cdot d$

Where, $d$ is the moment arm between the compression/tension centroids. The capacity of the reinforced beams is the summation of the aforementioned moment and $A_{s} f_{y} d$, where $A_{s}$ is the area of the flexural rebars and $f_{y}$ is the yield strength of steel (400 MPa).

\subsubsection{Canadian CSA A23.3-94/American ACI 318-02/ New Zealand NZS 3101-} 1995

CSA A23.3-94/ ACI 318-02/ NZS 3101-1995 design guidelines are formulated for designing traditional reinforced concrete that has low compressive strength and almost negligible tensile strength. These codes are therefore not applicable for the design of UHPFRC that has superior compressive and tensile strengths. The main factors why these traditional codes are not suitable for obtaining the flexural capacity of UHPFRC are that they do not include the effect of steel fibers and omit the tensile strength of concrete. This is evident in Tables 8 and 9.

\subsubsection{Ryerson Proposed Method (RPM)}

The next method for obtaining the flexural capacity of UHPFRC beams is a proposed method at Ryerson University. This method assumes that the compression and the neutral axis depths of the 
stress block are the same, which means that $\beta_{1}$ is simply one. The following procedure locates the neutral axis depth and calculates the moment capacity of the beams. After assuming that $\beta_{1}$ is one, the compression and tension forces in the section (including the force in the steel fibers which is approximately in the middle of the tension side of the stress block) are equated by taking moments about the neutral axis by substituting a variable (x) in place of the neutral axis depth in the compression force equation. Next, the moment capacity is calculated by taking moments (of the steel reinforcement and steel fibers) at the compression force. The aforementioned procedure is performed for the plain beam along with the different reinforced specimen (2-20M, 4-20M, 6$20 \mathrm{M}$, and $8-20 \mathrm{M}$ sections). It should be noted that the $\alpha$ which is used in calculating the moment capacities is the 0.85 suggested by Graybeal (2008). A new $\alpha$ value was proposed (RPM) but that value (0.56) did not change the moment capacity ( $\sim 5 \%$ difference).

The stress-strain relationship proposed in the RPM utilizes a constant, rectangular shape in tension with a maximum value of $10.3 \mathrm{MPa}$ as shown in Figure 34. As can be seen, the $10.3 \mathrm{MPa}$ used in this model, which is $70 \%$ of the tensile strength (14.7 MPa) resulted in the closest moment capacity (through trial and error procedure) to the experimental value. The compression component is trapezoidal in shape with a maximum concrete compressive strain of 0.008 (as opposed to 0.0035 used in CSA A23.3-04 for conventional concrete). Additionally, the model assumes a linear strain throughout the section depth. It should be noted that the stress-strain model developed with the ultimate descending strain of 0.008 which was used in the RPM was developed at Ryerson University by Yazdizadeh (2014). 


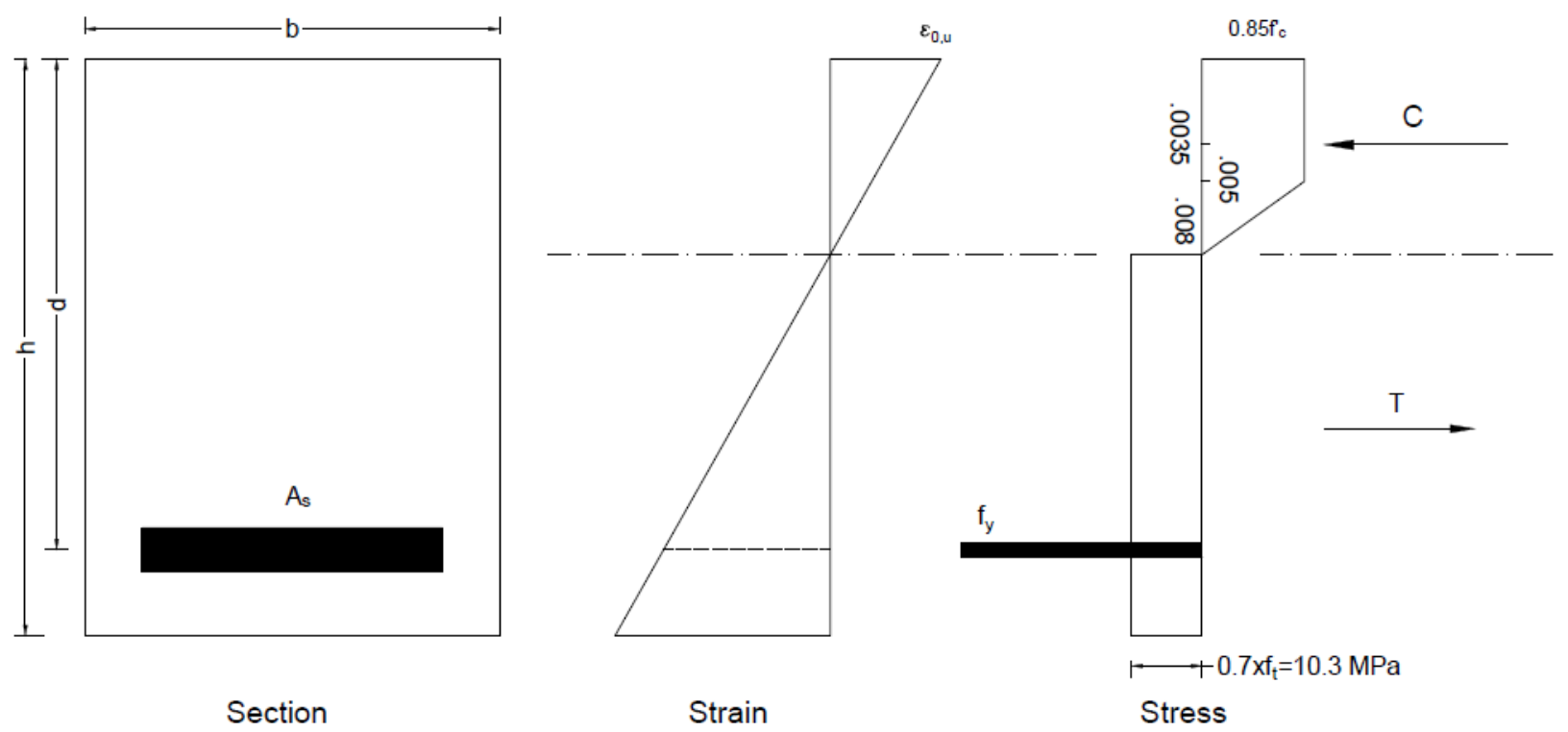

Figure 34: RPM stress-strain relationship

Flexural capacities calculated so far in this investigation have been limited in length (to under 2 meters) and type of reinforcement (main flexural reinforcement only). Therefore, the validity of the RPM has been further assed to consider the flexural capacity of a beam with a length of $4.6 \mathrm{~m}$ used in an investigation by Bae et al., 2016 (discussed in section 4.4.2). Additionally, a different type of reinforcement (Prestressing) in a study by Gowripalan and Gilbert (2000) has been considered. Gowripalan and Gilbert (2000) research was conducted on 200x400 mm UHPFRC (non-prestressed and prestressed) rectangular beam sections. In their investigation, the flexural capacities were calculated using moment curvature analysis and with reference to AS3600-1994 Australian design guidelines. The concrete sections examined have compressive and tensile strengths of $200 \mathrm{MPa}$ and $8 \mathrm{MPa}$, respectively. The developed stress strain relationship of Gowripalan and Gilbert (2000) which uses a triangular stress distribution in compression along with linear and constant distributions in tension, is shown in Figure 35. 


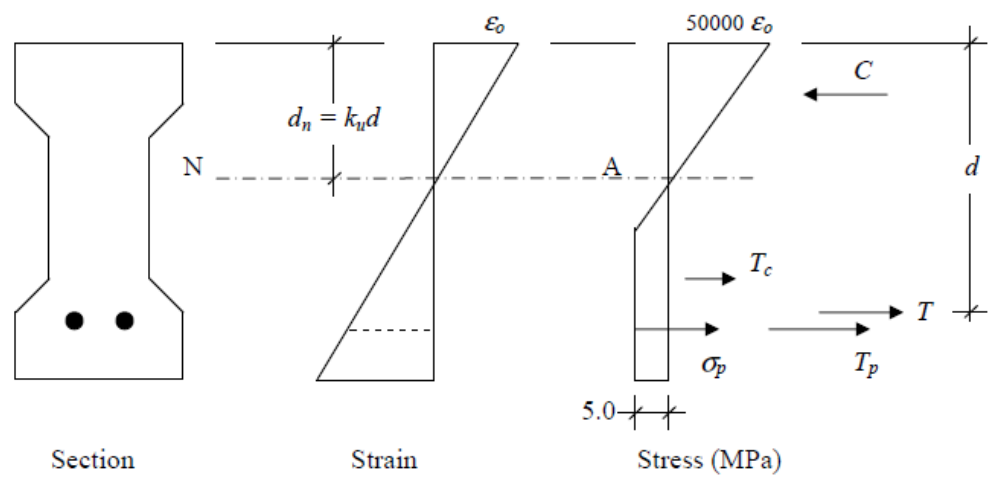

Figure 35: Gowripalan and Gilbert (2000) stress-strain relationship

Table 7 summarizes the moment capacity values obtained in Gowripalan and Gilbert (2000) and Bae et al., (2016) and compares them to the capacity found using the RPM. As can be seen, the RPM estimates the moment capacity accurately for beams with lengths up to $4.6 \mathrm{~m}$ (4.3 m span) and for rectangular prestressed beam sections. The accuracy of the RPM with non-prestressed rectangular beams is somewhat accurate as well.

Table 7: Comparison of moment capacity and RPM

\begin{tabular}{cccc}
\hline & Bae et al., (2016) & $\begin{array}{c}\text { Gowripalan and } \\
\text { Gilbert (2000) } \\
\text { (Non-prestressed) }\end{array}$ & $\begin{array}{c}\text { Gowripalan and } \\
\text { Gilbert (2000) } \\
\text { (Prestressed) }\end{array}$ \\
\hline $\begin{array}{c}\text { Moment capacity } \\
\text { (kN.m) }\end{array}$ & 322 & 69.3 & 182.9 \\
\hline RPM (kN.m) & 352.96 & 85.3 & 211.66 \\
\hline$\%$ error & $8.77 \%$ & $18.76 \%$ & $13.59 \%$ \\
\hline
\end{tabular}

\subsection{Moment Capacity Comparison: Experimental Versus Analytical Methods}

Tables 8 and 9 present a summary of the flexural capacity values obtained from the analytical methods and compare them against the experimental capacities. Table 8 shows moment capacity values for specimen with $915 \mathrm{~mm}$ span while Table 9 displays values for the $1830 \mathrm{~mm}$ span beams. 
As can be seen from the tables, the Canadian CSA A23.3-94, American ACI 318-02, and New Zealand NZS 3101-1995 design codes which uses Whitney's stress block are not suitable for the design of UHPFRC beams due to their low accuracy. On the other hand, Ryerson Proposed Method (RPM) and Bae at al., (2016) show great accuracy for specimen with a span of $1830 \mathrm{~mm}$, followed by Dobrusky's method. Furthermore, Bae at al., (2016) and the RPM are not suitable for specimen with a span of $915 \mathrm{~mm}$. However, Dobrusky’s simplified method (DSM) gives better accuracy for beams with a span of $915 \mathrm{~mm}$. Lastly, Bae et al., (2016) is the most accurate when dealing with beams with a span of $1830 \mathrm{~mm}$.

Table 8: Comparison of moment capacity for specimen span $915 \mathrm{~mm}$

\begin{tabular}{cccc}
\hline Method & $\begin{array}{c}2-20 M \\
\text { Moment capacity } \\
(\mathrm{kN.m})\end{array}$ & $\begin{array}{c}4-20 \mathrm{M} \\
\text { Moment capacity } \\
(\mathrm{kN.m})\end{array}$ & $\begin{array}{c}6-20 \mathrm{M} \\
\text { Moment capacity } \\
(\mathrm{kN.m})\end{array}$ \\
\hline Bae et al. & 133.3 & 186.1 & 226.6 \\
\hline DSM & 171.5 & 230.7 & 280.3 \\
\hline RPM & 134.2 & 189.5 & 233.1 \\
\hline ACI 318-02 & 62.4 & 122.5 & 170.7 \\
\hline CSA A23.3-94 & 62.0 & 120.6 & 166.5 \\
\hline NZS 3101-1995 & 61.2 & 118.0 & 160.0 \\
\hline Experimental & 170.5 & 239.01 & 335.5 \\
\hline Moment & & & \\
comparison for: & & & $67.5 \%$ \\
Bae et al. & $78.2 \%$ & $77.9 \%$ & $83.5 \%$ \\
DSM & $100.6 \%$ & $96.5 \%$ & $69.5 \%$ \\
RPM & $78.7 \%$ & $79.3 \%$ & $50.9 \%$ \\
ACI 318-02 & $36.6 \%$ & $51.3 \%$ & $49.6 \%$ \\
CSA A23.3-94 & $36.4 \%$ & $50.5 \%$ & $47.7 \%$ \\
NZS 3101-1995 & $35.9 \%$ & $49.4 \%$ & \\
\hline
\end{tabular}


Table 9: Comparison of moment capacity for specimen span $1830 \mathrm{~mm}$

\begin{tabular}{cccccc}
\hline Method & $\begin{array}{c}\text { Plain/Unreinforced } \\
\text { Moment capacity } \\
\text { (kN.m) }\end{array}$ & $\begin{array}{c}2-20 M \\
\text { Moment } \\
\text { capacity } \\
\text { (kN.m) }\end{array}$ & $\begin{array}{c}\text { 4-20M } \\
\text { Moment } \\
\text { capacity } \\
\text { (kN.m) }\end{array}$ & $\begin{array}{c}6-20 \mathrm{M} \\
\text { Moment } \\
\text { capacity } \\
\text { (kN.m) }\end{array}$ & $\begin{array}{c}8-20 \mathrm{M} \\
\text { Moment } \\
\text { capacity } \\
\text { (kN.m) }\end{array}$ \\
\hline Bae et al. & 77.6 & 133.3 & 186.1 & 226.6 & 264.24 \\
\hline DSM & 56.2 & 115.4 & 174.6 & 224.2 & 241.23 \\
\hline RPM & 76.6 & 134.2 & 189.5 & 233.1 & 251.8 \\
\hline ACl 318-02 & 31.2 & 62.4 & 122.5 & 170.7 & 146.4 \\
\hline CSA A23.3-94 & 31.0 & 62.0 & 120.6 & 166.5 & 139.8 \\
\hline NZS 3101-1995 & 30.6 & 61.2 & 118.0 & 160.0 & 137.3 \\
\hline Experimental & $54.9 *$ & $143.4 *$ & $201.3 *$ & 249.7 & 277.2 \\
\hline Moment & & & & & \\
comparison for: & & & & & \\
Bae et al. & $141.3 \%$ & $93.0 \%$ & $92.4 \%$ & $90.7 \%$ & $95.3 \%$ \\
DSM & $102.4 \%$ & $80.5 \%$ & $86.7 \%$ & $89.8 \%$ & $87.0 \%$ \\
RPM & $139.5 \%$ & $93.6 \%$ & $94.1 \%$ & $93.4 \%$ & $90.8 \%$ \\
ACl 318-02 & $56.8 \%$ & $43.5 \%$ & $60.9 \%$ & $68.4 \%$ & $52.8 \%$ \\
CSA A23.3-94 & $56.5 \%$ & $43.2 \%$ & $59.9 \%$ & $66.7 \%$ & $50.4 \%$ \\
NZS 3101-1995 & $55.7 \%$ & $42.7 \%$ & $58.6 \%$ & $64.1 \%$ & $49.5 \%$ \\
\hline
\end{tabular}

*Values from previous literature (Wahba, 2012, pp. 61) 


\section{CHAPTER 5}

\section{FINITE ELEMENT MODELLING}

\subsection{Introduction}

Various structures of complex shapes and geometries can be accurately modeled using FE analysis. FE modelling can be very sophisticated, and when done correctly can give desirable results. It should be noted that FE analysis will not give the exact solution since it is an approximate method of analysis. However, if the analysis is performed correctly the results will be very close to the exact solution. In order to receive desirable results from FE modeling, the user must understand the elementary principles of FE analysis in order to build a model with reliable results.

The purpose of this chapter is to develop an accurate 3D model using FE modeling that will predict the static response of reinforced concrete beams subjected to 4-point loading. The analysis in this chapter has been performed using a FE modelling program ABAQUS software (Simulia, 2019). The results from the numerical simulation will be validated using the results from the experimental testing of UHPFRC beams discussed in previous chapters. The concrete and reinforcing steel are represented by different built-in material models. Though, once combined they describe the composite behaviour of reinforced concrete (RC). Moreover, a Concrete Damage Plasticity (CDP) model is used to consider the stiffness degradation and nonlinearity of concrete. The following sections present a detailed overview for modeling and calibrating FE models.

It is worth noting that due to boundary restrictions with respect to size and machine capacity, very long beam spans or ones with high ultimate load capacities are hard to test in the laboratory. Therefore, FE analysis software packages are utilized in such cases. 


\subsection{Development of 3D Finite Element Model}

This section addresses key stages used in building up the FE model. This model will have to model the exact dimensions and boundary conditions as the experimentally tested beams. Proper and accurate material and geometrical parameters are selected in order to simulate the actual experimental testing.

\subsubsection{Material property and part selection}

The first step in creating the model is choosing the correct part and material properties for the various elements. The three main components of this FE model are the concrete beam, steel reinforcement, and all the supports. All these three components are created as 3D deformable solid elements. The steel reinforcement and supports are assigned as steel materials and thus given steel parameters (E.g. Elastic Modulus $200 \mathrm{GPa}$, positions ratio of 0.3, etc.) to match those of the actual test. The compressive strength and modulus of elasticity test with embedded FBG sensor developed by Yazdizadeh (2014) is used as a material stress-strain (ABAQUS input) for UHPFRC concrete. The indirect tension and fracture energy values developed by Wahba et al., (2012) are used as ABAQUS input. The beam is made of concrete in the actual test and so it is given concrete material parameters in the FE model. In addition to the elastic parameters given to the supports, the beam and reinforcing steel are given plastic parameters. In order to represent the correct behaviour of the tested beams, an accurate model should be considered. There are various built-in models in ABAQUS to represent the behaviour of reinforced concrete structures; however, the one used in this investigation is the Concrete Damage Plasticity (CDP) model as recommended by Othman and Marzouk (2017) in order to ensure accurate results. In CDP, four key input parameters should be considered for the concrete material model in order to describe the yield surface accurately and fully. These parameters are the dilation angle $(\psi)$, flow potential eccentricity $(\epsilon)$, 
biaxial to uniaxial strength ratio $\left(\sigma_{b o} / \sigma_{c o}\right)$ and the shape factor which defines the yield surface $\left(K_{c}\right)$, and their values are set to $40^{\circ}, 0.1,1.16$, and 0.67 , respectively.

Furthermore, modeling the strain hardening behaviour is performed using isotropic hardening which assumes uniform increase in the yield stress (Simulia, 2019). Additional damage parameters for describing the concrete performance are obtained from uniaxial stress-strain curves developed in the experimental program. In general, damage for tension and compression occurs in the softening range.

The damage parameter for compression is represented by a linear relationship with a damage value of zero for strains associated with the compressive strength and 0.80 maximum value at strain failure. This is done to eliminate computational difficulties related to zero stiffness associated with complete damage. It is worth noting that the steel fibers were not addressed separately in modelling since they are uniformly distributed in the matrix. Thus, they can be treated as part of the UHPFRC matrix.

\subsubsection{The main concrete damage plasticity model parameters}

This section examines some of the CDP model parameters discussed in the previous section.

In the CDP model, the dilation angle $(\psi)$ is used for controlling volumetric strain established during plastic deformation. Typical dilation angle values for concrete are in the range of $30^{\circ}$ to $45^{\circ}$. After several trials of using different dilation angles, a value of $40^{\circ}$ was selected in this model.

The shape parameter $\left(K_{c}\right)$ is used to modify the yield surface, which is necessary when accounting for different tri-axial tension and compression yield stresses (Simulia, 2019). Typical $K_{c}$ values are in the range of $0.5-1$ and a value of 0.67 is selected in this model after various trials. 
Flow eccentricity's influence on reinforced concrete beams is not significant since it deals with low confining pressures of volume change, however the experimental testing deals with stresses at high confining pressures (Park et al., 2001). Therefore, the 0.1 default value for the flow eccentricity is used in the model.

\subsubsection{Monotonic incremental static loading}

In order to model the experimental test loading which was supplied by a hydraulic pump applying loads at increments until failure, a reference point was created in the centre of the beam and this point was tied to the two upper cylinders resting on the top beam surface. Next, monotonic static loading was applied incrementally until failure. It is worth noting that the nonlinear geometry option (Nlgeom) was turned on during analysis due to large strains and change in material properties.

\subsubsection{Mesh selection}

Choosing the right mesh size for analysis will ensure that accurate results and minimized computational time are achieved, thus resulting in an accurate mathematical solution. Finite element modelling with nonlinear analysis simulation strongly depends on the mesh size. The mesh size can be based on fracture mechanics related to the aggregate size, the crack width, half the steel fiber length, or on numerical convergence studies (Marzouk and Chen, 1995; Hussein and Marzouk, 2000; Marzouk and Chen, 1993). The mesh size selected for the model in this study was $10 \mathrm{~mm}$ which is close to the $6.7 \mathrm{~mm}$ of the half fiber length. The beam in the FE model is uniformly meshed in such a way that the solid elements have unity aspect ratios (Figure 36). 


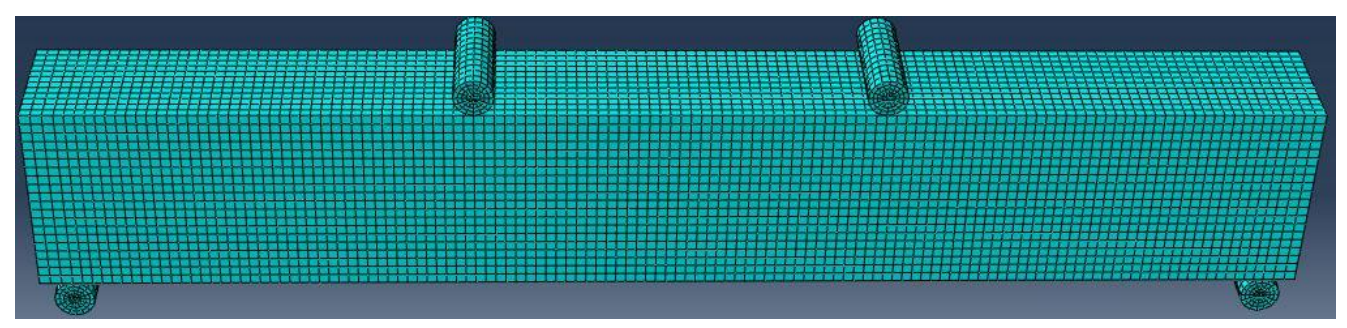

Figure 36: Mesh configuration

In any nonlinear concrete analysis, especially when the material is described by a softening constitutive relationship (same as the current model), the simulation results are critically dependant on the mesh size and geometry. A convergence study can be used to make sure the model is producing a mathematically accurate solution before making a parametric study built upon the model.

A second method is based on the fracture energy that can be measured experimentally and the fracture energy density can be calculated as recommended by Bazant and Oh (1983) to provide the mesh size. According to the brittle fracture concept of post cracking behaviour of concrete (Hillerborg et al., 1976), the fracture energy required to form a unit area of crack surface, $\mathrm{G}_{\mathrm{F}}$, can be calculated by measuring the tensile stress as a function of the crack opening displacement. Generally, the fracture energy can be calculated from the area under the net stress versus average displacement of a plain concrete specimen under direct tensile loading (Marzouk and Chen, 1995). Furthermore, the width of the fracture-process zone, $w_{C}$, is used by Bazant and Oh (1983) to define the average crack strain and the mesh size.

Convergence studies are normally required before using the model meshing, and the material model of nonlinear concrete should be examined first. Otherwise, the results will change with the 
mesh, rendering the model only valid for this case, and cannot be used to investigate any effects with different dimensions.

\subsection{Results of the Finite Element Analysis}

\subsubsection{Load carrying capacity}

The use of the CDP model led to a good agreement between the test results and the numerical modelling of the beam specimen in terms of the ultimate load capacity as shown in Table 10.

Table 10: Numerical (FE) vs experimental ultimate load capacity

\begin{tabular}{cccc}
\hline $\begin{array}{c}\text { Specimen } \\
\text { Name }\end{array}$ & $\begin{array}{c}\text { Experimental } \\
\text { Load Capacity } \\
(\mathrm{kN})\end{array}$ & $\begin{array}{c}\text { FE } \\
\text { Numerical } \\
\text { Load } \\
\text { Capacity } \\
(\mathrm{kN})\end{array}$ & $\begin{array}{c}\% \\
\text { Difference }\end{array}$ \\
\hline $2-20 \mathrm{M}-\mathrm{S}$ & 550.12 & 530.33 & $3.60 \%$ \\
\hline $4-20 \mathrm{M}-\mathrm{S}$ & 783.65 & 702.31 & $10.38 \%$ \\
\hline $6-20 \mathrm{M}-\mathrm{S}$ & 1108.65 & 980.94 & $11.52 \%$ \\
\hline $6-20 \mathrm{M}-\mathrm{L}$ & 409.37 & 377.27 & $7.84 \%$ \\
\hline $8-20 \mathrm{M}-\mathrm{L}$ & 454.48 & 414.25 & $8.85 \%$ \\
\hline
\end{tabular}

The difference between the results is within 3-12\% which suggests good calibration of the numerical models using the experimental results. Figure 37 shows the load-deformation graphs for both tested beams and finite element models (FEM). 

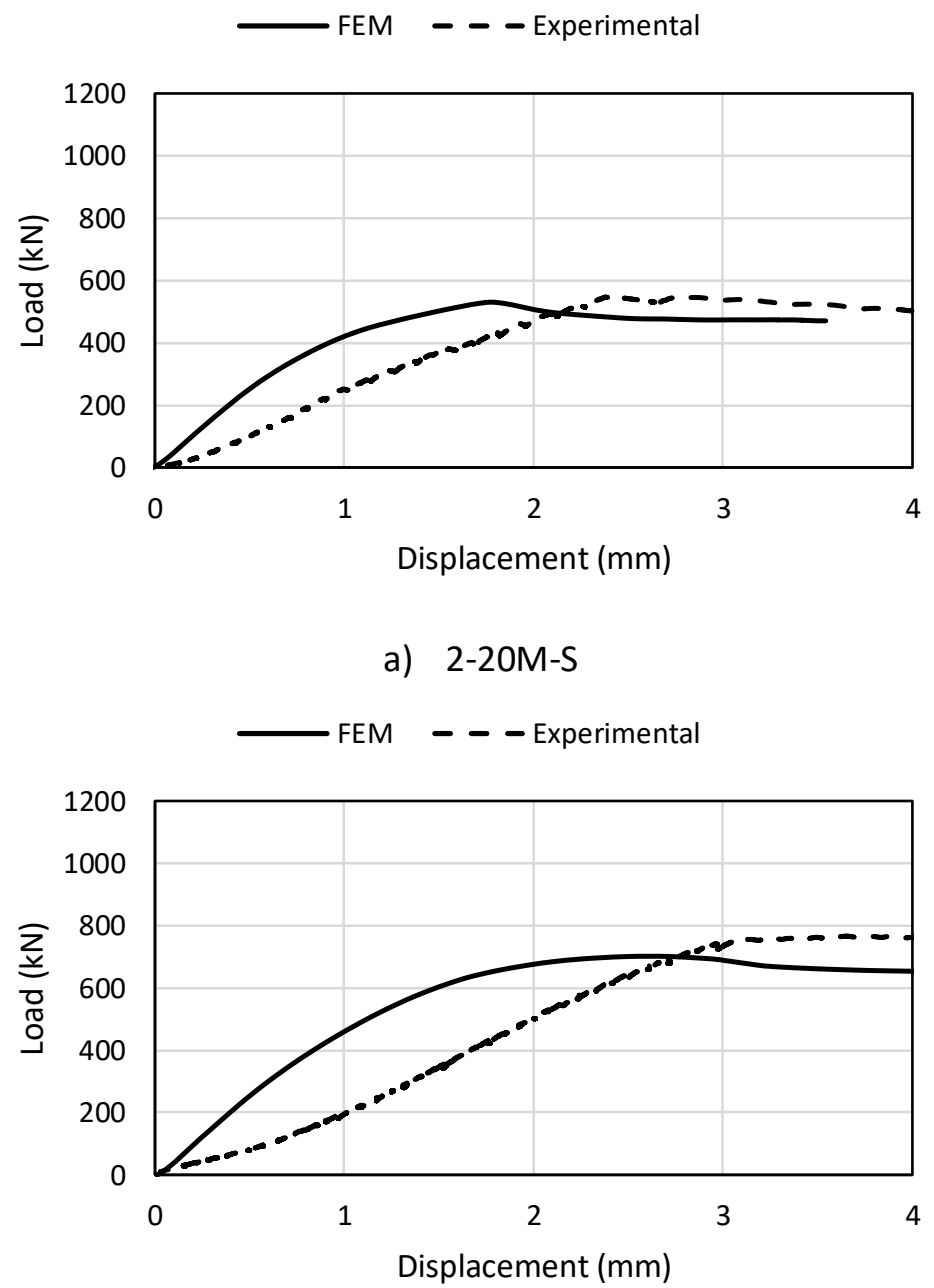

b) $4-20 M-S$

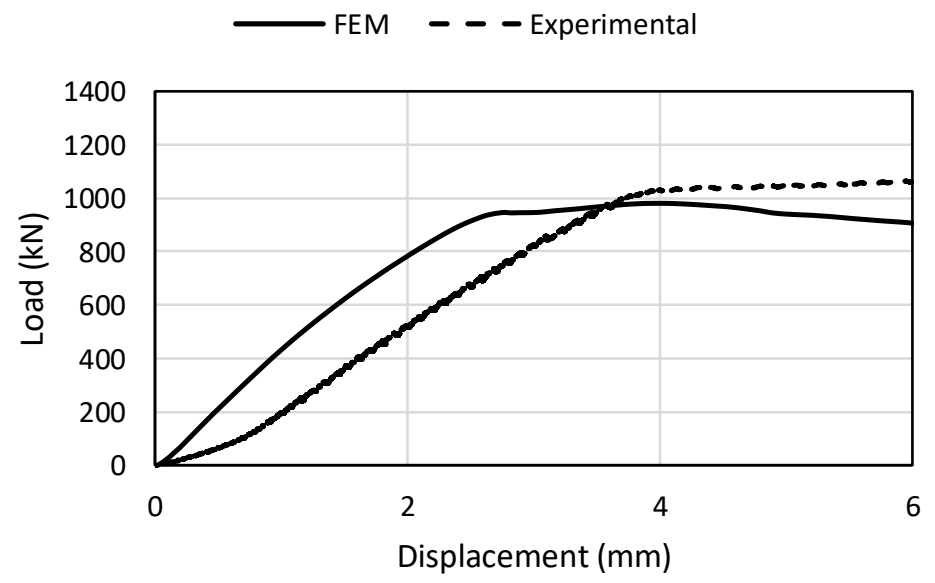

c) $6-20 \mathrm{M}-\mathrm{S}$ 


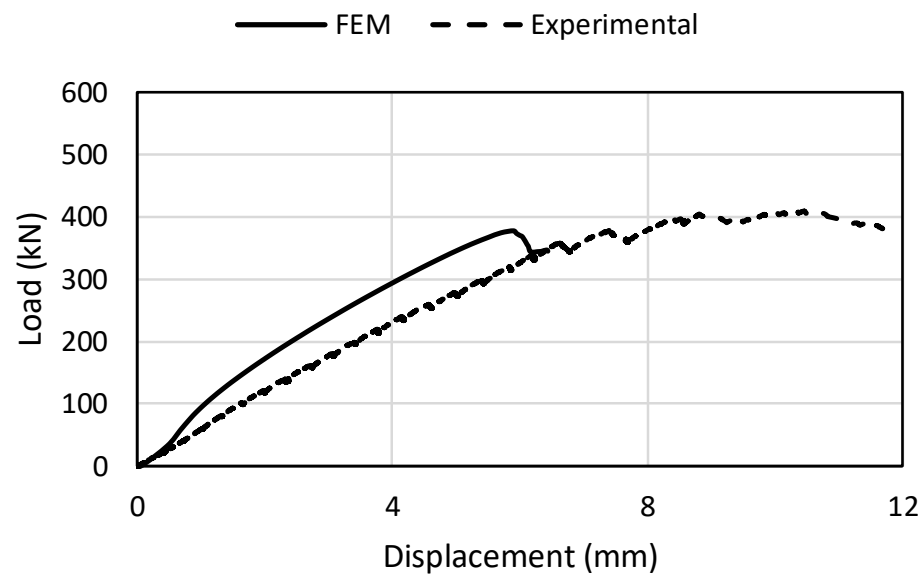

d) $6-20 \mathrm{M}-\mathrm{L}$

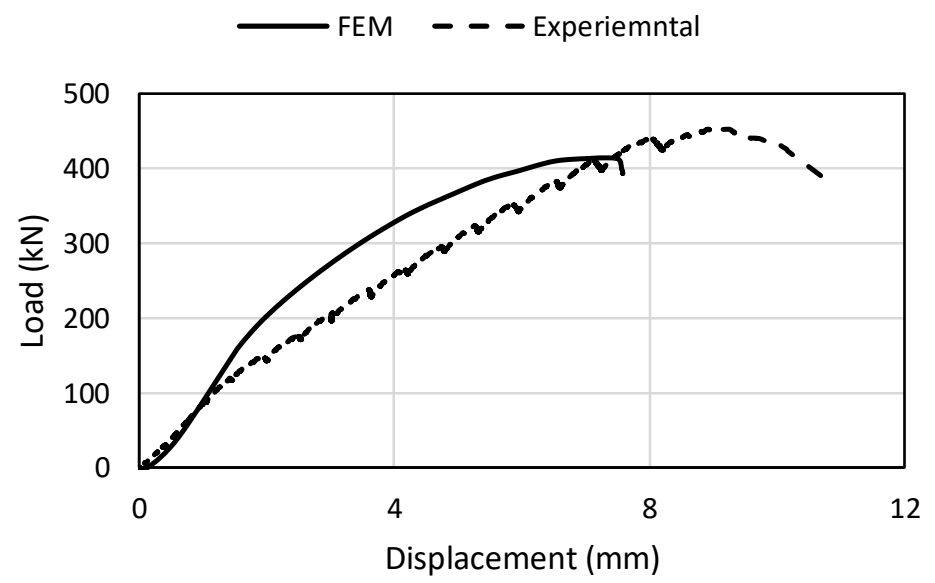

e) $8-20 M-L$

Figure 37: Load-deformation comparison 


\subsubsection{Crack contours}

Figure 38 shows tension damage patterns for the simulated numerical analysis and the observed crack patterns from the test results for the five-beam specimens. It is worth noting that numerical modelling cannot perfectly predict the crack patterns for all the static loading cases. However, a reasonable representation of the damage patterns can be given.

High damage (0.77-0.99) is observed for beam specimen with a span of $915 \mathrm{~mm}$ while beam specimen with a span of $1830 \mathrm{~mm}$ underwent lower damage (0.33-0.53). This high damage can be attributed to the higher ultimate loads of beams with $915 \mathrm{~mm}$ span. 


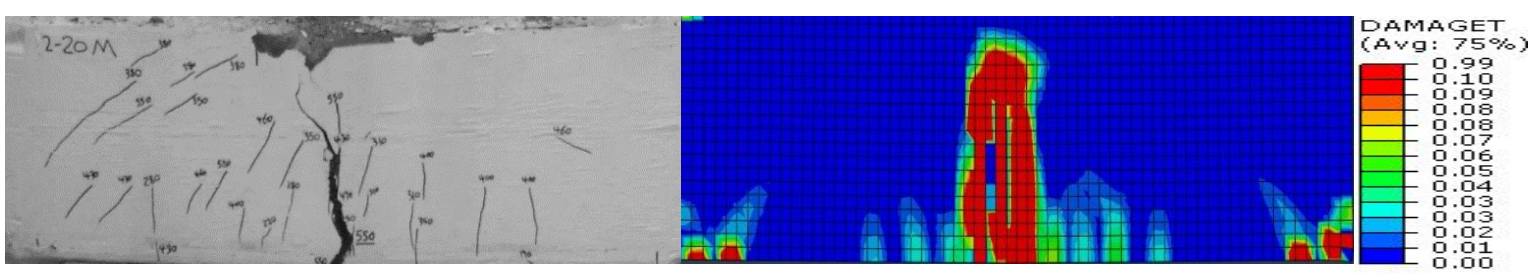

a) $2-20 M-S$

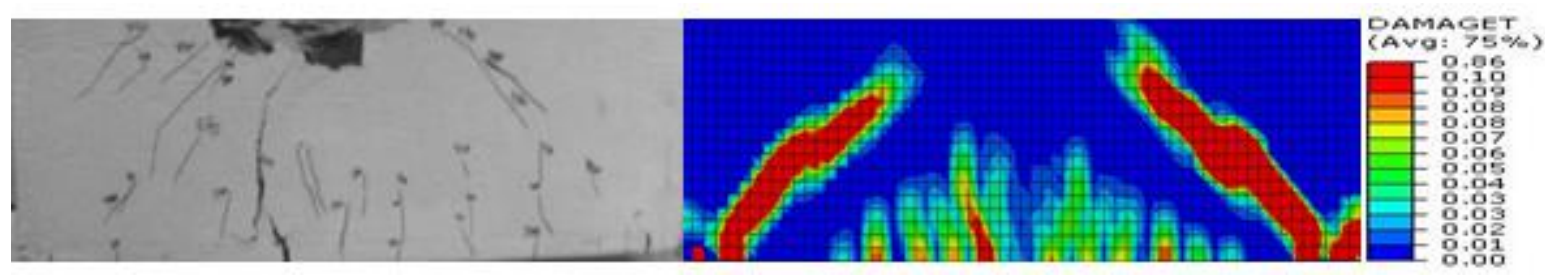

b) $4-20 M-S$

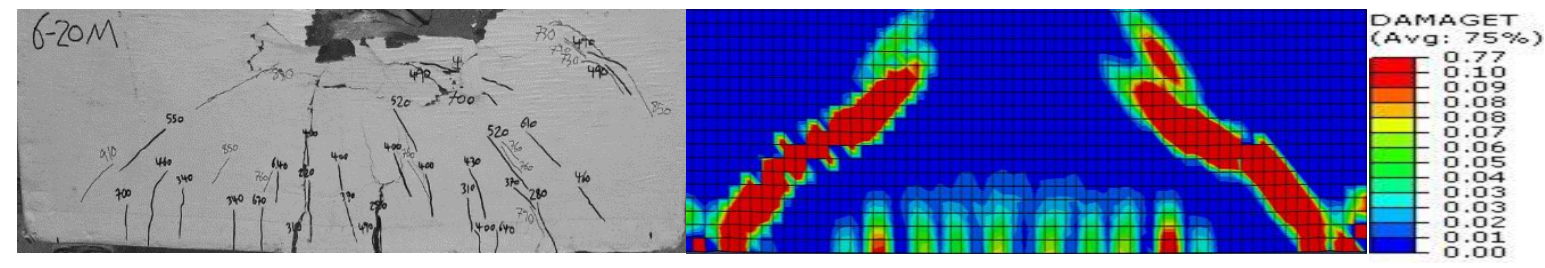

c) $6-20 M-S$

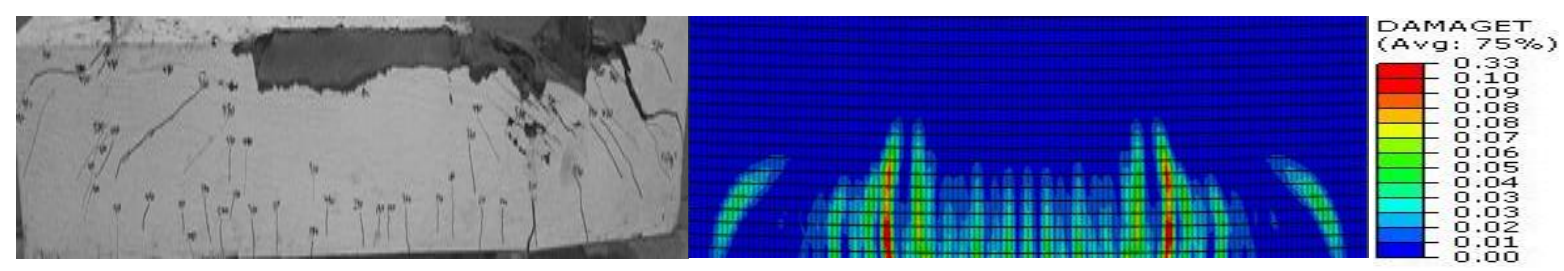

d) $6-20 M-L$

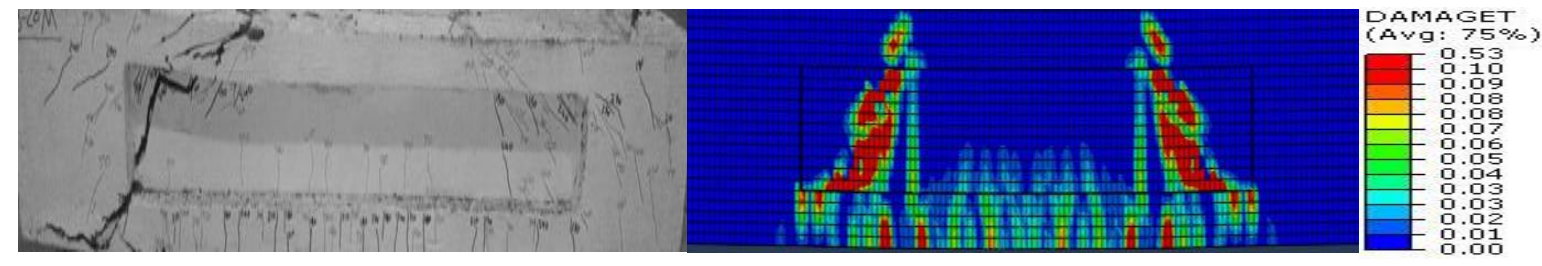

e) $8-20 M-L$

Figure 38: Numerical and experimental crack pattern comparison 


\subsection{FE Numerical Validation of Bae et al., (2016)}

There are limitations in our Ryerson structural engineering laboratory such as equipment capacity and limited space. Moreover, the high cost of UHPFRC materials makes it a difficult task to test longer beam spans in the laboratory. Therefore, FE analysis was used to validate the load capacity of an UHPFRC $4.6 \mathrm{~m}$ span beam tested previously in a flexural investigation study by Bae et al., (2016). The load capacity obtained by Bae et al., (2016) in their numerical investigation is within $14.72 \%$ of the results obtained using ABAQUS, which further validates the accuracy and robustness of the concrete damage plasticity constitutive model used to model the tested beams in this research. Load-deformation graphs for Bae et al., (2016) and ABAQUS software simulation results are shown in Figure 39.

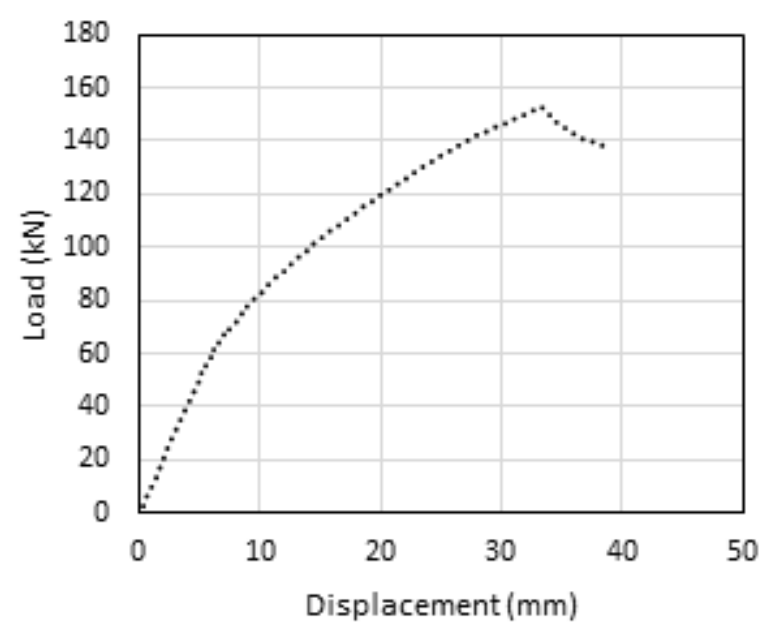

(a)

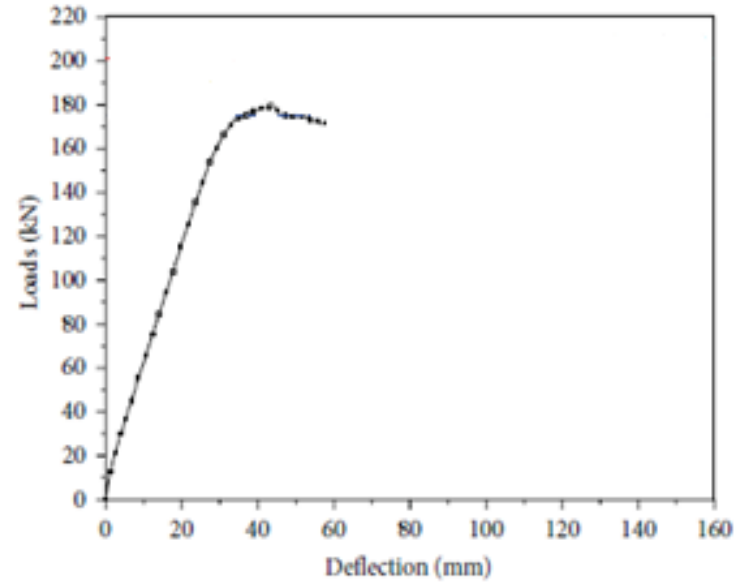

(b)

Figure 39: Load-deformation comparisons between ABAQUS simulation (a) and Bae et al., (2016) numerical results (b). 


\section{CHAPTER 6}

\section{CONCLUSIONS AND RECOMMENDATIONS}

\subsection{Conclusions}

The enhanced durability, strength and mechanical properties of UHPFRC makes it a unique material compared to conventional reinforced concrete. The development of the nano-materials for concrete dry materials using available materials in the market and the ease of curing without any special heat or pressure curing methods gives this material a competitive edge in the construction industry. Furthermore, the inclusion of steel fibers to the matrix greatly enhances tension properties such as fracture energy and tensile and compressive strengths.

The use of UHPFRC in the industry has been low due to limited research data, in addition to restricted design guidelines. The use of current building codes utilizes only $76 \%$ of the flexural capacity of UHPFRC beams using Whitney's stress block. The objective of this research is to investigate current building code design guidelines, other methods available in literature and finally to develop a method to determine the accurate flexural capacity of UHPFRC beams.

The following subsections present the conclusions of various research investigations used throughout this study.

\subsubsection{Experimental investigation conclusions}

Conventional concrete has low compressive and flexural strengths and almost negligible tensile strengths. Cylinder and prism testing, in addition to the flexural testing of beam specimens in this report proved the superiority of UHPFRC over conventional concrete. 
1. The compressive strength of UHPFRC based on cylinder testing is greater than $150 \mathrm{MPa}$ (163 $\mathrm{MPa}$ ) which is substantially higher than 25-40 MPa for conventional concrete.

2. The splitting (indirect) tensile strength of UHPFRC in this investigation is 8.2 MPa (compared to 2-3 MPa for conventional concrete).

3. The flexural strength of UHPFRC based on three-point bending prism testing is 19.2 MPa.

4. Four-point monotonic incremental static loading of UHPFRC beam specimens resulted in a higher than normal ultimate load capacities as presented in the load-deformation graphs in previous chapters. One of the main reasons for this large load capacity of UHPFRC is the presence of steel fibers which bridge the gap between the cracks, holding the concrete more tightly and preventing quick emergence of crack propagation to the surface, creating a super durable concrete.

Therefore, it is evident that the inclusion of steel fibers and using traditional moist curing techniques greatly enhances the structural and mechanical properties of reinforced concrete structures, without relying on any special curing techniques.

\subsubsection{UHPFRC beam flexural analysis conclusions}

1. Moment-curvature analysis is a useful technique for plotting moment and curvature values from first cracking, then at yield and all the way to the ultimate point. Obtaining accurate momentcurvature values can be done using strain compatibility and force-equilibrium analysis. Additional points on the graph can be obtained by choosing several strain values and performing forceequilibrium analysis.

2. The Canadian CSA A23.3-94, American ACI 318-02, and New Zealand NZS 3101-1995 design codes cannot be used for the design of UHPFRC structures due to their low accuracy (36\%-68\% 
accuracy). This low accuracy is attributed to the lack of steel fibers and exclusion of any tensile forces present in UHPFRC.

3. For the $1830 \mathrm{~mm}$ span beams, the RPM for reinforced beams showed great moment capacity accuracy (90-94\%), albeit, it overestimated the capacity for the unreinforced beam (139\%). In addition, the RPM showed lower accuracy for the $915 \mathrm{~mm}$ beams (69-79\%). Moreover, for the $1830 \mathrm{~mm}$ beams, Bae et al., (2016) showed great moment capacity accuracy for reinforced beams (90-95\%), and it overestimated the capacity for the unreinforced beam (141\%). Similar to the RPM, Bae et al., (2016) showed lower accuracy for the $915 \mathrm{~mm}$ beams (67-78\%).

4. Dobrusky's simplified method (DSM) showed great moment capacity accuracy for both 915 $\mathrm{mm}(83-100 \%)$ and $1830 \mathrm{~mm}(80-100 \%)$ rectangular beams. It is worth noting that DSM assumes the same neutral axis location for both reinforced and unreinforced concrete beams $(0.18 \mathrm{xh})$. Additionally, DSM assumes a triangular shape in compression which works well with UHPFRC.

5. RPM assumes the neutral axis depth to be determined at each strain to develop the moment curvature capacity of the beam. Moreover, a maximum strain of 0.008 is attained for UHPFRC as opposed to 0.0035 for conventional concrete found in CSA A23.3-04.

6. The maximum stress is assumed as $0.85 \mathrm{f}_{\mathrm{c}}$ '.

7. The validity of RPM is assessed for longer spans (than those tested) and for different types of concrete cross-sections and various reinforcement, including prestressed concrete. RPM showed good accuracy for beam spans up to 4.6 meters and for prestressed rectangular beam sections. Moreover, acceptable accuracy was obtained for non-prestressed beam sections. 


\subsubsection{FE numerical simulation conclusions}

1. The close proximity between the experimental and the numerical FE results for the UHPFRC beams prove the validity of the concrete damage plasticity model in estimating the monotonic incremental static response of UHPFRC materials.

2. The special compression and tension shapes for UHPFRC and the special CDP model parameters such as dilation angle, flow eccentricity, the shape factor, and the damage parameters are critical for obtaining accurate FE model simulations.

3. The static response of the UHPFRC beams was possible to model using a simple beam modelling technique without using complicated analysis.

4. Due to the large strains and nonlinear geometry of UHPFRC, the Nlgeom numerical feature was turned on during the analysis.

5. The mesh size for fiber reinforced concrete can be assumed based on half the steel fiber length. In this numerical modelling, the mesh size selected was $10 \mathrm{~mm}$ which is close to the $6.7 \mathrm{~mm}$ of the half fiber length used in the experimental investigation. Additionally, the beam was uniformly meshed to achieve unity in aspect ratios.

\subsection{Recommendations for Future Work}

The current study successfully achieved the objective of finding analytical methods for estimating the flexural capacity of UHPFRC beams with great accuracy. However, due to lack of a full and extensive investigation, there are limitations in this study. Thus, future studies can benefit from the findings of this current research by considering the following suggestions: 
1. Improvements in the numerical model can be made with an improved uniaxial tensile model for UHPFRC that takes into consideration tension stiffening along with hardening and softening responses.

2. Using UHPFRC calibrated material models to examine the response of RC structures with different shapes and geometries.

3. Extending the UHPFRC calibrated constitutive models for simulating RC structures under different load conditions such as impact.

4. The effect of shear reinforcement and stirrups should be investigated, with and without steel fibers to examine the shear capacity of UHPFRC for both short and long span beams.

5. The use of special high capacity hydraulic jack for future testing is recommended for investigating UHPFRC beams with more reinforcements (tension, compression and stirrups).

6. The effect of compression (top) reinforcement should be considered for all UHPFRC short and long span beams tested in this investigation. Additionally, the effect of compression reinforcement should be considered for other loading conditions, such as impact.

7. Other fiber content such as $1 \%, 1.5 \%$ and $3 \%$ should be investigated experimentally and analytically.

8. The validity of the analytical methods used in this study should be assessed for beams reinforced with fibers of different shapes (E.g., twisted, end-hooked, coiled), sections (such as square, rectangular and flat), and material like wood, horse-hair, glass, carbon and polymers.

9. Finally, the validity of the analytical methods on other structures like slabs, shear walls and columns should be investigated. 


\section{APPENDIX: BEAM DESIGN CALCULATIONS}

\section{Bae et al., (2016)}

Concrete compressive strength $\left(f_{c}^{\prime}\right)=163 \mathrm{MPa}$; concrete tensile strength $\left(f_{t}\right)=14.7 \mathrm{MPa}$; clear cover $=30 \mathrm{~mm}$; steel yield stress $\left(f_{y}\right)=400 \mathrm{MPa}$; and UHPFRC stress block parameters based on Graybeal (2008) $(\alpha$ and $\beta)=0.85$ and 0.65

\section{a) Unreinforced (plain) beam}

$$
\begin{aligned}
& C=\frac{A_{s} f_{y}+\gamma f_{t} b h}{\alpha_{1} f_{c}^{\prime} \beta_{1} b-0.5(\eta-1) f_{t} b+\gamma \eta f_{t} b}=\frac{0+0.7 \times 14.7 \times 178 \times 305}{0.85 \times 163 \times 0.65 \times 178-0.5 \times 0.4 \times 14.7 \times 178+0.7 \times 1.4 \times 14.7 \times 178}=30.9 \mathrm{~mm} \\
& e=\left(e_{\text {sfibers }}+0.003\right)(c / 0.003)=(0.0036+0.003)(30.9 / 0.003)=67.98 \mathrm{~mm} \\
& e-c=67.98-30.9=37.1 \mathrm{~mm} \\
& h-e=305-67.98=237.02 \mathrm{~mm} \\
& c / 2=30.9 / 2=15.45 \mathrm{~mm} \\
& M=\left(\alpha_{1} f_{c}^{\prime} \beta_{1} c b\right)\left(\frac{c}{2}\right)+\left\{f_{t}(e-c) b\right\}\left(\frac{2}{3}\right)(e-c)+\left\{\gamma f_{t}(h-e) b\right\}\left(e-c+\frac{h-e}{c}\right)+A_{s} f_{y}(d-c) \\
& M=(0.85 \times 163 \times 0.65 \times 30.9 \times 178)(15.45)+\left(\frac{14.7 \times 37.1 \times 178 \times 2}{3 \times 37.1}\right)+ \\
& (0.7 \times 14.7 \times 237.02 \times 178 \times 155.61)+0=77.6 \mathrm{kN} . \mathrm{m}
\end{aligned}
$$

\section{b) Beams reinforced with $2-20 \mathrm{M}$}

$$
\begin{aligned}
& C=\frac{A_{s} f_{y}+\gamma f_{t} b h}{\alpha_{1} f_{c}^{\prime} \beta_{1} b-0.5(\eta-1) f_{t} b+\gamma \eta f_{t} b}=\frac{600 \times 400+0.7 \times 14.7 \times 178 \times 305}{0.85 \times 163 \times 0.65 \times 178-0.5 \times 0.4 \times 14.7 \times 178+0.7 \times 1.4 \times 14.7 \times 178}=44.2 \mathrm{~mm} \\
& e=\left(e_{\text {sfibers }}+0.003\right)(c / 0.003)=(0.0036+0.003)(44.2 / 0.003)=97.24 \mathrm{~mm} \\
& e-c=97.24-44.2=53.04 \mathrm{~mm}
\end{aligned}
$$




$$
\begin{aligned}
& h-e=305-97.24=207.76 \mathrm{~mm} \\
& d-c=265-44.2=220.8 \mathrm{~mm} \\
& c / 2=44.2 / 2=22.1 \mathrm{~mm} \\
& M=\left(\alpha_{1} f_{c}^{\prime} \beta_{1} c b\right)\left(\frac{c}{2}\right)+\left\{f_{t}(e-c) b\right\}\left(\frac{2}{3}\right)(e-c)+\left\{\gamma f_{t}(h-e) b\right\}\left(e-c+\frac{h-e}{c}\right)+A_{s} f_{y}(d-c) \\
& M=(0.85 \times 163 \times 0.65 x 44.2 \times 178)(22.1)+\left(\frac{14.7 \times 53.04 \times 178 \times 2 \times 53.04}{3}\right)+ \\
& (0.7 \times 14.7 \times 207.76 \times 178 \times 156.92)+(600 x 400 \times 220.8)=133.3 \mathrm{kN} . \mathrm{m}
\end{aligned}
$$

\section{c) Beams reinforced with $4-20 M$}

$$
\begin{aligned}
& C=\frac{A_{s} f_{y}+\gamma f_{t} b h}{\alpha_{1} f_{c}^{\prime} \beta_{1} b-0.5(\eta-1) f_{t} b+\gamma \eta f_{t} b}=\frac{1200 \times 400+0.7 \times 14.7 \times 178 \times 305}{0.85 \times 163 \times 0.65 \times 178-0.5 \times 0.4 \times 14.7 \times 178+0.7 \times 1.4 \times 14.7 \times 178}=57.5 \mathrm{~mm} \\
& e=\left(e_{\text {sfibers }}+0.003\right)(c / 0.003)=(0.0036+0.003)(57.5 / 0.003)=126.5 \mathrm{~mm} \\
& e-c=126.5-57.5=69.0 \mathrm{~mm} \\
& h-e=305-126.5=178.5 \mathrm{~mm} \\
& d-c=265-57.5=207.5 \mathrm{~mm} \\
& c / 2=57.5 / 2=28.75 \mathrm{~mm} \\
& M=\left(\alpha_{1} f_{c}^{\prime} \beta_{1} c b\right)\left(\frac{c}{2}\right)+\left\{f_{t}(e-c) b\right\}\left(\frac{2}{3}\right)(e-c)+\left\{\gamma f_{t}(h-e) b\right\}\left(e-c+\frac{h-e}{c}\right)+A_{s} f_{y}(d-c) \\
& M=(0.85 \times 163 \times 0.65 \times 57.5 \times 178)(28.75)+\left(\frac{14.7 \times 69.0 \times 178 \times 2 \times 69.0}{3}\right) \\
& +(0.7 \times 14.7 \times 178.5 \times 178 \times 158.25)+(1200 \times 400 \times 207.5)=186.1 \mathrm{kN} . \mathrm{m}
\end{aligned}
$$




\section{d) Beams reinforced with 6-20M}

$$
\begin{aligned}
& C=\frac{A_{s} f_{y}+\gamma f_{t} b h}{\alpha_{1} f_{c}^{\prime} \beta_{1} b-0.5(\eta-1) f_{t} b+\gamma \eta f_{t} b}=\frac{1800 \times 400+0.7 \times 14.7 \times 178 \times 305}{0.85 \times 163 \times 0.65 \times 178-0.5 \times 0.4 \times 14.7 \times 178+0.7 \times 1.4 \times 14.7 \times 178}=70.8 \mathrm{~mm} \\
& e=\left(e_{\text {sfibers }}+0.003\right)(c / 0.003)=(0.0036+0.003)(70.8 / 0.003)=155.76 \mathrm{~mm} \\
& e-c=155.76-70.8=84.96 \mathrm{~mm} \\
& h-e=305-155.76=149.24 \mathrm{~mm} \\
& d-c=251.67-70.8=180.87 \mathrm{~mm} \\
& c / 2=70.8 / 2=35.4 \mathrm{~mm} \\
& M=\left(\alpha_{1} f_{c}^{\prime} \beta_{1} c b\right)\left(\frac{c}{2}\right)+\left\{f_{t}(e-c) b\right\}\left(\frac{2}{3}\right)(e-c)+\left\{\gamma f_{t}(h-e) b\right\}\left(e-c+\frac{h-e}{c}\right)+A_{s} f_{y}(d-c) \\
& M=(0.85 \times 163 \times 0.65 \times 70.8 \times 178)(35.4)+\left(\frac{14.7 \times 84.96 \times 178 \times 2 \times 84.96}{3}\right) \\
& +(0.7 \times 14.7 \times 149.24 \times 178 \times 159.58)+(1800 \times 400 \times 180.87)=226.6 \mathrm{kN} . \mathrm{m}
\end{aligned}
$$

\section{Dobrusky's simplified French model (DSM) (2017)}

DSM sample calculations will be shown for specimen with span of $1830 \mathrm{~mm}$ since the procedure is the same for the shorter spans $(910 \mathrm{~mm})$, except for the beam length.

Beam span between the supports $(L)=1830 \mathrm{~mm}$; concrete tensile strength $\left(f_{t}\right)=14.7 \mathrm{MPa}$; clear cover $=30 \mathrm{~mm}$; steel yield stress $\left(f_{y}\right)=400 \mathrm{MPa}$

Dobrusky's proposed force equation for the steel fibers:

$F_{c}=\frac{f_{t} \cdot b \cdot h^{2}}{0.383 . L}=\frac{14.7 \times 178 \times 305^{2}}{0.383 \times 1830}=347300 \mathrm{~N}$ 


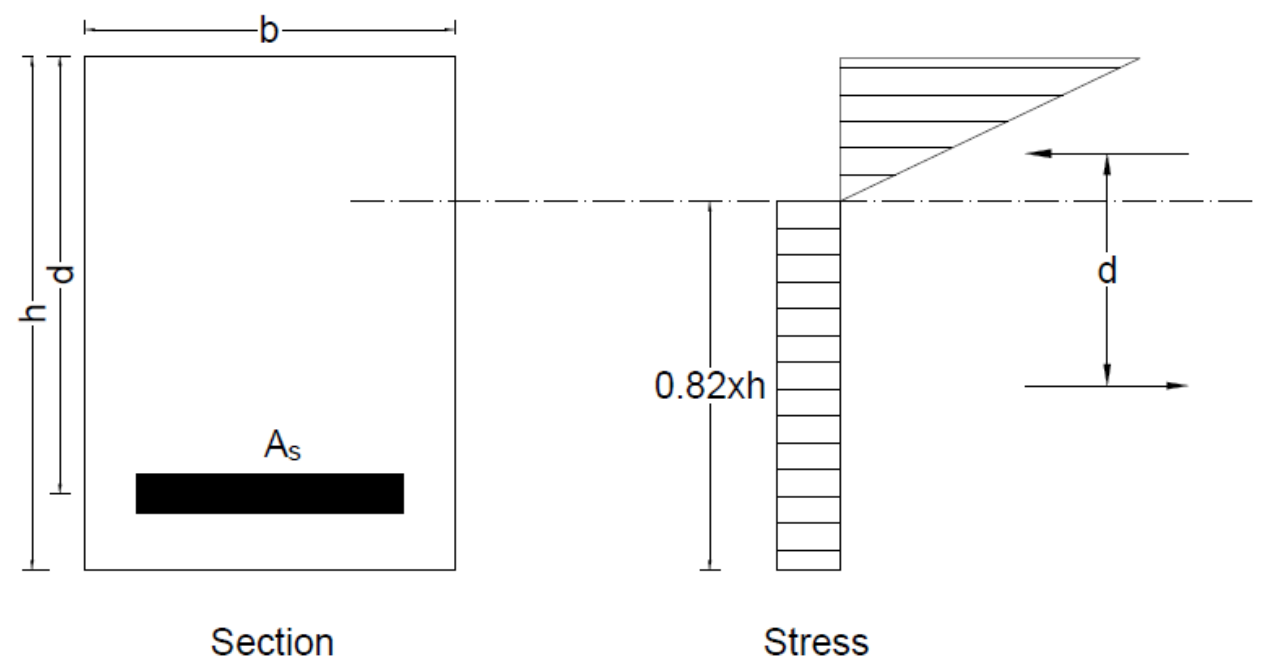

Figure 40: DSM stress block

Height of rectangular stress block: $0.82 \times h=0.82 \times 305=250.1 \mathrm{~mm}$

Height of triangular stress block: $0.18 \times \mathrm{xh}=0.18 \times 305=54.9 \mathrm{~mm}$

Moment arm (d) is the distance between half of the rectangular and triangular sections of the stress block, as shown in Figure 40.

Moment arm $>\mathrm{d}=125.1+36.6=161.7 \mathrm{~mm}$

$M=F . d=347300 \times 161.7=56.2 \mathrm{kN} . \mathrm{m} \gg$ due to steel fibers only (unreinforced concrete section)

$M_{\text {flexural reinforcement }}=A_{s} f_{y} d$

\section{a) Beams reinforced with $2-20 \mathrm{M}$}

$$
\begin{aligned}
& M=M_{\text {steel fibres }}+M_{\text {flexural reinforcement }} \\
& M=56.2 \times 10^{6}+(600 \times 400 \times 246.7)=115.4 \mathrm{kN} . \mathrm{m}
\end{aligned}
$$




\section{b) Beams reinforced with 4-20M}

$$
\begin{aligned}
& M=M_{\text {steel fibres }}+M_{\text {flexural reinforcement }} \\
& M=56.2 \times 10^{6}+(600 \times 400 \times 246.7)=174.6 \mathrm{kN} . \mathrm{m}
\end{aligned}
$$

\section{c) Beams reinforced with $6-20 \mathrm{M}$}

$$
M=M_{\text {steel fibres }}+M_{\text {flexural reinforcement }}
$$

$M=56.2 \times 10^{6}+(1800 \times 400 \times 233.4)=224.2 \mathrm{kN} \cdot \mathrm{m}$

\section{Ryerson Proposed Method (RPM)}

For the RPM a sample calculation for the 2-20M moment capacity will be presented. Additionally, the moment capacity for the non-prestressed and prestressed sections (from Chapter 4) will be presented.

\section{a) Beams reinforced with $2-20 \mathrm{M}$}

Concrete compressive strength $\left(f_{c}^{\prime}\right)=163 \mathrm{MPa}$; concrete tensile strength $\left(f_{t}\right)=14.7 \mathrm{MPa}$; clear cover $=30 \mathrm{~mm}$; steel yield stress $\left(f_{y}\right)=400 \mathrm{MPa}$; UHPFRC stress block parameters $(\alpha$ and $\beta)=$ 0.85 and $0.65 ;$ and effective depth $(d)=265 \mathrm{~mm}$

Neutral axis location will be found by taking moments about the neutral axis location (whose height is assumed as ' $\mathrm{X}$ '). In the force calculations, concrete and steel strength reduction factors are taken as 1 and therefore, not shown in the equations. It should be noted that since in the RPM the neutral axis height is assumed to be same as the stress block compressive height, the term ' $\mathrm{a}$ ' in the force equations is replaced with ' $\mathrm{X}$ ' as shown in Figure 41. 


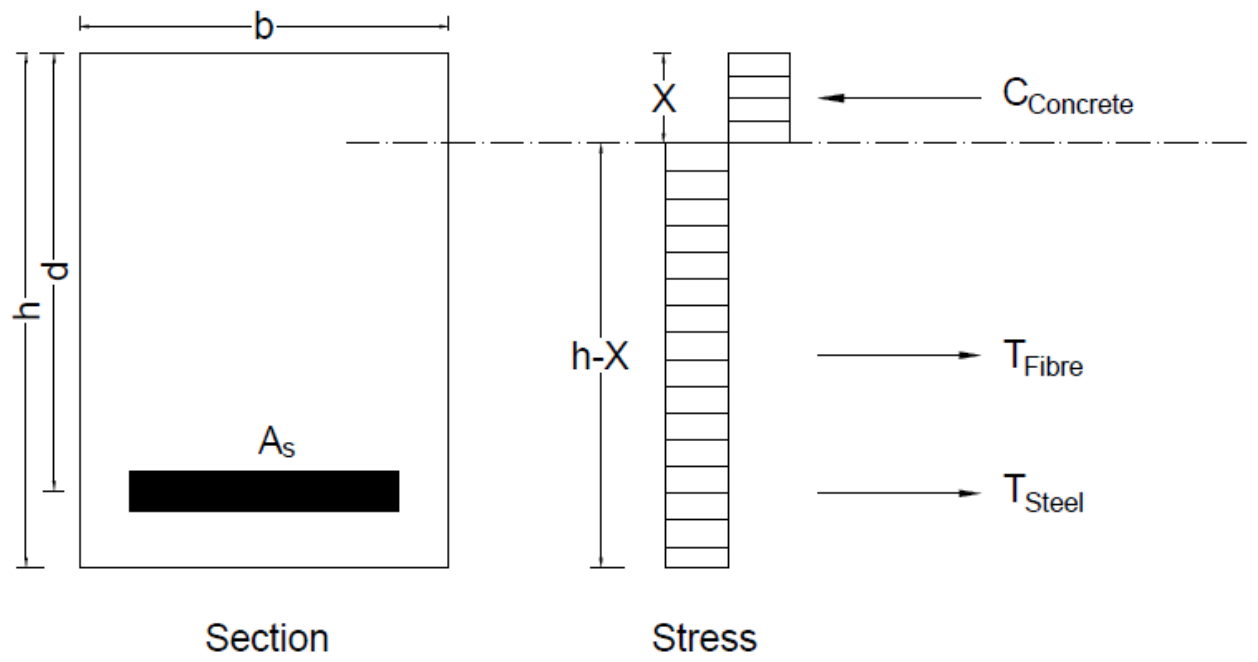

Figure 41: RPM stress block

Calculating compression and tension forces (due to flexural reinforcement and steel fibers) in the concrete section:

$\mathrm{C}=\alpha_{1} x f_{c}^{\prime} x a \times b=0.85 \times 163 \times X \times 178=24662 X$

$T_{\text {Steel }}=A_{s} f_{y}=600 \times 400=240000 \mathrm{~N}$

$T_{F S}=\gamma x f_{t}=0.7 x 14.7=10.3 \mathrm{MPa} \gg>$ Fiber Stress

$T_{F F}=T_{F S} x(h-N . A)^{*} x b=10.3 x(305-30.9) x 178=478150.72 N>$ Fiber Force

* It should be noted that when calculating the height of the tensile section in the stress block, the neutral axis location (30.9 $\mathrm{mm}$ from the top) for the 2-20M section from Bae et al., (2016) method was used. The calculations were redone by substituting a variable $(X)$ instead of a value from Bae et al., (2016) but this process did not change the results ( $\sim \%$ difference only).

Taking moments at the neutral axis location:

$24662 \frac{X^{2}}{2}+478150.72\left(\frac{305}{2}-\frac{X}{2}\right)+240000(265-X)=0$ 
$12331 X^{2}-479075.36 X+136517984.8=0$

$X=19.4 \mathrm{~mm}$

Taking moments at the top compression force:

$M=T_{\text {Steel }}\left(h-q-\frac{X}{2}\right)+T_{F F}\left(S+\frac{X}{2}\right)=240000\left(305-40-\frac{19.4}{2}\right)+478150.72(142.8+$ $\left.\frac{19.4}{2}\right)=134.2 \mathrm{kN} \cdot \mathrm{m}$

In the above moment equation, two variable names were chosen randomly as follows: $q$ is the distance from the extreme tension fiber to the centre of the main flexural reinforcement $(2-20 \mathrm{M})$; while $S$ is the distance from the centre of the tensile component of the stress block to the location of the neutral axis.

\section{b) Non-prestressed beam section}

Cross-sectional dimensions $(\mathrm{b}$ and $\mathrm{h})=200 \times 400 \mathrm{~mm}$; Concrete compressive strength $\left(f_{c}^{\prime}\right)=200$ $\mathrm{MPa}$; concrete tensile strength $\left(f_{t}\right)=8 \mathrm{MPa}$; prestressing stress $\left(f_{p u}\right)=1800 \mathrm{MPa}$; and UHPFRC stress block parameters $(\alpha$ and $\beta)=0.85$ and 0.65

$\mathrm{C}=\alpha_{1} x f_{c}^{\prime} x a \times b=0.85 \times 200 \times X \times 200=34000 X$

$T_{\text {Steel }}=0$

$T_{F S}=\gamma x f_{t}=0.7 x 8=5.6 \mathrm{MPa} \gg$ > Stress

$T_{F F}=T_{F S} x(h-N . A) x b=5.6 x(400-19.19) \times 200=426507.2 N \gg$ Force

Taking moments at the neutral axis location:

$34000 \frac{X^{2}}{2}+426507.2\left(\frac{400}{2}-\frac{X}{2}\right)=0$ 
$17000 X^{2}-213253.6 X+85301440=0$

$X=6.27 \mathrm{~mm}$

Taking moments at the top compression force:

$M=T_{F F}\left(S+\frac{X}{2}\right)=426507.2\left(196.87+\frac{6.27}{2}\right)=85.3 \mathrm{kN} . \mathrm{m}$

In the above moment equation, $S$ is the distance from the centre of the tensile component of the stress block to the location of the neutral axis.

\section{c) Prestressed beam section}

Cross-sectional dimensions $(\mathrm{b}$ and $\mathrm{h})=200 \times 400 \mathrm{~mm}$; Concrete compressive strength $\left(f_{c}^{\prime}\right)=200$ MPa; concrete tensile strength $\left(f_{t}\right)=8 \mathrm{MPa}$; prestressing stress $\left(f_{p u}\right)=1800 \mathrm{MPa}$; UHPFRC stress block parameters $(\alpha$ and $\beta)=0.85$ and 0.65 ; prestressing area $\left(A_{p}\right)=250 \mathrm{~mm}^{2}$; and effective $\operatorname{depth}(d)=300 \mathrm{~mm}$

$\mathrm{C}=\alpha_{1} x f_{c}^{\prime} \times a \times b=0.85 \times 200 \times X \times 200=34000 X$

$T_{\text {Steel }}=A_{s} f_{p u}=250 \times 1800=450000 \mathrm{~N}$

$T_{F S}=\gamma x f_{t}=0.7 x 8=5.6 \mathrm{MPa} \gg$ > Stress

$T_{F F}=T_{F S} x(h-N . A) x b=5.6 x(400-38.46) \times 200=404924.8 N \gg$ Force

Taking moments at the neutral axis location:

$34000 \frac{X^{2}}{2}+404924.8\left(\frac{400}{2}-\frac{X}{2}\right)+450000(300-X)=0$

$17000 X^{2}-652462.4 X+215984960=0$

$X=19.2 \mathrm{~mm}$ 
Taking moments at the top compression force:

$M=T_{\text {Steel }}\left(h-q-\frac{X}{2}\right)+T_{F F}\left(S+\frac{X}{2}\right)=450000\left(400-100-\frac{19.2}{2}\right)+404924.8(190.4+$ $\left.\frac{19.2}{2}\right)=211.66 \mathrm{kN} \cdot \mathrm{m}$

In the above moment equation, two variable names were chosen randomly as follows: $q$ is the distance from the extreme tension fiber to the centre of the main flexural reinforcement (2-20M); while $S$ is the distance from the centre of the tensile component of the stress block to the location of the neutral axis. 


\section{REFERENCES}

Abrishami, H. H., \& Mitchell, D. (1996). Influence of Splitting Cracks on Tension Stiffening. ACI Structural Journal, 93(6), 703-710. doi:10.14359/517

Abrishami, H. H., \& Mitchell, D. (1997). Influence of Steel Fibers on Tension Stiffening. ACI Structural Journal, 94(6), 769-776. doi:10.14359/9736

ACI Committee 318, "Building Code Requirement for Structural Concrete (ACI 318-02) and Commentary (318R-02)," American Concrete Institute, Farmington Hills, Mich., 2002, (pp. 443)

Alwan, J. M., Naaman, A. E., and Guerrero, P. (1999). Effect of Mechanical Clamping on the Pull-Out Response of Hooked Steel Fibers Embedded in Cementitious Matrices. Concrete Science \& Engineering, 1, 15-25.

Aoude, H., Belghiti, M., Cook, W. D., \& Mitchell, D. (2012). Response of Steel FiberReinforced Concrete Beams with and without Stirrups. ACI Structural Journal, 109(3), 359-367. doi:10.14359/51683749

Ashour, S. A., Hasanain, G. S., and Wafa, F. F. (1992). Shear Behaviour of High-Strength Fiber Reinforced Concrete Beams. ACI Structural Journal, 89(2), 176-184.

ASTM Standard C39/C39M, (2001). "Standard Test Method for Compressive Strength of Cylindrical Concrete Specimens”, ASTM International, West Conshohocken, PA, USA, www.astm.org.

ASTM Standard C496/C496M, (2004). "Standard Test Method for Splitting Tensile Strength of Cylindrical Concrete Specimens”, ASTM International, West Conshohocken, PA, USA, www.astm.org.

ASTM Standard C1609/C1609M, (2007). "Test Method for Flexural Performance of FiberReinforced Concrete (Using Beam with Third-Point Loading)", ASTM International, West Conshohocken, PA, USA, www.astm.org.

ASTM Standard C1437, (2015). "Standard Test Method for Flow of Hydraulic Cement Mortar", ASTM International, West Conshohocken, PA, USA, www.astm.org

Bae, B.-I., Choi, H.-K., \& Choi, C.-S. (2016). Flexural Strength Evaluation of Reinforced Concrete Members with Ultra High Performance Concrete. Advances in Materials Science and Engineering, 5, 1-10. doi: 10.1155/2016/2815247

Bazant, Z.P., Oh, B.H. (1983). Crack bond theory for fracture of concrete. Materials and Structures, 16(93), 155-177.

Belytschko, T., Liu, W. K., \& Moran, B. (2014). Nonlinear finite elements for continua and structures (2nd ed.). West Sussex, England: John Wiley \& Sons. 
Collins, M. P., \& Mitchell, D. (1991). Prestressed Concrete Structures. Englewood Cliffs, NJ: Prentice-Hall.

CSA-A23.3-94, "Design of Concrete Structures for Buildings," Canadian Standards Association, Ontario, Canada, 1994, (pp. 199)

D’Alessandro, K. C. (2013). Biaxial Behaviour of Ultra-High Performance Concrete and Untreated UHPC Waffle Slab Bridge Deck Design and Testing (Doctoral dissertation, Virginia Polytechnic Institute and State University, 2013) (pp. 26-35). Blacksburg, VA: ProQuest Dissertations Publishing. Retrieved from https://search-proquestcom.ezproxy.lib.ryerson.ca/docview/1512626878?pq-origsite=summon.

Dinh, H. H., Parra-Montesinos, G. J., and Wight, J. K., (2010). Shear Behaviour of Steel FiberReinforced Concrete Beams without Stirrup Reinforcement. ACI Structural Journal, 107(5), 597-606.

Dobrusky, S. (2017). Inverse Analysis Tailored for both Strain Hardening and Strain Softening UHPFRC. RILEM-fib-AFGC International Symposium on Ultra-High Performance Fiber-Reinforced Concrete (pp. 211-220). Montpellier: RILEM Publications SARL.

Dobrusky, S., \& Bernardi, S. (2017). Uni-Axial Tensile Tests for UHPFRC. RILEM-fib-AFGC International Symposium on Ultra-High Performance Fiber-Reinforced Concrete (pp. 165-174). Montpellier : RILEM Publications SARL.

EN 1992-1-1:2004, "Eurocode 2: Design of Concrete Structures,” Comité Européen de Normalisation (CEN), Brussels, Belgium, 2004, (pp. 230)

Federal Highway Administration. (2006). Material Property Characterization of Ultra-High Performance Concrete. Georgetown: Research, Development, and Technology Turner Fairbank Highway Research Center.

Gowripalan, N., \& Gilbert, I. R. (2000). Design Guidelines for Ductal Prestressed Concrete Beam (pp. 1-53, Tech.). Thornleigh, NSW: VSL Australia Pty.

Graybeal, B., (2005). "Characterization of the Behaviour of Ultra-high Performance Concrete", $\mathrm{PhD}$. Dissertation, University of Maryland, USA, $383 \mathrm{pp}$.

Graybeal, B. A. (2008). Flexural Behaviour of an Ultrahigh-Performance Concrete I-Girder. Journal of Bridge Engineering, 13(6), 602-610. doi:10.1061/(asce)10840702(2008)13:6(602)

Hillerborg, A., (1985). The Theoretical Basis of a Method to Determine the Fracture Energy of Concrete. Materials and Structures, 18(4), 291-296.

Hillerborg, A., Modéer, M. and Petersson, P., (1976). Analysis of Crack Formation and Crack Growth in Concrete by Means of Fracture Mechanics and Finite Elements. Cement and Concrete Research, 6(6), 773-781. 
Hussein, A., \& Marzouk, H. (2000). Behaviour of High-Strength Concrete under Biaxial Stresses. ACI Structural Journal, 97(1), 27-36. doi:10.14359/802

Hussein, A., \& Marzouk, H. (2000). Finite element evaluation of the boundary conditions for biaxial testing of high strength concrete. Materials and Structures, 33(5), 299-308. doi:10.1007/bf02479700

Kim, D. J., Naaman, A. E., \& El-Tawil, S. (2009). High Performance Fiber Reinforced Cement Composites with Innovative Slip Hardending Twisted Steel Fibers. International Journal of Concrete Structures and Materials, 3(2), 119-126. doi:10.4334/IJCSM.2009.3.2.119

Kim, D. J., Wille, K., Naaman, A. E., \& El-Tawil, S. (2011). Strength Dependent Tensile Behavior of Strain Hardening Fiber Reinforced Concrete. High Performance Fiber Reinforced Cement Composites 6 RILEM State of the Art Reports, 3-10. doi:10.1007/97894-007-2436-5_1

Large North America. (2019). Retrieved March 2, 2019, from http://www.ductal-lafarge.com

Lublinear, J., Oliver, J., Oller, S. and Onate, E., (1989). "A Plastic-damage Model for Concrete", Solids and Structures, 25(3), 299-326.

Maca, P., Sovjak, R., \& Vavrinik, T. (2013). Experimental Investigation of Mechanical Properties of UHPFRC. Procedia Engineering, 65, 14-19. doi:10.1016/j.proeng.2013.09.004

Mansur, M. A., Ong, K. C. G., and Paramsivam, P. (1986). Shear Strength of Fibrous Concrete Beams without Stirrups. Journal of Structural Engineering, 112(9), 2066-2079.

Marzouk, H., \& Chen, W. (1995). Fracture Energy and Tension Properties of High-Strength Concrete. Journal of Materials in Civil Engineering, 108-116.

Marzouk, H., \& Chen, Z. (1993). Finite Element Analysis of High-Strength Concrete Slabs. ACI Structural Journal, 90(5), 505-513. doi:10.14359/3943

Marzouk, H., \& Chen, Z. (1993). Finite Element Analysis of High-Strength Concrete Slabs. Canadian Journal of Civil Engineering, 20, 696-707.

Marzouk, H., Emam, M., \& Hial, M. (1998). Sensitivity of shear strength to fracture energy of high-strength concrete slabs. Canadian Journal of Civil Engineering, 25, 40-50.

Minelli, F. (2005). Plain and Fiber Reinforced Concrete Beams under Shear Loading: Structural Behaviour and Design Applications (Doctoral dissertation, University of Brescia, 2005), Starrylink Editrice, Brescia, Italy.

Minelli, F., and Plizzari, G. A. (2006). Steel Fibers as Shear Reinforcement for Beams. Proceedings of the Second International fib Congress, (pp. 12). Naples.

Naaman, A. E. (2007). HIGH PERFORMANCE FIBER REINFORCED CEMENT COMPOSITES: CLASSIFICATION AND APPLICATIONS. CBM-CI International Workshop, (pp. 389-399). Karachi. 
Naeimi, N., \& Moustafa, M. A. (2017). Three-dimensional Finite Element modeling of UHPC using total strain crack models. RILEM-fib-AFGC International Symposium on UltraHigh Performance Fiber-Reinforced Concrete (pp. 313-324). Montpellier: RILEM Publications SARL.

NS 3473, "Norwegian Standard for Design of Concrete Structures," The Norwegian Council for Building Standardisation, N.B.R., Oslo, Norway, 1989.

NZS 3101-1995, “The Design of Concrete Structures," Standards New Zealand, Wellington, New Zealand, 1995, (pp. 520)

Othman, H., \& Marzouk, H. (2016). Impact Response of Ultra-High-Performance Reinforced Concrete Plates. ACI Structural Journal, 113(6), 1325-1334. doi:10.14359/51689157

Othman, H., \& Marzouk, H. (2017). Applicability of damage plasticity constitutive model for ultra-high performance fibre-reinforced concrete under impact loads. International Journal of Impact Engineering, 114, 20-31. doi:10.1016/j.ijimpeng.2017.12.013

Othman, H. (2016). Performance of Ultra-High Performance Fiber Reinforced Concrete Plates Under Impact Loads (Doctoral dissertation, Ryerson University, 2016). Toronto, ON. Retrieved from https://digital.library.ryerson.ca/islandora/object/RULA:5737.

Ozbakkaloglu, T., \& Saatcioglu, M. (2004). Rectangular Stress Block for High-Strength Concrete. ACI Structural Journal, 101(4), 475-483. doi:10.14359/13333

Oztekin, E., Pul, S., \& Husem, M. (2003). Determination of Rectangular Stress Block Parameters for High Performance Concrete. Engineering Structures, 25(3), 371-376. doi:10.1016/s0141-0296(02)00172-4

Park, S., Xia, Q. and Zhou, M., (2001). "Dynamic Behaviour of Concrete at High Strain Rates and Pressures: II. Numerical simulation”, International Journal of Impact Engineering, 25(9), pp.887-910.

RILEM Technical Committee TDF-162. (2002). Design of steel fiber reinforced concrete usingthe $\sigma-\mathrm{W}$ methods: Principles and applications. Recommendations of RILEM TC 162-TDF.Materials and Structures, 35(249), 262-277.

Rossi, P., Daviau-Desnoyers, D., Tailhan, J-L (2017). Probabilistic Numerical Model of UltraHigh Performance Fibre Reinforced Concrete (UHPFRC) Cracking Process. RILEM-fibAFGC International Symposium on Ultra-High Performance Fiber-Reinforced Concrete (pp. 303-312). Montpellier: RILEM Publications SARL.

Simulia, (2019). “ABAQUS 6.14 User’s Manuals”, Dassault Systèmes Simulia Corp.

Singh, M., Sheikh, A., Ali, M. M., Visintin, P., \& Griffith, M. (2017). Experimental and numerical study of the flexural behaviour of ultra-high performance fibre reinforced concrete beams. Construction and Building Materials, 138, 12-25. doi:10.1016/j.conbuildmat.2017.02.002 
Sorelli, L., Ulm, F., \& Toutlemonde, F. (2007). Fracture Stability and Micromechanics of Strain Hardening Cementitious. 6th International Conference on Fracture Mechanics of Concrete and Concrete Structures, (pp. 1403-1412). Catania.

Steinberg, E. (2010). Structural Reliability of Prestressed UHPC Flexure Models for Bridge Girders. Journal of Bridge Engineering, 15(1), 65-72. doi:10.1061/(ASCE)BE.19435592.0000039

Wahba, K., Marzouk, H., \& Dawood, N. (2012). Fracture Energy Properties of Ultra High Performance Fiber Reinforced Concrete. 3RD INTERNATIONAL STRUCTURAL SPECIALTY CONFERENCE. Edmonton: CSCE.

Wahba, K., Marzouk, H., \& Dawood, N. (2012). Structural Behaviour of UHPFRC Beams Without Stirrups . 3rd International Structural Specialty Conference. Edmonton : CSCE.

Wahba, Kirllos, "Mechanical and Structural Properties of Ultra High Performance Fiber Reinforced Concrete" (2012). Theses and dissertations. Paper 1698.

Wille, K., Kim, D. J., \& Naaman, A. E. (2011). Strain-Hardening UHP-FRC with Low Fiber Contents. Materials and Structures, 44, 583-598. doi:10.1617/s11527-010-9650-4

Wille, K., Naaman, A. E., \& Parra-Montesinos, G. J. (2011). Ultra-High Performance Concrete with Compressive Strength Exceeding $150 \mathrm{MPa}(22 \mathrm{ksi})$ : A Simpler Way. ACI Structural Journal, 108(1), 46-54. doi:10.14359/51664215

Wille, K., Naaman, A. E., El-Tawil, S., \& Parra-Montesinos, G. J. (2012). Ultra-High Performance Concrete and Fiber Reinforced Concrete: Achieving Strength and Ductility without Heat Curing. Materials and Structures, 45(3), 309-324. doi:10.1617/s11527-0119767-0

$\mathrm{Xu}, \mathrm{M} .$, \& Wille, K. (2015). Fracture energy of UHP-FRC under direct tensile loading applied at low strain rates. Composites Part B: Engineering, 80, 116-125.

doi:10.1016/j.compositesb.2015.05.031

Yazdizadeh, Z., (2014). "Use of Fiber Brag Gating Sensors in Civil Engineering Applications", MSc. thesis, Ryerson University, Toronto, Canada, 103. 